\title{
Tailored linker chemistries for the efficient and selective activation of ADCs with KSPi payloads
}

\author{
Hans-Georg Lerchen ${ }^{*[s]}$, Beatrix Stelte-Ludwig ${ }^{[\S]}$, Anette Sommer ${ }^{[\neq]}$, Sandra Berndt ${ }^{[\neq]}$, Anne-Sophie \\ Rebstock $^{[\sharp]}$, Sarah Johannes ${ }^{[\S]}$, Christoph Mahlert ${ }^{[\S]}$, Simone Greven ${ }^{[\S]}$, Lisa Dietz ${ }^{[\S]}$ and Hannah \\ Jörißen $^{[\S]}$ \\ ${ }^{[\S]}$ Bayer AG, Pharmaceuticals, Research \& Development, 42113 Wuppertal, Germany \\ ${ }^{[\neq]}$Bayer AG, Pharmaceuticals, Research \& Development, 13353 Berlin, Germany \\ ${ }^{[\#]}$ Bayer AG, CropScience, 69009 Lyon, France
}

Outline

1. Synthesis of peptidic precursors

2. Synthesis of Compound 2

3. Synthesis of ADC precursors

4. Synthesis of small molecule tool compounds

5. Synthesis of ADCs

6. Analytical characterization of ADCs

a. Analysis of aggregation by SEC-HPLC and determination of DAR and concentration

b. Distribution of the payload on ADC, analytical method and data

7. In vitro Assays

a. Surface plasmon resonance (SPR)

b. Flow cytometry

c. Internalization

d. Cell proliferation assays 
e. Legumain cleavage assay

f. Elastase cleavage assay

g. Cathepsin B cleavage assay

h. Quantification of metabolite formation

i. Preparation of rat lysosome extract

j. Lysosomal stability assay

k. Permeability assay

8. In vivo studies

9. Literature for Supporting Information

10. Cover page 


\section{General information}

All reactants or reagents of which the preparation has not been described herein were purchased from generally accessible commercial sources and were used without further purification. For all other reactants or reagents for which the preparation likewise is not described herein and which were not commercially available or were obtained from sources which are not generally accessible, a reference is given to the published literature in which their preparation is described. Some of the compounds and intermediates are also described in a patent application or in previous publications of this group. ${ }^{\mathrm{S} 1, \mathrm{~S} 2}$

LC-MS analysis of the toxophores was performed using one of the following methods:

Method 1 (LC-MS): Instrument: Waters ACQUITY SQD UPLC system; column: Waters Acquity UPLC HSS T3 $1.8 \mu 50 \times 1 \mathrm{~mm}$; mobile phase A: $1 \mathrm{~L}$ of water $+0.25 \mathrm{~mL}$ of $99 \%$ strength formic acid; mobile phase $B: 1 \mathrm{~L}$ of acetonitrile $+0.25 \mathrm{~mL}$ of $99 \%$ strength formic acid; gradient: $0.0 \mathrm{~min}$ $90 \% \mathrm{~A} \rightarrow 1.2 \mathrm{~min} 5 \% \mathrm{~A} \rightarrow 2.0 \mathrm{~min} 5 \% \mathrm{~A}$ oven: $50^{\circ} \mathrm{C}$; flow rate: $0.40 \mathrm{~mL} / \mathrm{min}$; UV detection: 208 $-400 \mathrm{~nm}$.

Method 2 (LC-MS): Instrument: Waters ACQUITY SQD UPLC system; column: Waters Acquity UPLC HSS T3 $1.8 \mu 50 \times 1 \mathrm{~mm}$; mobile phase A: $1 \mathrm{~L}$ of water $+0.25 \mathrm{~mL}$ of $99 \%$ strength formic acid; mobile phase $B: 1 \mathrm{~L}$ of acetonitrile $+0.25 \mathrm{~mL}$ of $99 \%$ strength formic acid; gradient: $0.0 \mathrm{~min}$ $95 \% \mathrm{~A} \rightarrow 6.0 \mathrm{~min} 5 \% \mathrm{~A} \rightarrow 7.5 \mathrm{~min} 5 \%$ A oven: $50^{\circ} \mathrm{C}$; flow rate: $0.35 \mathrm{~mL} / \mathrm{min}$; UV detection: $210-$ $400 \mathrm{~nm}$.

Method 3 (LC-MS): MS instrument type: Thermo Scientific FT-MS; instrument type UHPLC+: Thermo Scientific UltiMate 3000; column: Waters, HSST3, 2.1 x 75 mm, C18 $1.8 \mu \mathrm{m}$; mobile phase $A$ : $1 \mathrm{~L}$ of water $+0.01 \%$ formic acid; mobile phase $B: 1 \mathrm{~L}$ of acetonitrile $+0.01 \%$ formic acid; gradient: $0.0 \min 10 \% \mathrm{~B} \rightarrow 2.5 \min 95 \% \mathrm{~B} \rightarrow 3.5 \mathrm{~min} 95 \% \mathrm{~B}$; oven: $50^{\circ} \mathrm{C}$; flow rate: 0.90 $\mathrm{mL} / \mathrm{min}$; UV detection: $210 \mathrm{~nm} /$ Optimum Integration Path 210-300 nm.

Method 4 (UPLC-HRMS): Instrument: Waters TOF; Instrument UPLC: Waters Acquity I-CLASS; column: Waters, HSST3, $2.1 \times 50 \mathrm{~mm}$, C18 $1.8 \mu \mathrm{m}$; mobile phase A: $1 \mathrm{~L}$ water $+0.01 \%$ formic acid; mobile phase $\mathrm{B}: 1 \mathrm{~L}$ acetonitrile $+0.01 \%$ formic acid; gradient: $0.0 \mathrm{~min} 2 \% \mathrm{~B} \rightarrow 0.5 \mathrm{~min}$ $2 \% \mathrm{~B} \rightarrow 7.5 \mathrm{~min} 95 \% \mathrm{~B} \rightarrow 10.0 \mathrm{~min} 95 \% \mathrm{~B}$; oven: $50^{\circ} \mathrm{C}$; flow rate: $1.00 \mathrm{~mL} / \mathrm{min}$; UV-detection: $210 \mathrm{~nm}$. 


\section{Synthesis of peptidic precursors}

\section{Intermediate 1}

tert-Butyl- $N$-[(benzyloxy)carbonyl]-L-alanyl-D-alaninate<smiles>C[C@H](NC(=O)OCc1ccccc1)C(=O)N[C@@H](C)C(=O)OC(C)(C)C</smiles>

A solution of $N$-[(benzyloxy)carbonyl]-L-alanine $(2.00 \mathrm{~g}, 8.96 \mathrm{mmol})$ in DMF $(100 \mathrm{~mL})$ was supplemented with tert-butyl-D-alaninate-hydrogen chloride $(1.79 \mathrm{~g}, 9.86 \mathrm{mmol}), N, N$ diisopropylethylamine $(4.2 \mathrm{~mL}, 24 \mathrm{mmol})$ and HATU $(4.43 \mathrm{~g}, 11.6 \mathrm{mmol})$ and the reaction was stirred for 2 hours at room temperature. The mixture was concentrated to dryness under reduced pressure and the residue was purified by preparative HPLC to yield $1.44 \mathrm{~g}$ of the product.

LC-MS (Method 1): $R_{t}=0.9 \mathrm{~min} ; \mathrm{MS}($ ESIpos): $\mathrm{m} / \mathrm{z}=351(\mathrm{M}+\mathrm{H})+$.

\section{Intermediate 2}

$N$-[(benzyloxy)carbonyl]-L-alanyl-D-alanine<smiles>C[C@H](NC(=O)[C@H](C)NC(=O)OCc1ccccc1)C(=O)O</smiles>

Tert-butyl- $N$-[(benzyloxy) carbonyl]-L-alanyl-D-alaninate $(3.12 \mathrm{~g}, 8.90 \mathrm{mmol})$ was diluted in dichloromethane $(100 \mathrm{~mL})$. Trifluoroacetic acid $(25 \mathrm{~mL})$ was added and the reaction was stirred for 6 hours at room temperature. The mixture was concentrated under reduced pressure and the residue was diluted in acetonitrile/water and lyophilized to yield $1.57 \mathrm{~g}$ of the product.

\section{Intermediate 3}

tert-Butyl $N$-[(benzyloxy)carbonyl]-L-alanyl-D-alanyl-L-asparaginate<smiles>C[C@H](NC(=O)OCc1ccccc1)C(=O)N[C@@H](C)C(=O)N[C@@H](CC(N)=O)C(=O)OC(C)(C)C</smiles>

A solution of $\mathrm{N}$-[(benzyloxy)carbonyl]-L-alanyl-D-alanine $(2.62 \mathrm{~g}, 8.90 \mathrm{mmol})$ in DMF $(150 \mathrm{~mL})$ was supplemented with tert-butyl L-asparaginate $(1.84 \mathrm{~g}, \quad 9.79 \mathrm{mmol}), \quad \mathrm{N}, \mathrm{N}$ diisopropylethylamine $(4.7 \mathrm{~mL}, 27 \mathrm{mmol})$ and HATU $(4.40 \mathrm{~g}, 11.6 \mathrm{mmol})$ and the reaction was 
stirred at room temperature for 1 hour. The mixture was concentrated to dryness under reduced pressure and the residue was purified by preparative HPLC to yield $3.8 \mathrm{~g}$ of the product.

LC-MS (Method 1): $R_{t}=0.73$ min; MS (ESIpos): $\mathrm{m} / \mathrm{z}=465(M+H)+$

\section{Intermediate 4}

$N$-[(benzyloxy)carbonyl]-L-alanyl-D-alanyl-L-asparagine_-trifluoroacetic acid salt<smiles>CC(NC(=O)OCc1ccccc1)C(=O)N[C@@H](C)C(=O)N[C@@H](CC(N)=O)C(=O)O</smiles>

Tert-butyl- $N$-[(benzyloxy)carbonyl]-L-alanyl-D-alanyl-L-asparaginate $(600 \mathrm{mg}, 1.29 \mathrm{mmol})$ was diluted in dichloromethane $(20 \mathrm{~mL})$. Trifluoroacetic acid $(15 \mathrm{~mL})$ was added and the reaction was stirred for 90 minutes at room temperature. The mixture was concentrated to dryness under reduced pressure and the residue was purified by preparative HPLC to yield $238 \mathrm{mg}$ of the product.

LC-MS (Method 1): $R_{t}=0.53$ min; MS (ESIpos): $\mathrm{m} / \mathrm{z}=409(M+H)+$

\section{Intermediate 5}

tert-Butyl- $N$-[(benzyloxy)carbonyl]-L-alanyl- $N$-methyl-L-alaninate<smiles>C[C@H](NC(=O)OCc1ccccc1)C(=O)N(C)[C@@H](C)C(=O)OC(C)(C)C</smiles>

A solution of $N$-[(benzyloxy)carbonyl]-L-alanine $(750 \mathrm{mg}, 3.36 \mathrm{mmol})$ in DMF $(25 \mathrm{~mL})$ was supplemented with tert-butyl $N$-methyl-L-alaninate hydrogen chloric acid salt $(723 \mathrm{mg}, 3.70$ mmol), N,N-diisopropylethylamine (1.6 mL, $9.1 \mathrm{mmol})$ and HATU $(1.66 \mathrm{~g}, 4.37 \mathrm{mmol})$ and the reaction was stirred at room temperature for 30 minutes. The mixture was concentrated to dryness under reduced pressure and the residue was purified by preparative HPLC to yield 1.14 $\mathrm{g}$ of the product.

LC-MS (Method 1): $R_{t}=1.01 \mathrm{~min} ;$ MS (ESIpos): $\mathrm{m} / \mathrm{z}=364(\mathrm{M}+\mathrm{H})+$. 


\section{Intermediate 6}

$N$-[(benzyloxy)carbonyl]-L-alanyl- $N$-methyl-L-alanine<smiles>C[C@H](NC(=O)OCc1ccccc1)C(=O)N(C)[C@@H](C)C(=O)O</smiles>

Tert-butyl- $N$-[(benzyloxy)carbonyl]-L-alanyl- $N$-methyl-L-alaninate $(1.14 \mathrm{~g}, 3.11 \mathrm{mmol})$ was diluted in dichloromethane $(20 \mathrm{~mL})$. Trifluoroacetic acid $(20 \mathrm{~mL})$ was added and the reaction was stirred for 1 hour at room temperature. The mixture was concentrated under reduced pressure and the residue was diluted in acetonitrile/water and lyophilized to yield $1.16 \mathrm{~g}$ of the product. LC-MS (Method 1): $R_{t}=0.68$ min; MS (ESIpos): $\mathrm{m} / \mathrm{z}=308(M+H)+$.

\section{Intermediate 7}

tert-Butyl $N$-[(benzyloxy)carbonyl]-L-alanyl-N-methyl-L-alanyl-L-asparaginate<smiles>C[C@H](NC(=O)OCc1ccccc1)C(=O)N(C)[C@@H](C)C(=O)N[C@@H](CC(N)=O)C(=O)OC(C)(C)C</smiles>

A solution of $N$-[(benzyloxy)carbonyl]-L-alanyl- $N$-methyl-L-alanine (592 mg, $1.92 \mathrm{mmol}$ ) in DMF (32 $\mathrm{mL}$ ) was supplemented with tert-butyl L-asparaginate (398 mg, $2.11 \mathrm{mmol}), \mathrm{N}, \mathrm{N}$ diisopropylethylamine $(1.0 \mathrm{~mL}, 5.8 \mathrm{mmol})$ and HATU $(949 \mathrm{mg}, 2.50 \mathrm{mmol})$, and the reaction was stirred for 1 hour at room temperature. The mixture was concentrated to dryness under reduced pressure and the residue was purified by preparative HPLC to yield $898 \mathrm{mg}$ of the product.

LC-MS (Method 1): $R_{t}=0.75$ min; MS (ESIpos): $\mathrm{m} / \mathrm{z}=478(M+H)+$.

\section{Intermediate 8}

$N$-[(benzyloxy)carbonyl]-L-alanyl- $N$-methyl-L-alanyl-L-asparagine<smiles>C[C@H](NC(=O)OCc1ccccc1)C(=O)N(C)[C@@H](C)C(=O)N[C@@H](CC(N)=O)C(=O)O</smiles> 
Tert-butyl- $N$-[(benzyloxy)carbonyl]-L-alanyl- $N$-methyl-L-alanyl-L-asparaginate $\quad\left(\begin{array}{lll}2.81 & \mathrm{~g}, \quad 5.88\end{array}\right.$ $\mathrm{mmol}$ ) was diluted in dichloromethane $(66 \mathrm{~mL})$. Trifluoroacetic acid $(33 \mathrm{~mL})$ was added and the reaction was stirred for 3 hours at room temperature. The mixture was concentrated to dryness under reduced pressure and the residue was purified by preparative HPLC to yield $848 \mathrm{mg}$ of the product.

LC-MS (Method 1): $R_{t}=0.57 \mathrm{~min} ; M S(E S I p o s): ~ m / z=422(M+H)+$.

\section{Intermediate 9}

2-(trimethylsilyl)ethyl $N$-[(benzyloxy)carbonyl]-L-alanyl- $N$-methyl-L-alanyl-D-asparaginate<smiles>C[C@H](NC(=O)OCc1ccccc1)C(=O)N(C)[C@@H](C)C(=O)N[C@@H](CC(N)=O)C(=O)OCC[Si](C)(C)C</smiles>

A solution of $N$-[(benzyloxy)carbonyl]-L-alanyl- $N$-methyl-L-alanine $(86.0 \mathrm{mg}, 279 \mu \mathrm{mol})$ in DMF $(25 \mathrm{~mL})$ was supplemented with acetic acid-2-(trimethylsilyl)ethyl D-asparaginate $(680 \mu \mathrm{L}, 330$ $\mu \mathrm{mol}), N, N$-diisopropylethylamine $(150 \mu \mathrm{L}, 840 \mu \mathrm{mol})$ and HATU (127 mg, $335 \mu \mathrm{mol})$, and the reaction was stirred for 1 hour at room temperature. The mixture was concentrated to dryness under reduced pressure and the residue was purified by preparative HPLC to yield $898 \mathrm{mg}$ of the product.

LC-MS (Method 1): $R_{t}=0.94 \mathrm{~min} ;$ MS (ESIpos): $\mathrm{m} / \mathrm{z}=523(\mathrm{M}+\mathrm{H})+$.

\section{Intermediate 10}

$N$-[(benzyloxy)carbonyl]-L-alanyl- $N$-methyl-L-alanyl-D-asparagine<smiles>CC(NC(=O)OCc1ccccc1)C(=O)N(C)[C@@H](C)C(=O)N[C@@H](CC(N)=O)C(=O)O</smiles>

2-(trimethylsilyl)ethyl $N$-[(benzyloxy)carbonyl]-L-alanyl- $N$-methyl-L-alanyl-D-asparaginate (45.0 $\mathrm{mg}, 86.1 \mu \mathrm{mol}$ ) was dissolved in $5 \mathrm{~mL}$ of 2,2,2-trifluoroethanol. Zinc chloride (70 mg, $517 \mu \mathrm{mol})$ was added and the reaction was stirred at $50^{\circ} \mathrm{C}$ for 3 hours. The mixture was diluted with water and $151 \mathrm{mg}(517 \mu \mathrm{mol})$ ethylene diamine- $N, N, N, N$-tetraacetic acid was added. The mixture was stirred for a few minutes. The reaction was concentrated under reduced pressure and the residue was purified by preparative HPLC to yield $10.5 \mathrm{mg}$ of the product.

LC-MS (Method 1): $\mathrm{R}_{\mathrm{t}}=0.58 \mathrm{~min} ; \mathrm{MS}\left(\right.$ ESIpos): $\mathrm{m} / \mathrm{z}=423[\mathrm{M}+\mathrm{H}]^{+}$ 


\section{Synthesis of Compound 2}<smiles>CC(C)(C)OC(=O)NCCC(=O)O</smiles><smiles>NCCC(=O)N[C@@H](CCC(=O)OCc1ccccc1)C(=O)OCc1ccccc1</smiles><smiles>CC(C)(C)C(C(=O)N(CCc1ccccc1)CCC(NC(=O)OCC[Si](C)(C)C)C(=O)O)n1cc(-c2ccccc2F)cc1-c1ccccc1F</smiles>

Intermediate 12

Compound 1

DMF, DIPEA, HATU<smiles>CC(C)(C)C(c1cc(-c2cc(F)ccc2F)cn1Cc1ccccc1)N(CCC(N)C(=O)NCCC(=O)N[C@@H](CCC(=O)OCc1ccccc1)C(=O)OCc1ccccc1)C(=O)CO</smiles><smiles>C[C@H]1C[C@@H](C)C1</smiles><smiles>CC(C)(C)C(c1cc(-c2cc(F)ccc2F)cn1Cc1ccccc1)N(CCC(NC(=O)OCC[Si](C)(C)C)C(=O)NCCC(=O)N[C@@H](CCOC(=O)OCc1ccccc1)C(=O)OCc1ccccc1)C(=O)CO</smiles>

Scheme S1: Synthesis of Compound 2

\section{Intermediate 11}

Dibenzyl N-(tert-butoxycarbonyl)-beta-alanyl-D-glutamate<smiles>CC(C)(C)OC(=O)NCCC(=O)N[C@@H](CCC(=O)OCc1ccccc1)C(=O)OCc1ccccc1</smiles>

A solution of dibenzyl-D-glutamate $(3.78 \mathrm{~g}, 11.5 \mathrm{mmol})$ and $\mathrm{N}$-(tert-butoxycarbonyl)-beta-alanine $(2.40 \mathrm{~g}, 12.7 \mathrm{mmol})$ in DMF $(75 \mathrm{~mL})$ was supplemented with $N, N$-diisopropylethylamine $(6.0 \mathrm{~mL}$, $35 \mathrm{mmol})$ and HATU $(5.27 \mathrm{~g}, 13.9 \mathrm{mmol})$, and the reaction was stirred for 1 hour at room temperature. The reaction was concentrated to dryness under reduced pressure, and the residue was purified by preparative HPLC to yield $7.00 \mathrm{~g}$ of the product. 
LC-MS (Method 1): Rt = $1.10 \mathrm{~min} ; \mathrm{MS}($ ESIpos): $\mathrm{m} / \mathrm{z}=498(\mathrm{M}+\mathrm{H})+$.

\section{Intermediate 12}

Dibenzyl beta-alanyl-D-glutamate<smiles>NCCC(=O)N[C@@H](CCC(=O)OCc1ccccc1)C(=O)OCc1ccccc1</smiles>

A solution of dibenzyl $\mathrm{N}$-(tert-butoxycarbonyl)-beta-alanyl-D-glutamate $(7.50 \mathrm{~g}, 14.2 \mathrm{mmol})$ in dichloromethane $(70 \mathrm{~mL})$ was supplemented with trifluoroacetic acid $(50 \mathrm{~mL})$, and the reaction was stirred for 1 hour at room temperature. The mixture was then concentrated to dryness under reduced pressure, and the residue was suspended in diethyl ether and pentan and the mixture was filtrated. The residue was dissolved in acetonitrile/water (1:1) and the mixture was lyophilized to yield $6.5 \mathrm{~g}$ of the product.

LC-MS (Method 1): Rt = $0.66 \mathrm{~min} ; \mathrm{MS}($ ESIpos): $\mathrm{m} / \mathrm{z}=398(\mathrm{M}+\mathrm{H})+$.

\section{Intermediate 13}

Dibenzyl N-[(2S)-4-[\{(1R)-1-[1-benzyl-4-(2,5-difluorophenyl)-1H-pyrrol-2-yl]-2,2-

dimethylpropyl\}(hydroxyacetyl)amino]-2-(\{[2-(trimethylsilyl)ethoxy]carbonyl\}amino)butanoyl]beta-alanyl-D-glutamate<smiles>CC(C)(C)C(c1cc(-c2cc(F)ccc2F)cn1Cc1ccccc1)N(CC[C@H](NC(=O)OCC[Si](C)(C)C)C(=O)NCCC(=O)N[C@@H](CCC(=O)OCc1ccccc1)C(=O)OCc1ccccc1)C(=O)CO</smiles>

The solution of (2S)-4-[\{(1R)-1-[1-benzyl-4-(2,5-difluorophenyl)-1H-pyrrol-2-yl]-2,2dimethylpropyl\}(hydroxyacetyl)amino]-2-(\{[2-(trimethylsilyl)ethoxy]carbonyl\}amino)butanoic $\operatorname{acid}^{\mathrm{S} 2}(500 \mathrm{mg}, 760 \mu \mathrm{mol})$ in DMF $(75 \mathrm{~mL})$ was supplemented with dibenzyl beta-alanyl-Dglutamate (584 mg, $1.14 \mathrm{mmol}), N, N$-diisopropylethylamine (400 $\mu \mathrm{L}, 2.3 \mathrm{mmol})$ and HATU (434 $\mathrm{mg}, 1.14 \mathrm{mmol}$ ). The reaction was stirred at room temperature for $1 \mathrm{~h}$ and then concentrated to 
dryness under reduced pressure. The residue was purified by preparative HPLC to yield $552 \mathrm{mg}$ of the product.

LC-MS (Method 1): $R_{t}=1.54$ min; MS (ESIpos): $\mathrm{m} / \mathrm{z}=1038(\mathrm{M}+\mathrm{H})+$.

\section{Compound 2}

Dibenzyl N-\{(2S)-2-amino-4-[\{(1R)-1-[1-benzyl-4-(2,5-difluorophenyl)-1H-pyrrol-2-yl]-2,2-

dimethylpropyl\}(hydroxyacetyl)amino]butanoyl\}-beta-alanyl-D-glutamate trifluor acetic acid salt<smiles>CC(C)(C)C(c1cc(-c2cc(F)ccc2F)cn1Cc1ccccc1)N(CCC(N)C(=O)NCCC(=O)N[C@@H](CCC(=O)OCc1ccccc1)C(=O)OCc1ccccc1)C(=O)CO</smiles>

Dibenzyl $\quad N-[(2 S)-4-[\{(1 \mathrm{R})-1-[1-$ benzyl-4-(2,5-difluorophenyl)-1H-pyrrol-2-yl]-2,2-dimethylpropyl\} (hydroxyacetyl)amino]-2-(\{[2-(trimethylsilyl)ethoxy]carbonyl\}amino)butanoyl]-beta-alanyl-Dglutamate $(553 \mathrm{mg}, 533 \mu \mathrm{mol}$ ) was dissolved in $15 \mathrm{~mL}$ of 2,2,2-trifluoroethanol. Zinc chloride (871 $\mathrm{mg}, 6.39 \mathrm{mmol}$ ) was added, and the reaction was stirred at $50^{\circ} \mathrm{C}$ for 2 hours. The mixture was diluted with water/acetonitrile (1:1), supplemented with $1.87 \mathrm{~g}(6.39 \mathrm{mmol})$ of ethylene diamine- $N, N, N, N$-tetraacetic acid and stirred for a few minutes. The reaction was concentrated under reduced pressure and the residue was purified by preparative HPLC. Concentration of the appropriate fractions and lyophilization of the residue from acetonitrile/water yielded $371 \mathrm{mg}$ of the product.

LC-MS (Method 1): $R_{t}=1.02 \mathrm{~min}$; MS (ESIpos): $\mathrm{m} / \mathrm{z}=894[\mathrm{M}+\mathrm{H}]^{+}$ 


\section{Synthesis of ADCs precursors}<smiles>CC(C)(C)C(c1cc(-c2cccc(F)c2)cn1Cc1ccccc1)C(C(=O)CO)N(CCC(N)C(=O)NCCC(=O)N[C@@H](CCC(=O)OCc1ccccc1)C(=O)OCc1ccccc1)C(=O)OCc1ccccc1</smiles>

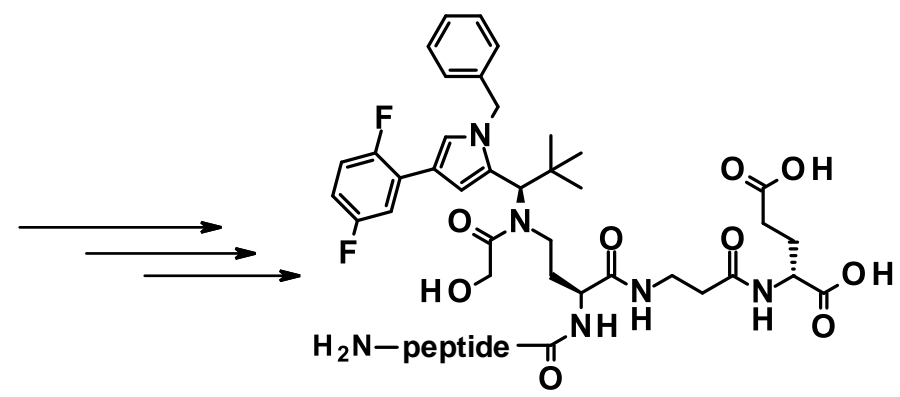

Compound 2

\section{Compounds 3a-h}

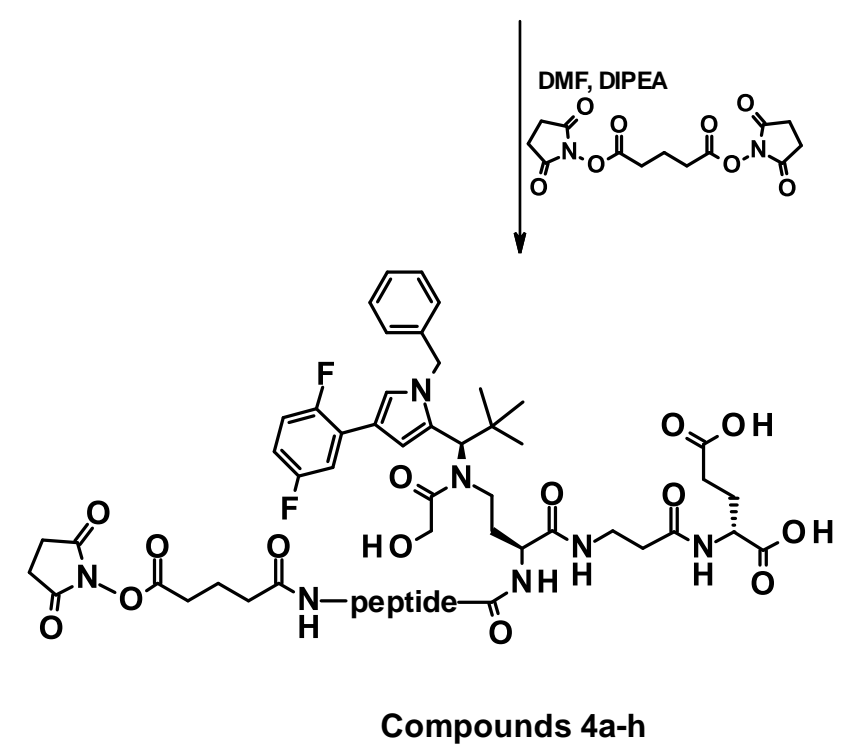

Scheme S2: Synthesis of Compound 4a-h 


\section{Intermediate 14}

Dibenzyl N-[(2S)-4-[\{(1R)-1-[1-benzyl-4-(2,5-difluorophenyl)-1H-pyrrol-2-yl]-2,2-

dimethylpropyl $\}$ (hydroxyacetyl)amino $-2-\left\{\left[N^{2}\right.\right.$-(tert-butoxycarbonyl)-L-

asparaginyl]amino\}butanoyl]-beta-alanyl-D-glutamate

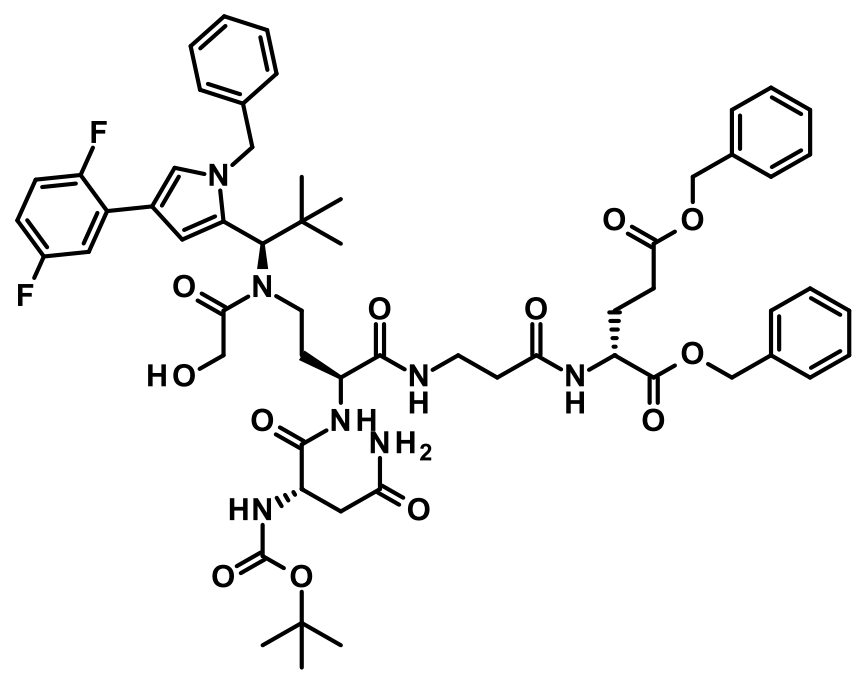

Dibenzyl N-\{(2S)-2-amino-4-[\{(1R)-1-[1-benzyl-4-(2,5-difluorophenyl)-1H-pyrrol-2-yl]-2,2dimethylpropyl\}(hydroxyacetyl)amino]butanoyl\}-beta-alanyl-D-glutamate (500 mg, $515 \mu \mathrm{mol}$ ) and 2,5-dioxopyrrolidin-1-yl $N^{2}$-(tert-butoxycarbonyl)-L-asparaginate (254 mg, $772 \mu \mathrm{mol}$ ) were dissolved in DMF $(20 \mathrm{~mL})$ and the mixture was supplemented with $N, N$-diisopropylethylamine $(270 \mu \mathrm{L}, 1.5 \mathrm{mmol})$. The reaction was stirred overnight and the mixture was concentrated to dryness under reduced pressure. The residue was purified by preparative HPLC to yield $516 \mathrm{mg}$ of the product.

LC-MS (Method 1): $\mathrm{R}_{\mathrm{t}}=1.35 \mathrm{~min} ; \mathrm{MS}$ (ESIpos): $\mathrm{m} / \mathrm{z}=1108[\mathrm{M}+\mathrm{H}]^{+}$

\section{Intermediate 15}

Dibenzyl N-\{(2S)-2-(L-asparaginylamino)-4-[\{(1R)-1-[1-benzyl-4-(2,5-difluorophenyl)-1H-pyrrol2-yl]-2,2-dimethylpropyl\}(hydroxyacetyl)amino]butanoyl\}-beta-alanyl-D-glutamate<smiles>CC(C)(C)[C@H](c1cc(-c2cc(F)ccc2F)cn1Cc1ccccc1)N(CC[C@H](NC(=O)[C@H](N)CC(=O)O)C(=O)NCCC(=O)N[C@@H](CCC(=O)OCc1ccccc1)C(=O)OCc1ccccc1)C(=O)CO</smiles> 
Dibenzyl $\quad N$-[(2S)-4-[\{(1R)-1-[1-benzyl-4-(2,5-difluorophenyl)-1H-pyrrol-2-yl]-2,2-dimethylpropyl\} (hydroxyacetyl)amino]-2-\{[ $N^{2}$-(tert-butoxycarbonyl)-L-asparaginyl]amino\}butanoyl]-beta-alanylD-glutamate $(1.02 \mathrm{~g}, 917 \mu \mathrm{mol})$ was dissolved in $20 \mathrm{~mL}$ of 2,2,2-trifluoroethanol. Zinc chloride (750 mg, $5.50 \mathrm{mmol}$ ) of were added, and the reaction was stirred at $50{ }^{\circ} \mathrm{C}$ for 30 minutes. The mixture was diluted with $10 \mathrm{~mL}$ water/acetonitrile (1:1) and supplemented with $1.61 \mathrm{~g}$ (5.50 mmol) of ethylene diamine- $N, N, N, N$-tetraacetic acid. The mixture was stirred for a few minutes. The reaction was concentrated under reduced pressure and the residue was purified by preparative HPLC. Concentration of the appropriate fractions and lyophilization yielded $745 \mathrm{mg}$ of the product.

LC-MS (Method 1): $R_{t}=1.05 \mathrm{~min} ; \mathrm{MS}$ (ESIpos): $\mathrm{m} / \mathrm{z}=1008[\mathrm{M}+\mathrm{H}]^{+}$

\section{Intermediate 16}

Dibenzyl (2R)-2-\{[(6S,9S,12S,15S)-12-(2-amino-2-oxoethyl)-15-\{2-[\{(1R)-1-[1-benzyl-4-(2,5difluorophenyl)-1H-pyrrol-2-yl]-2,2-dimethylpropyl\}(hydroxyacetyl)amino]ethyl\}-2,2,6,9tetramethyl-4,7,10,13,16,20-hexaoxo-3-oxa-5,8,11,14,17-pentaazaicosan-20yl]amino\}pentanedioate<smiles>C[C@H](NC(=O)OC(C)(C)C)C(=O)N[C@@H](C)C(=O)N[C@@H](CC(N)=O)C(=O)N[C@@H](CCN(C(=O)CO)C(c1cc(-c2cc(F)ccc2F)cn1Cc1ccccc1)C(C)(C)C)C(=O)NCCC(=O)N[C@@H](CCC(=O)OCc1ccccc1)C(=O)OCc1ccccc1</smiles>

A solution of dibenzyl $N$-\{(2S)-2-(L-asparaginylamino)-4-[\{(1R)-1-[1-benzyl-4-(2,5difluorophenyl)-1H-pyrrol-2-yl]-2,2-dimethylpropyl\}(hydroxyacetyl)amino]butanoyl\}-beta-alanylD-glutamate $(100 \mathrm{mg}, 89.1 \mu \mathrm{mol})$ in DMF $(10 \mathrm{~mL})$ was supplemented with dibenzyl $N$-(tertbutoxycarbonyl)-L-alanyl-L-alanine ( $27.8 \mathrm{mg}, 107 \mu \mathrm{mol}), N, N$-diisopropylethylamine $(62 \mu \mathrm{L}, 360$ $\mu \mathrm{mol})$ and HATU $(40.7 \mathrm{mg}, 107 \mu \mathrm{mol})$ and the reaction was stirred for 10 minutes at room temperature. The mixture was concentrated to dryness under reduced pressure and the residue was purified by preparative HPLC to yield $99 \mathrm{mg}$ of the product.

LC-MS (Method 1): $R_{t}=1.30 \mathrm{~min} ; M S(E S I p o s): m / z=1250(M+H)+$. 


\section{Intermediate 17}

Dibenzyl (2R)-2-\{[(6S,9S,12S,15S)-15-amino-9-(2-amino-2-oxoethyl)-6-\{2-[\{(1R)-1-[1-benzyl-4(2,5-difluorophenyl)-1H-pyrrol-2-yl]-2,2-dimethylpropyl\}(hydroxyacetyl)amino]ethyl\}-12-methyl5,8,11,14-tetraoxo-4,7,10,13-tetraazahexadecanan-1-oyl]amino\}pentanedioate<smiles>C[C@H](N)C(=O)N[C@@H](C)C(=O)N[C@@H](CC(N)=O)C(NCCC(=O)N[C@@H](CCC(=O)OCc1ccccc1)C(=O)OCc1ccccc1)C(=O)NCCN(C(=O)CO)C(c1cc(-c2cc(F)ccc2F)cn1Cc1ccccc1)C(C)(C)C</smiles>

Dibenzyl (2R)-2-\{[(6S,9S,12S,15S)-12-(2-amino-2-oxoethyl)-15-\{2-[\{(1R)-1-[1-benzyl-4-(2,5difluorophenyl)-1H-pyrrol-2-yl]-2,2-dimethylpropyl\}(hydroxyacetyl)amino]ethyl\}-2,2,6,9tetramethyl-4,7,10,13,16,20-hexaoxo-3-oxa-5,8,11,14,17-pentaazaicosan-20yl]amino\}pentanedioate $(99.0 \mathrm{mg}, 79.2 \mu \mathrm{mol})$ was dissolved in $10 \mathrm{~mL}$ of 2,2,2-trifluoroethanol. Zinc chloride $(64.7 \mathrm{mg}, 475 \mu \mathrm{mol})$ was added, and the reaction was stirred at $50{ }^{\circ} \mathrm{C}$ for 30 minutes. The mixture was diluted with $10 \mathrm{~mL}$ water and supplemented with $200 \mu \mathrm{L}$ of TFA and $139 \mathrm{mg}(475 \mu \mathrm{mol})$ of ethylene diamine- $N, N, N, N$-tetraacetic acid. The mixture was stirred for a few minutes. The reaction was filtrated and the filtrate was concentrated under reduced pressure. The residue was purified by preparative HPLC. The appropriate fractions were concentrated and lyophilizated to yield $86 \mathrm{mg}$ of the product.

LC-MS (Method 1): $\mathrm{R}_{\mathrm{t}}=1.05 \mathrm{~min} ; \mathrm{MS}$ (ESIpos): $\mathrm{m} / \mathrm{z}=1150[\mathrm{M}+\mathrm{H}]^{+}$

\section{Compound 3a}

L-alanyl-L-alanyl- $N^{1}-\{(2 S)-4-[\{(1 \mathrm{R})-1$-[1-benzyl-4-(2,5-difluorophenyl)-1H-pyrrol-2-yl]-2,2dimethylpropyl\}(hydroxyacetyl)amino]-1-[(3-\{[(1R)-1,3-dicarboxypropyl]amino\}-3oxopropyl)amino]-1-oxobutan-2-yl\}-L-aspartamide-trifluoroacetic acid salt 


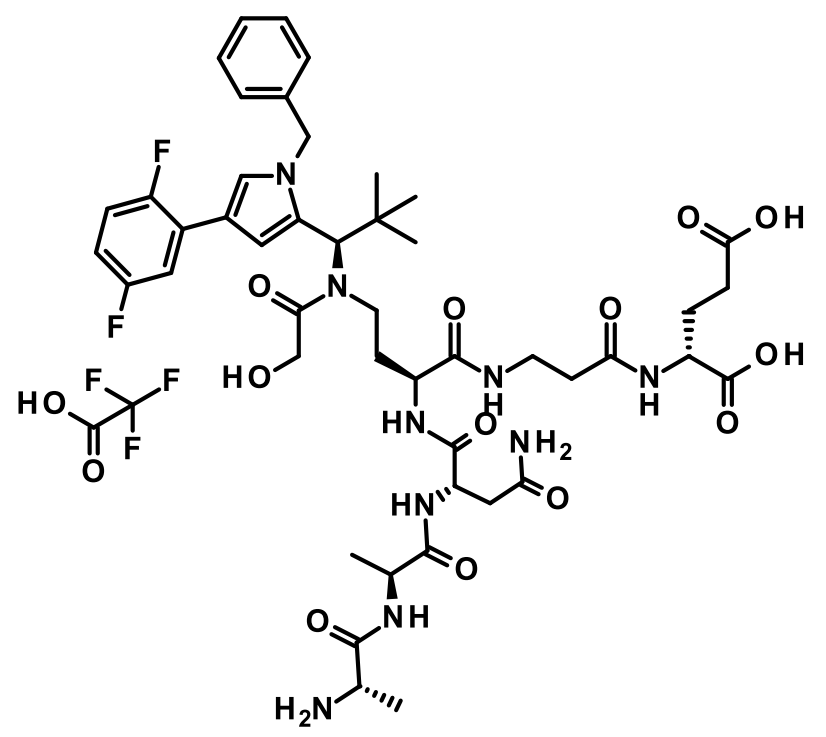

A solution of dibenzyl (2R)-2-\{[(6S,9S,12S,15S)-15-amino-9-(2-amino-2-oxoethyl)-6-\{2-[\{(1R)-1[1-benzyl-4-(2,5-difluorophenyl)-1H-pyrrol-2-yl]-2,2-dimethylpropyl\}(hydroxyacetyl) amino]ethyl\}-12-methyl-5,8,11,14-tetraoxo-4,7,10,13-tetraazahexadecanan-1oyl]amino\}pentanedioate $(40.0 \mathrm{mg}, 31.6 \mu \mathrm{mol})$ in ethanol $(10 \mathrm{~mL})$ was supplemented with palladium on charcoal $(10 \%, 5 \mathrm{mg})$. The mixture was hydrogenated at ambient pressure for 1 hour. The solids were filtered off and the residue was washed several times with acetonitrile/water (1:1). The filtrate was concentrated under reduced pressure and the remaining residue was lyophilized to yield $34 \mathrm{mg}$ of the title product.

LC-MS (Method 1): $\mathrm{R}_{\mathrm{t}}=0.76 \mathrm{~min} ; \mathrm{MS}\left(\right.$ ESIpos): $\mathrm{m} / \mathrm{z}=970[\mathrm{M}+\mathrm{H}]^{+}$

\section{Compound 4a}

$N$-\{5-[(2,5-dioxopyrrolidin-1-yl)oxy]-5-oxopentanoyl\}-L-alanyl-L-alanyl-N ${ }^{1}-\{(2 S)-4-[\{(1 \mathrm{R})-1-[1-$ benzyl-4-(2,5-difluorophenyl)-1H-pyrrol-2-yl]-2,2-dimethylpropyl\}(hydroxyacetyl)amino]-1-[(3$\{[(1 \mathrm{R})$-1,3-dicarboxypropyl]amino\}-3-oxopropyl)amino]-1-oxobutan-2-yl\}-L-aspartamide 


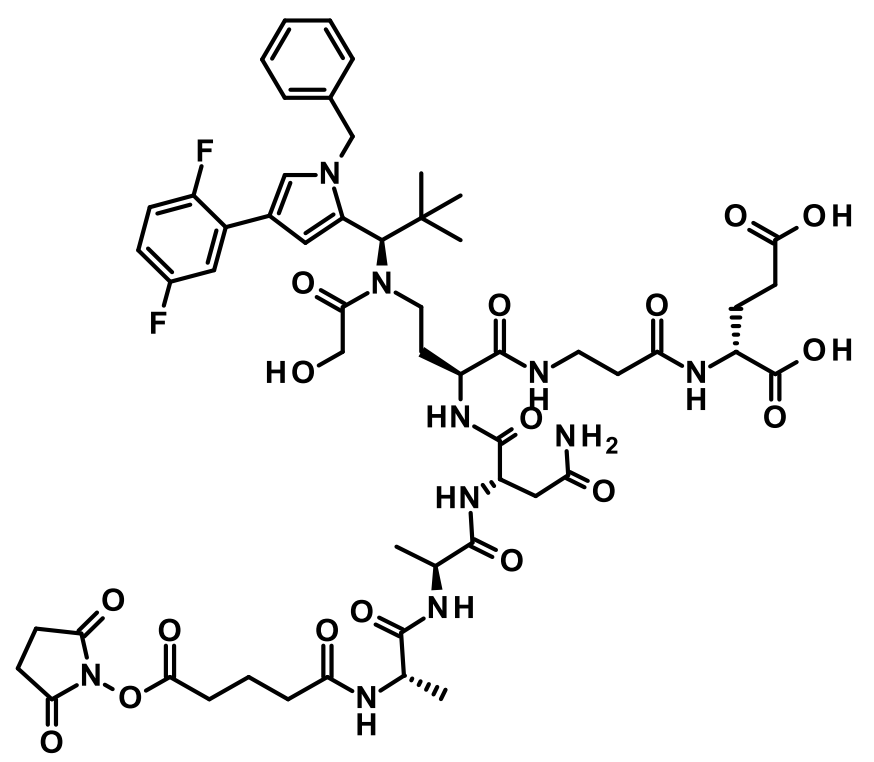

L-alanyl-L-alanyl- $N^{1}-\{(2 S)-4-[\{(1 \mathrm{R})-1-[1-$ benzyl-4-(2,5-difluorophenyl)-1H-pyrrol-2-yl]-2,2dimethylpropyl\}(hydroxyacetyl)amino]-1-[(3-\{[(1R)-1,3-dicarboxypropyl]amino\}-3oxopropyl)amino]-1-oxobutan-2-yl\}-L-aspartamide) (34.0 mg, $31.4 \mu \mathrm{mol})$ and 1,1'-[(1,5dioxopentane-1,5-diyl)bis(oxy)]di(pyrrolidine-2,5-dione) (12.3 mg, $37.6 \mu \mathrm{mol})$ were dissolved in DMF $(3 \mathrm{~mL})$ and $N, N$-diisopropylethylamine $(11 \mu \mathrm{L}, 63 \mu \mathrm{mol})$ was added. The reaction was stirred for 30 minutes. The mixture was concentrated under reduced pressure and the residue was purified by preparative HPLC. Concentration of the appropriate fractions and lyophilization yielded $18 \mathrm{mg}$ of the product.

LC-MS (Method 1): $R_{t}=0.93$ min; MS (ESIpos): $\mathrm{m} / \mathrm{z}=1203[\mathrm{M}+\mathrm{Na}]^{+}$

HPLC-HRMS (Method 4): $\mathrm{R}_{\mathrm{t}}=0.94 \mathrm{~min} ; \mathrm{MS}$ (ESIneg): m/z: calcd for $\mathrm{C}_{55} \mathrm{H}_{69} \mathrm{~N}_{10} \mathrm{O}_{17} \mathrm{~F}_{2}[\mathrm{M}-\mathrm{H}]$ : 1179.4810; found: $1179.4827(\mathrm{M}-\mathrm{H})^{-}$. 


\section{Intermediate 18}

Dibenzyl (2R)-2-\{[(5S,8R,11S,14S)-11-(2-amino-2-oxoethyl)-14-\{2-[\{(1R)-1-[1-benzyl-4-(2,5difluorophenyl)-1H-pyrrol-2-yl]-2,2-dimethylpropyl\}(hydroxyacetyl)amino]ethyl\}-5,8-dimethyl3,6,9,12,15,19-hexaoxo-1-phenyl-2-oxa-4,7,10,13,16-pentaazanonadecan-19yl]amino\}pentanedioate<smiles>C[C@H](NC(=O)[C@H](C)NC(=O)[C@H](CC(N)=O)NC(O)C(CCN(C(=O)CO)C(c1cc(-c2cc(F)ccc2F)cn1Cc1ccccc1)C(C)(C)C)NCCC(=O)N[C@@H](CCC(=O)OCc1ccccc1)C(=O)OCc1ccccc1)C(=O)N[C@@H](C)C(=O)OCc1ccccc1</smiles>

A solution of dibenzyl $N$-\{(2S)-2-amino-4-[\{(1R)-1-[1-benzyl-4-(2,5-difluorophenyl)-1H-pyrrol-2yl]-2,2-dimethylpropyl\}(hydroxyacetyl)amino]butanoyl\}-beta-alanyl-D-glutamate $(80.0 \mathrm{mg}, 78.4$ $\mu \mathrm{mol})$ in DMF $(10 \mathrm{~mL})$ was supplemented with $N$-[(benzyloxy)carbonyl]-L-alanyl-D-alanyl-Lasparagine (51.5 mg, $94.1 \mu \mathrm{mol}), N, N$-diisopropylethylamine $(41 \mu \mathrm{L}, 240 \mu \mathrm{mol})$ and HATU (44.7 $\mathrm{mg}, 118 \mu \mathrm{mol})$ and the reaction was stirred for 1 hour at room temperature. The mixture was concentrated to dryness under reduced pressure and the residue was purified by preparative HPLC to yield $73 \mathrm{mg}$ of the product.

LC-MS (Method 1): $\mathrm{R}_{\mathrm{t}}=1.33 \mathrm{~min} ; \mathrm{MS}$ (ESIpos): $\mathrm{m} / \mathrm{z}=1284[\mathrm{M}+\mathrm{H}]^{+}$ 


\section{Compound 3b}

L-alanyl-D-alanyl- $N^{\prime}-\{(2 S)-4-[\{(1 \mathrm{R})-1$-[1-benzyl-4-(2,5-difluorophenyl)-1H-pyrrol-2-yl]-2,2dimethylpropyl\}(hydroxyacetyl)amino]-1-[(3-\{[(1R)-1,3-dicarboxypropyl]amino\}-3oxopropyl)amino]-1-oxobutan-2-yl\}-L-aspartamide

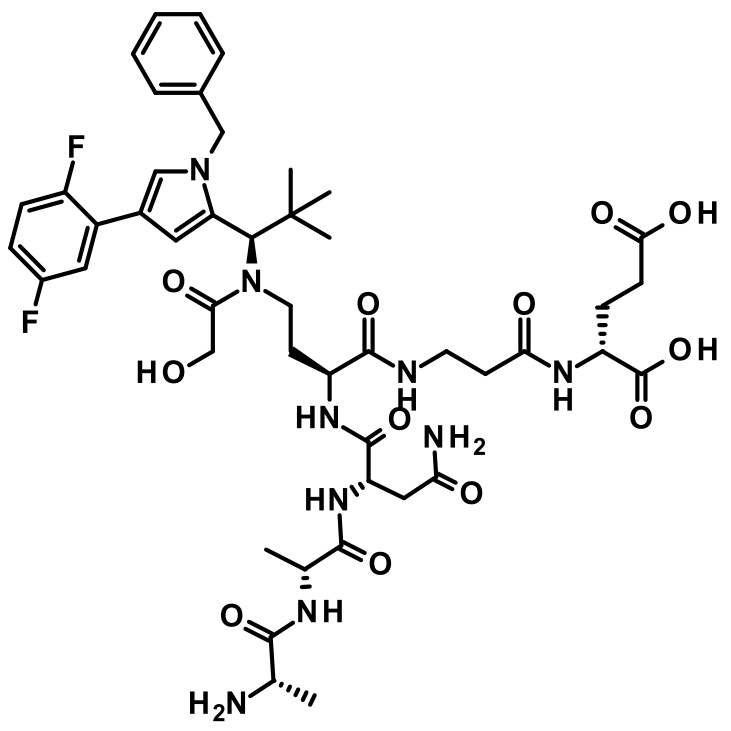

A solution of dibenzyl (2R)-2-\{[(5S,8R,11S,14S)-11-(2-amino-2-oxoethyl)-14-\{2-[\{(1R)-1-[1benzyl-4-(2,5-difluorophenyl)-1 H-pyrrol-2-yl]-2,2-dimethylpropyl\}(hydroxyacetyl)amino]ethyl\}5,8-dimethyl-3,6,9,12,15,19-hexaoxo-1-phenyl-2-oxa-4,7,10,13,16-pentaazanonadecan-19yl]amino\}pentanedioate $(73.0 \mathrm{mg}, 56.8 \mu \mathrm{mol})$ in ethanol $(20 \mathrm{~mL})$ was supplemented with palladium on charcoal $(10 \%, 7 \mathrm{mg})$. The mixture was hydrogenated at ambient pressure for 1 hour. The solids were filtered off and the residue was washed several times with acetonitrile/water (1:1). The filtrate was concentrated under reduced pressure and the remaining residue was lyophilized to give $34 \mathrm{mg}$ of the title product.

LC-MS (Method 1): $R_{t}=0.77 \min ;$ MS (ESIpos): $\mathrm{m} / \mathrm{z}=970[\mathrm{M}+\mathrm{H}]^{+}$

\section{Compound 4b}

$N$-\{5-[(2,5-dioxopyrrolidin-1-yl)oxy]-5-oxopentanoyl\}-L-alanyl-D-alanyl- $N^{1}-\{(2 S)-4-[\{(1 \mathrm{R})-1-[1-$ benzyl-4-(2,5-difluorophenyl)-1H-pyrrol-2-yl]-2,2-dimethylpropyl\}(hydroxyacetyl)amino]-1-[(3$\{[(1 \mathrm{R})$-1,3-dicarboxypropyl]amino\}-3-oxopropyl)amino]-1-oxobutan-2-yl\}-L-aspartamide 


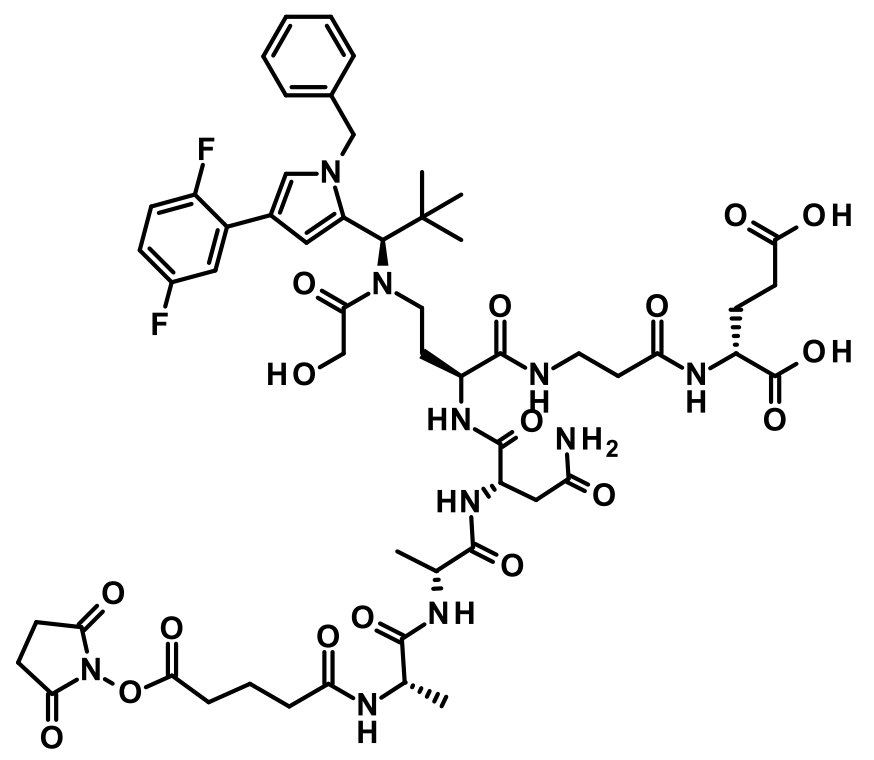

L-alanyl-D-alanyl- $N^{\prime}-\{(2 S)-4-[\{(1 \mathrm{R})-1$-[1-benzyl-4-(2,5-difluorophenyl)-1H-pyrrol-2-yl]-2,2dimethylpropyl\}(hydroxyacetyl)amino]-1-[(3-\{[(1R)-1,3-dicarboxypropyl]amino\}-3oxopropyl)amino]-1-oxobutan-2-yl\}-L-aspartamide (12 mg, $12.4 \mu \mathrm{mol})$ and 1,1'-[(1,5dioxopentane-1,5-diyl)bis(oxy)]di(pyrrolidine-2,5-dione) (10 mg, $30.9 \mu \mathrm{mol}$ ) were dissolved in DMF (8 mL) and $N, N$-diisopropylethylamine $(7.8 \mu \mathrm{L}, 45 \mu \mathrm{mol})$ was added. The mixture was stirred for 1 hour. The mixture was concentrated under reduced pressure and the residue was purified by preparative HPLC. Concentration of the appropriate fractions and lyophilization yielded $8 \mathrm{mg}$ of the product.

LC-MS (Method 1): $R_{t}=0.94$ min; MS (ESIpos): $\mathrm{m} / \mathrm{z}=1180[\mathrm{M}+\mathrm{Na}]^{+}$

HPLC-HRMS (Method 4): $\mathrm{R}_{\mathrm{t}}=0.94 \mathrm{~min}$; MS (ESI): m/z: calcd for $\mathrm{C}_{55} \mathrm{H}_{69} \mathrm{~N}_{10} \mathrm{O}_{17} \mathrm{~F}_{2}[\mathrm{M}-\mathrm{H}]^{*}$ : 1179.4810; found: $1179.4808(\mathrm{M}-\mathrm{H})^{-}$.

\section{$\underline{\text { Intermediate } 19}$}

Dibenzyl (2R)-2-\{[(5S,8S,11S,14S)-11-(2-amino-2-oxoethyl)-14-\{2-[\{(1R)-1-[1-benzyl-4-(2,5difluorophenyl)-1 H-pyrrol-2-yl]-2,2-dimethylpropyl\}(hydroxyacetyl)amino]ethyl\}-5,7,8-trimethyl3,6,9,12,15,19-hexaoxo-1-phenyl-2-oxa-4,7,10,13,16-pentaazanonadecan-19yl]amino\}pentanedioate 


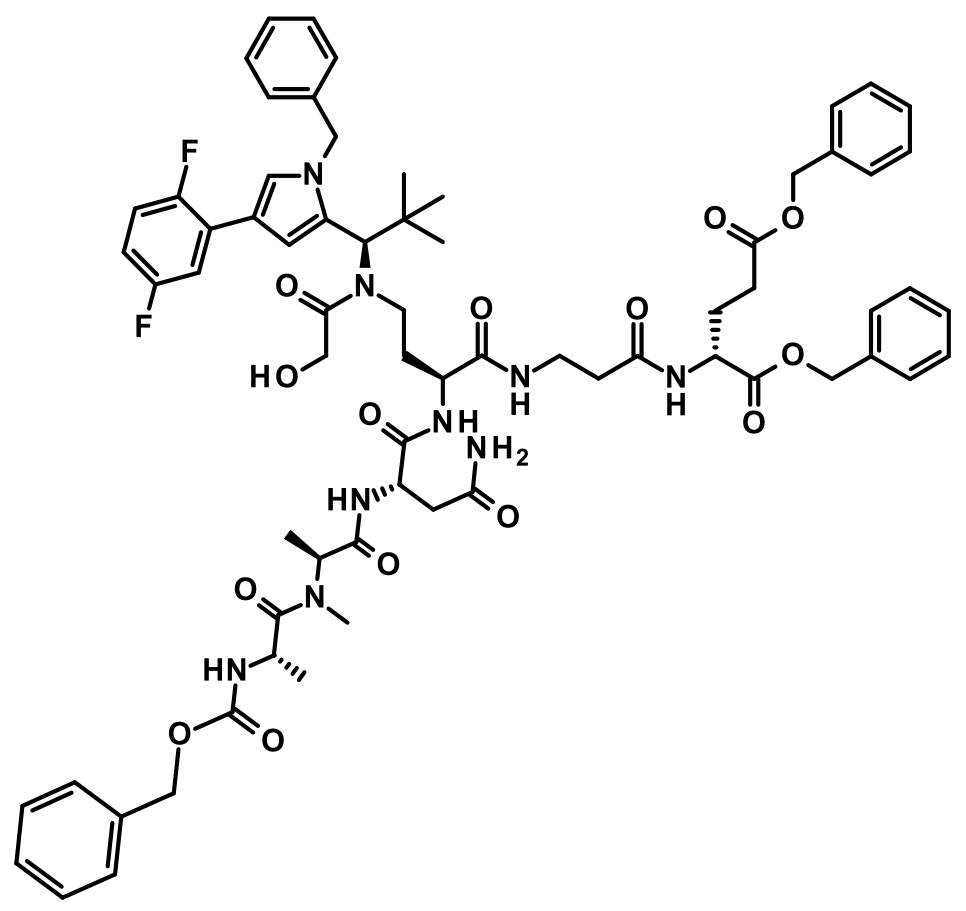

A solution of dibenzyl $N$-\{(2S)-2-amino-4-[\{(1R)-1-[1-benzyl-4-(2,5-difluorophenyl)-1 H-pyrrol-2yl]-2,2-dimethylpropyl\}(hydroxyacetyl)amino]butanoyl\}-beta-alanyl-D-glutamate (548 mg, 544 $\mu \mathrm{mol})$ in DMF (69 $\mathrm{mL}$ ) was supplemented with $N$-[(benzyloxy)carbonyl]-L-alanyl- $N$-methyl-Lalanyl-L-asparagine $(281 \mathrm{mg}, 598 \mu \mathrm{mol}), \mathrm{N}, \mathrm{N}$-diisopropylethylamine $(280 \mu \mathrm{L}, 1.6 \mathrm{mmol})$ and HATU (269 mg, $707 \mu \mathrm{mol})$ and the reaction was stirred for 1.5 hours at room temperature. The mixture was concentrated to dryness under reduced pressure and the residue was purified by preparative HPLC to yield $591 \mathrm{mg}$ of the product.

LC-MS (Method 1): $R_{t}=1.33 \mathrm{~min} ;$ MS (ESIpos): $\mathrm{m} / \mathrm{z}=1298[\mathrm{M}+\mathrm{H}]^{+}$

\section{Compound 3c}

L-alanyl- $N$-methyl-L-alanyl- $N^{\prime}-\{(2 S)-4-[\{(1 R)-1$-[1-benzyl-4-(2,5-difluorophenyl)-1 $H$-pyrrol-2-yl]2,2-dimethylpropyl\}(hydroxyacetyl)amino]-1-[(3-\{[(1R)-1,3-dicarboxypropyl]amino\}-3oxopropyl)amino]-1-oxobutan-2-yl\}-L-aspartamide 


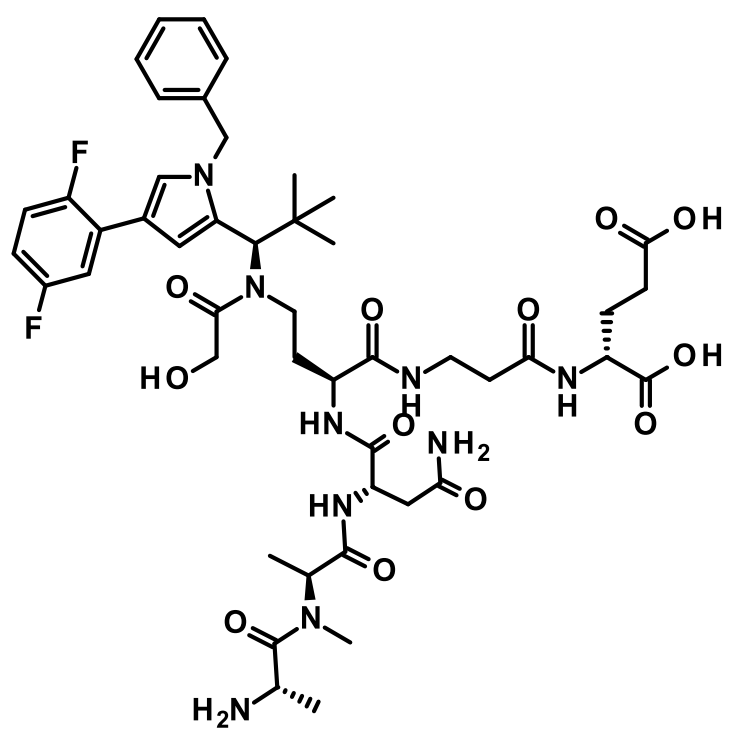

A solution of dibenzyl (2R)-2-\{[(5S,8S,11S,14S)-11-(2-amino-2-oxoethyl)-14-\{2-[\{(1R)-1-[1benzyl-4-(2,5-difluorophenyl)-1 H-pyrrol-2-yl]-2,2-dimethylpropyl\}(hydroxyacetyl)amino]ethyl\}5,7,8-trimethyl-3,6,9,12,15,19-hexaoxo-1-phenyl-2-oxa-4,7,10,13,16-pentaazanonadecan-19yl]amino\}pentanedioate $(593 \mathrm{mg}, 457 \mu \mathrm{mol})$ in $\mathrm{DCM} /$ methanol $(1.1,75 \mathrm{~mL})$ was supplemented with palladium on charcoal $(10 \%, 50 \mathrm{mg})$. The mixture was hydrogenated at ambient pressure for 1 hour. The solids were filtered off and the residue was washed several times with acetonitrile/water (1:1). The filtrate was concentrated under reduced pressure and the remaining residue was lyophilized to give $449 \mathrm{mg}$ of the title product.

LC-MS (Method 1): $\mathrm{R}_{\mathrm{t}}=0.80 \mathrm{~min} ; \mathrm{MS}$ (ESIpos): $\mathrm{m} / \mathrm{z}=984[\mathrm{M}+\mathrm{H}]^{+}$

\section{Compound 4c}

$N$-\{5-[(2,5-dioxopyrrolidin-1-yl)oxy]-5-oxopentanoyl\}-L-alanyl- $N$-methyl-L-alanyl- $N^{\prime}-\{(2 S)-4-$ [\{(1R)-1-[1-benzyl-4-(2,5-difluorophenyl)-1H-pyrrol-2-yl]-2,2dimethylpropyl\}(hydroxyacetyl)amino]-1-[(3-\{[(1R)-1,3-dicarboxypropyl]amino\}-3oxopropyl)amino]-1-oxobutan-2-yl\}-L-aspartamide 


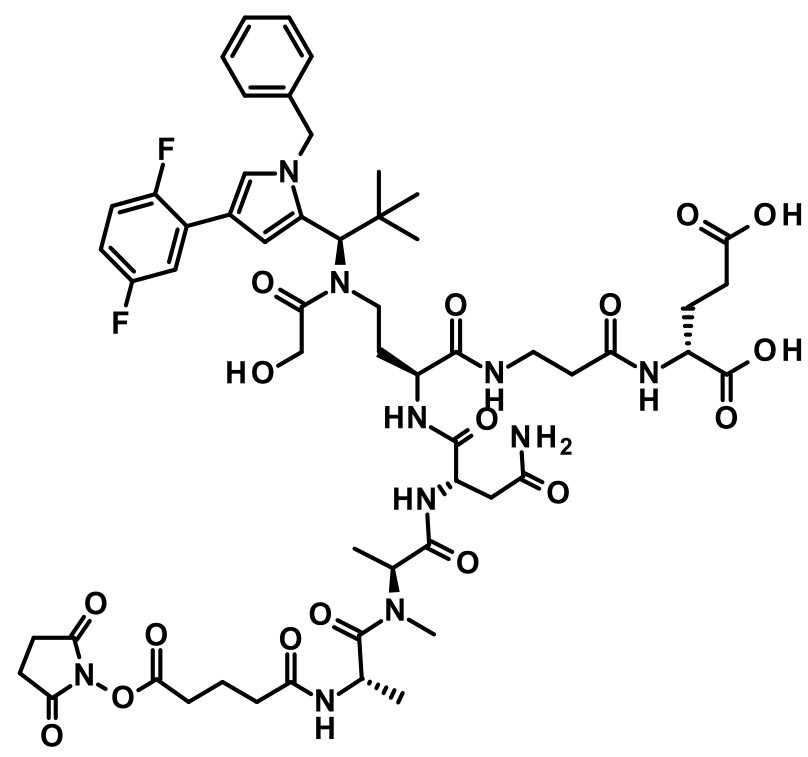

L-alanyl- $N$-methyl-L-alanyl- $N^{\prime}-\{(2 S)-4-[\{(1 \mathrm{R})-1-[1-$ benzyl-4-(2,5-difluorophenyl)-1H-pyrrol-2-yl]2,2-dimethylpropyl\}(hydroxyacetyl)amino]-1-[(3-\{[(1R)-1,3-dicarboxypropyl]amino\}-3oxopropyl)amino]-1-oxobutan-2-yl\}-L-aspartamide (100 mg, $102 \mu \mathrm{mol})$ and 1,1'-[(1,5dioxopentane-1,5-diyl)bis(oxy)]di(pyrrolidine-2,5-dione) (82.9 mg, $254 \mu \mathrm{mol})$ were dissolved in DMF $(10 \mathrm{~mL})$ and $N, N$-diisopropylethylamine $(53 \mu \mathrm{L}, 300 \mu \mathrm{mol})$ was added. The reaction was stirred for 30 minutes. The mixture was concentrated under reduced pressure and the residue was purified by preparative HPLC. Concentration of the appropriate fractions and lyophilization yielded $86 \mathrm{mg}$ of the product.

LC-MS (Method 1): $\mathrm{R}_{\mathrm{t}}=0.93 \mathrm{~min} ; \mathrm{MS}$ (ESIpos): $\mathrm{m} / \mathrm{z}=1195[\mathrm{M}+\mathrm{Na}]^{+}$

HPLC-HRMS (Method 4): $\mathrm{R}_{\mathrm{t}}=0.96 \mathrm{~min}$; MS (ESI): m/z: calcd for $\mathrm{C}_{56} \mathrm{H}_{71} \mathrm{~N}_{10} \mathrm{O}_{17} \mathrm{~F}_{2}[\mathrm{M}-\mathrm{H}]$ : 1193.4967; found: $1193.4991(\mathrm{M}-\mathrm{H})^{-}$.

\section{Intermediate 20}

Dibenzyl (2R)-2-\{[(5S,8S,11R,14S)-11-(2-amino-2-oxoethyl)-14-\{2-[\{(1R)-1-[1-benzyl-4-(2,5difluorophenyl)-1H-pyrrol-2-yl]-2,2-dimethylpropyl\}(hydroxyacetyl)amino]ethyl\}-5,7,8-trimethyl3,6,9,12,15,19-hexaoxo-1-phenyl-2-oxa-4,7,10,13,16-pentaazanonadecan-19yl]amino\}pentanedioate 


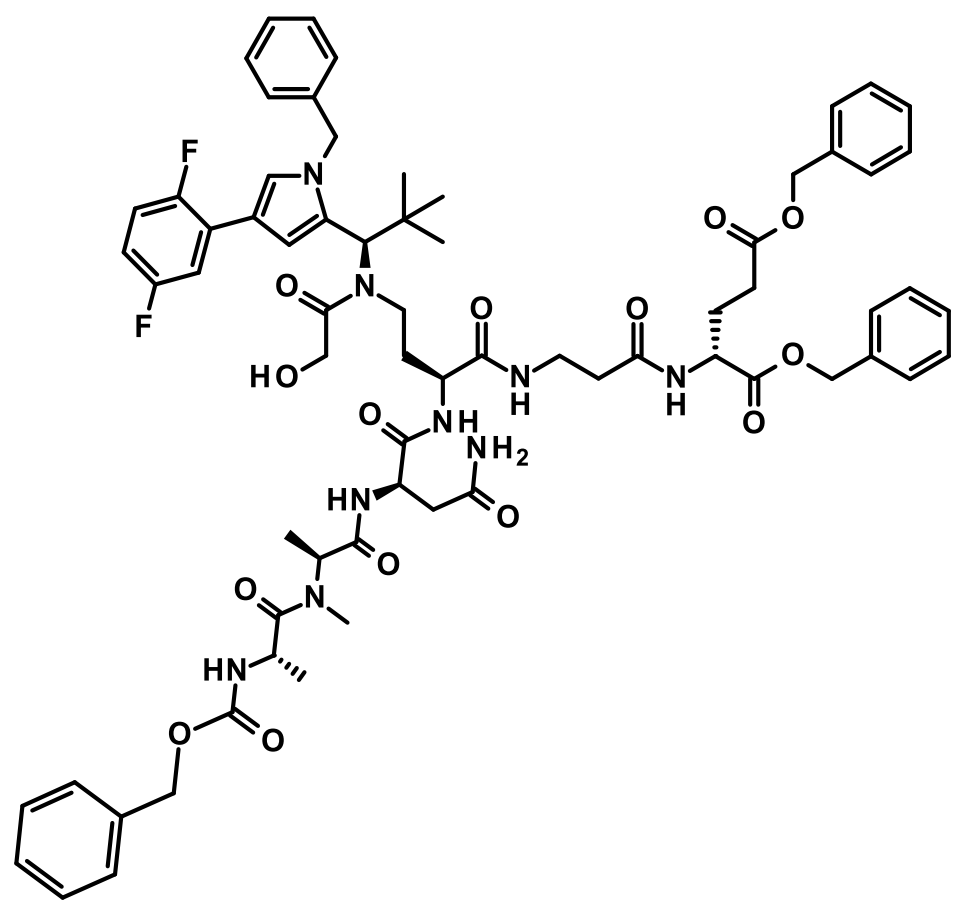

A solution of dibenzyl $\mathrm{N}$-\{(2S)-2-amino-4-[\{(1R)-1-[1-benzyl-4-(2,5-difluorophenyl)-1H-pyrrol-2yl]-2,2-dimethylpropyl\}(hydroxyacetyl)amino]butanoyl\}-beta-alanyl-D-glutamate (18.4 mg, 18.3 $\mu \mathrm{mol})$ in DMF (3 $\mathrm{mL})$ was supplemented with $N$-[(benzyloxy)carbonyl]-L-alanyl-N-methyl-Lalanyl-D-asparagine $(8.50 \mathrm{mg}, 20.1 \mu \mathrm{mol}), N, N$-diisopropylethylamine $(9.6 \mu \mathrm{L}, 55 \mu \mathrm{mol})$ and HATU $(9 \mathrm{mg}, 23.8 \mu \mathrm{mol})$ and the reaction was stirred for 2 hours at room temperature. The mixture was concentrated to dryness under reduced pressure and the residue was purified by preparative HPLC to yield $13 \mathrm{mg}$ of the product.

LC-MS (Method 1): $R_{t}=1.33 \mathrm{~min} ;$ MS (ESIpos): $\mathrm{m} / \mathrm{z}=1299[\mathrm{M}+\mathrm{H}]^{+}$

\section{Compound 3d}

L-alanyl- $N$-methyl-L-alanyl- $N$ '-\{(2S)-4-[\{(1R)-1-[1-benzyl-4-(2,5-difluorophenyl)-1 $H$-pyrrol-2-yl]2,2-dimethylpropyl\}(hydroxyacetyl)amino]-1-[(3-\{[(1R)-1,3-dicarboxypropyl]amino\}-3oxopropyl)amino]-1-oxobutan-2-yl\}-D-aspartamide 


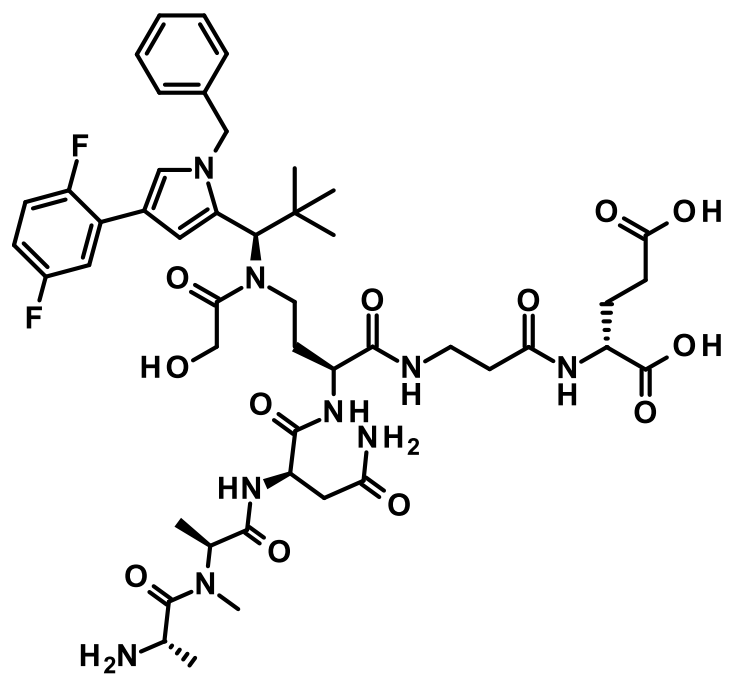

A solution of dibenzyl (2R)-2-\{[(5S,8S,11R,14S)-11-(2-amino-2-oxoethyl)-14-\{2-[\{(1R)-1-[1benzyl-4-(2,5-difluorophenyl)-1 H-pyrrol-2-yl]-2,2-dimethylpropyl\}(hydroxyacetyl)amino]ethyl\}5,7,8-trimethyl-3,6,9,12,15,19-hexaoxo-1-phenyl-2-oxa-4,7,10,13,16-pentaazanonadecan-19yl]amino\}pentanedioate $(13.0 \mathrm{mg}, 10.0 \mu \mathrm{mol})$ in DCM/methanol $(1: 1,5 \mathrm{~mL})$ was supplemented with palladium on charcoal $(10 \%, 5 \mathrm{mg})$. The mixture was hydrogenated at ambient pressure for 1 hour. The solids were filtered off and the residue was washed several times with acetonitrile/water (1:1). The filtrate was concentrated under reduced pressure and the remaining residue was lyophilized to yield $9 \mathrm{mg}$ of the product.

LC-MS (Method 2): $\mathrm{R}_{\mathrm{t}}=2.53 \mathrm{~min} ; \mathrm{MS}\left(\right.$ ESIpos): $\mathrm{m} / \mathrm{z}=984[\mathrm{M}+\mathrm{H}]^{+}$

\section{Compound 4d}

$N-\{5-[(2,5-d i o x o p y r r o l i d i n-1-y l) o x y]-5-o x o p e n t a n o y \mid\}-L-a l a n y l-N$-methyl-L-alanyl- $N^{1}-\{(2 S)-4-$ [\{(1R)-1-[1-benzyl-4-(2,5-difluorophenyl)-1H-pyrrol-2-yl]-2,2-

dimethylpropyl\}(hydroxyacetyl)amino]-1-[(3-\{[(1R)-1,3-dicarboxypropyl]amino\}-3oxopropyl)amino]-1-oxobutan-2-yl\}-D-aspartamide 


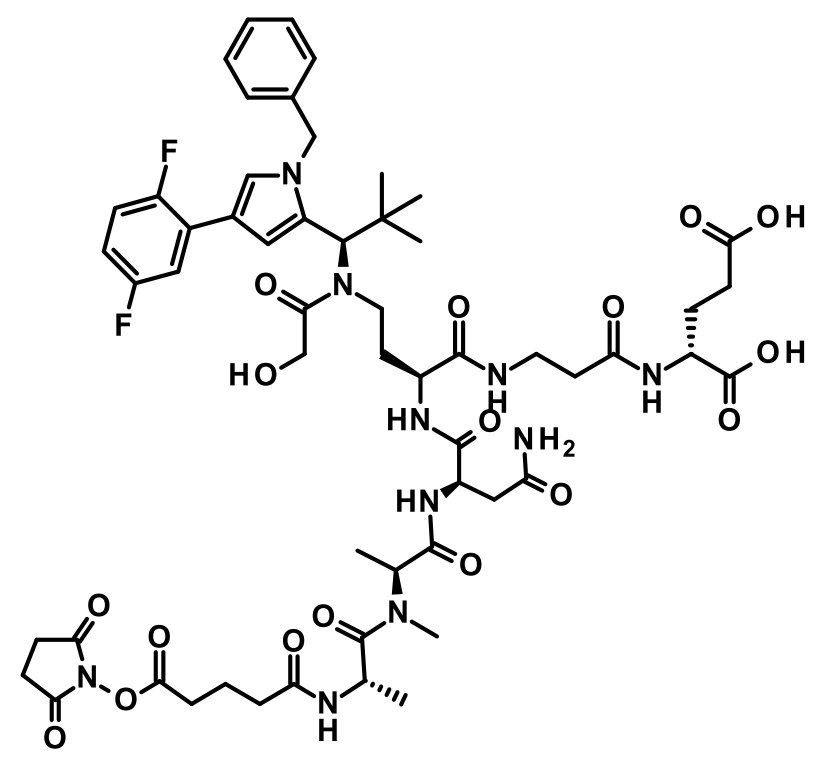

L-alanyl- $N$-methyl-L-alanyl- $N^{\prime}-\{(2 S)-4-[\{(1 \mathrm{R})-1-[1$-benzyl-4-(2,5-difluorophenyl)-1H-pyrrol-2-yl]2,2-dimethylpropyl\}(hydroxyacetyl)amino]-1-[(3-\{[(1R)-1,3-dicarboxypropyl]amino\}-3-

oxopropyl)amino]-1-oxobutan-2-yl\}-D-aspartamide $(9.00 \mathrm{mg}, 9.15 \mu \mathrm{mol})$ and 1,1'-[(1,5dioxopentane-1,5-diyl)bis(oxy)]di(pyrrolidine-2,5-dione) (7.5 mg, $23 \mu \mathrm{mol})$ were dissolved in DMF $(4 \mathrm{~mL})$ and $N, N$-diisopropylethylamine $(4.8 \mu \mathrm{L}, 27 \mu \mathrm{mol})$ was added. The reaction was stirred for 1.5 hours at room temperature. The mixture was concentrated under reduced pressure and the residue was purified by preparative HPLC. Concentration of the appropriate fractions and lyophilization yielded $8 \mathrm{mg}$ of the product.

LC-MS (Method 2): $R_{t}=3.01 \mathrm{~min} ;$ MS (ESIpos): $\mathrm{m} / \mathrm{z}=1195[\mathrm{M}+\mathrm{H}]^{+}$

\section{Compound 3e}

$N$-\{(2S)-2-(L-asparaginylamino)-4-[\{(1R)-1-[1-benzyl-4-(2,5-difluorophenyl)-1H-pyrrol-2-yl]-2,2dimethylpropyl\}(hydroxyacetyl)amino]butanoyl\}-beta-alanyl-D-glutamic acid

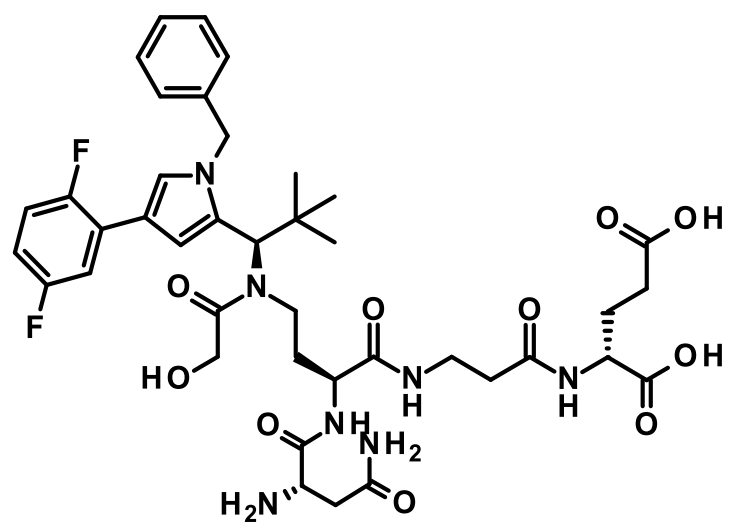

A solution of dibenzyl $N$-\{(2S)-2-(L-asparaginylamino)-4-[\{(1R)-1-[1-benzyl-4-(2,5difluorophenyl)-1 H-pyrrol-2-yl]-2,2-dimethylpropyl\}(hydroxyacetyl)amino]butanoyl\}-beta-alanylD-glutamate $(50.0 \mathrm{mg}, 42.6 \mu \mathrm{mol})$ in $\mathrm{DCM} / \mathrm{methanol}(1: 1,10 \mathrm{~mL})$ was supplemented with 
palladium on charcoal $(10 \%, 10 \mathrm{mg})$. The mixture was hydrogenated at ambient pressure for 1 hour. The solids were filtered off and the residue was washed several times with acetonitrile/water (1:1). The filtrate was concentrated under reduced pressure and the remaining residue was lyophilized to yield $35 \mathrm{mg}$ of the product.

LC-MS (Method 1): $\mathrm{R}_{\mathrm{t}}=0.79 \mathrm{~min} ; \mathrm{MS}\left(\right.$ ESIpos): $\mathrm{m} / \mathrm{z}=828[\mathrm{M}+\mathrm{H}]^{+}$

\section{Compound $4 \mathrm{e}$}

$N-\{(2 S)-4-[\{(1 \mathrm{R})-1-[1-$ benzyl-4-(2,5-difluorophenyl)-1H-pyrrol-2-yl]-2,2-

dimethylpropyl\}(hydroxyacetyl)amino]-2-[( $N^{2}-\{5-[(2,5-$ dioxopyrrolidin-1-yl)oxy]-5-oxopentanoyl\}L-asparaginyl)amino]butanoyl\}-beta-alanyl-D-glutamic acid

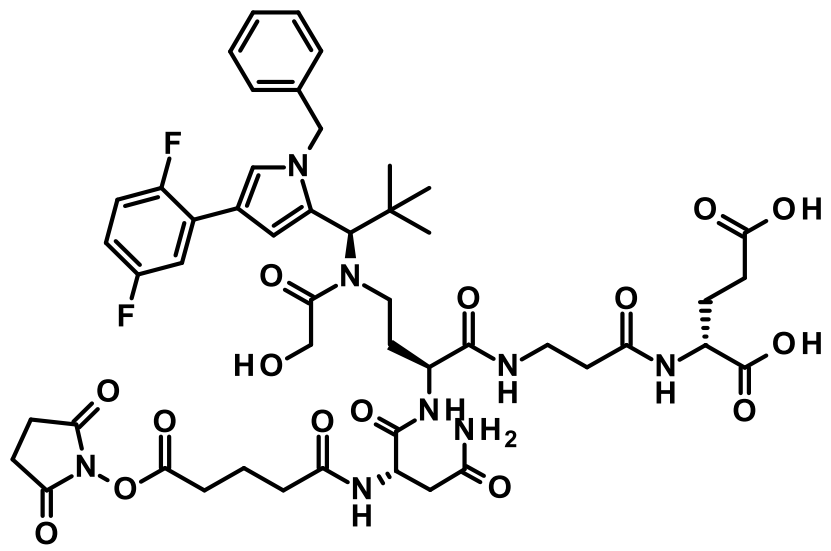

$N$-\{(2S)-2-(L-asparaginylamino)-4-[\{(1R)-1-[1-benzyl-4-(2,5-difluorophenyl)-1H-pyrrol-2-yl]-2,2dimethylpropyl\}(hydroxyacetyl)amino]butanoyl\}-beta-alanyl-D-glutamic acid (18.0 mg, 21.3

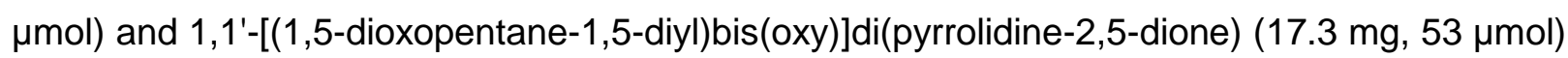
were dissolved in DMF $(5 \mathrm{~mL})$ and $N, N$-diisopropylethylamine $(15 \mu \mathrm{L}, 85 \mu \mathrm{mol})$ was added. The reaction was stirred for 1 hour. The mixture was concentrated under reduced pressure and the residue was purified by preparative HPLC. Concentration of the appropriate fractions and lyophilization yielded $14 \mathrm{mg}$ of the product.

LC-MS (Method 1): $\mathrm{R}_{\mathrm{t}}=0.95 \mathrm{~min} ; \mathrm{MS}$ (ESIpos): $\mathrm{m} / \mathrm{z}=1037[\mathrm{M}+\mathrm{H}]^{+}$

HPLC-HRMS (Method 4): $\mathrm{R}_{t}=0.95 \mathrm{~min} ; \mathrm{MS}(\mathrm{ESI}): \mathrm{m} / \mathrm{z}$ : calcd for $\mathrm{C}_{49} \mathrm{H}_{59} \mathrm{~N}_{8} \mathrm{O}_{15} \mathrm{~F}_{2}[\mathrm{M}-\mathrm{H}]:$ 1037.4068; found: $1037.4054(\mathrm{M}+\mathrm{H})^{+}$.

\section{Intermediate 21}

Dibenzyl N-[(2S)-4-[\{(1R)-1-[1-benzyl-4-(2,5-difluorophenyl)-1H-pyrrol-2-yl]-2,2dimethylpropyl\}(hydroxyacetyl)amino]-2-\{[ $N^{2}$-(tert-butoxycarbonyl)-Dasparaginyl]amino\}butanoyl]-beta-alanyl-D-glutamate 


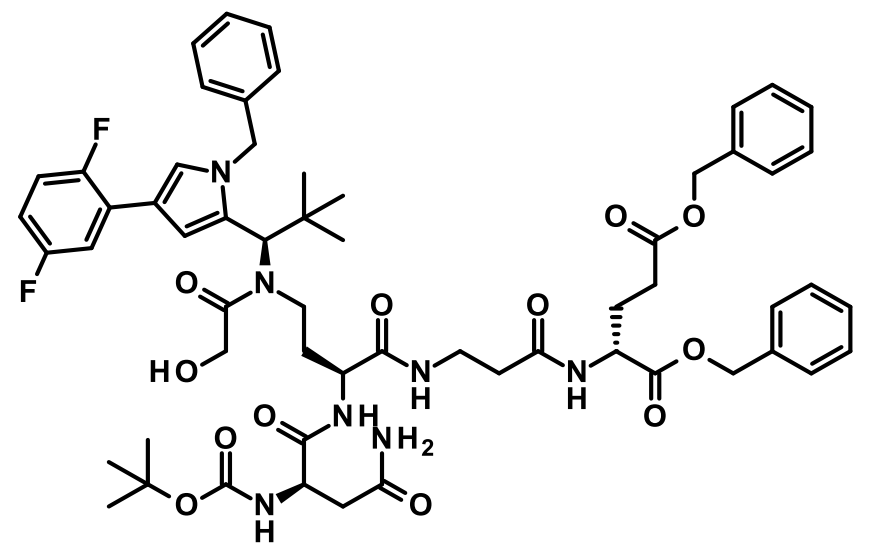

A sloution of dibenzyl $N$-\{(2S)-2-amino-4-[\{(1R)-1-[1-benzyl-4-(2,5-difluorophenyl)-1H-pyrrol-2yl]-2,2-dimethylpropyl\}(hydroxyacetyl)amino]butanoyl\}-beta-alanyl-D-glutamate $(27.0 \mathrm{mg}, 28.2$ $\mu \mathrm{mol})$ and $N, N$-diisopropylethylamine $(15 \mu \mathrm{L}, 85 \mu \mathrm{mol})$ in DMF $(5.0 \mathrm{~mL})$ was supplemented with $N^{2}$-(tert-butoxycarbonyl)-D-asparagine $(7.87 \mathrm{mg}, 33.9 \mu \mathrm{mol})$ and the reaction was stirred at room temperature for 2 hours. The mixture was concentrated to dryness under reduced pressure and the residue was purified by preparative HPLC to yield $22 \mathrm{mg}$ of the product.

LC-MS (Method 1): $\mathrm{R}_{\mathrm{t}}=1.37 \mathrm{~min} ; \mathrm{MS}$ (ESIpos): $\mathrm{m} / \mathrm{z}=1108[\mathrm{M}+\mathrm{H}]^{+}$

\section{Intermediate 22}

$N$-[(2S)-4-[\{(1R)-1-[1-benzyl-4-(2,5-difluorophenyl)-1 H-pyrrol-2-yl]-2,2-

dimethylpropyl\}(hydroxyacetyl)amino]-2-\{[ $N^{2}$-(tert-butoxycarbonyl)-D-

asparaginyl]amino\}butanoyl]-beta-alanyl-D-glutamic acid

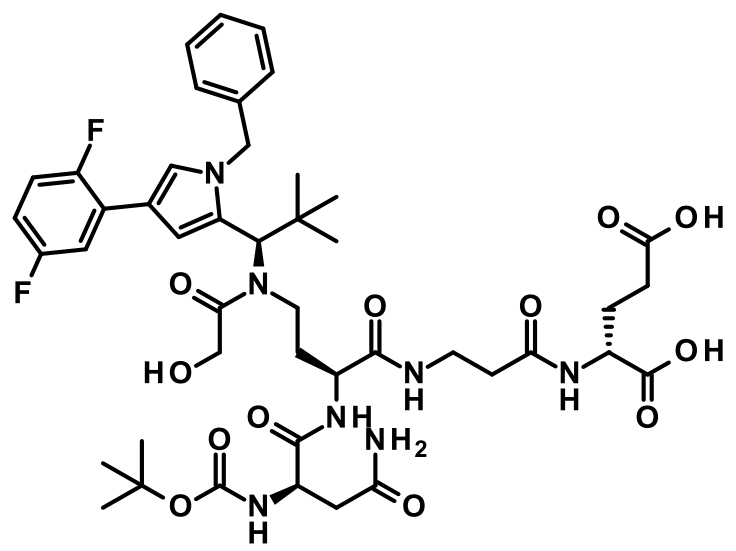

A solution of dibenzyl $N$-[(2S)-4-[\{(1R)-1-[1-benzyl-4-(2,5-difluorophenyl)-1H-pyrrol-2-yl]-2,2dimethylpropyl\}(hydroxyacetyl)amino]-2-\{[ $N^{2}$-(tert-butoxycarbonyl)-D-asparaginyl]amino $\}$ butanoyl]-beta-alanyl-D-glutamate $(22.5 \mathrm{mg}, 20.3 \mu \mathrm{mol})$ in $\mathrm{DCM} / \mathrm{methanol}(1.1 \mathrm{mg}, 10 \mathrm{~mL})$ was supplemented with palladium on charcoal $(10 \%, 15 \mathrm{mg})$. The mixture was hydrogenated at ambient pressure for 1.5 hours. The solids were filtered off and the residue was washed several times with acetonitrile/water (1:1). The filtrate was concentrated under reduced pressure and the remaining residue was lyophilized to yield $15 \mathrm{mg}$ of the product. 
LC-MS (Method 1): $R_{t}=1.05$ min; MS (ESIpos): $\mathrm{m} / \mathrm{z}=928[\mathrm{M}+\mathrm{H}]^{+}$

\section{Compound 3f}

$N$-\{(2S)-2-(D-asparaginylamino)-4-[\{(1R)-1-[1-benzyl-4-(2,5-difluorophenyl)-1H-pyrrol-2-yl]-2,2dimethylpropyl\}(hydroxyacetyl)amino]butanoyl\}-beta-alanyl-D-glutamic acid

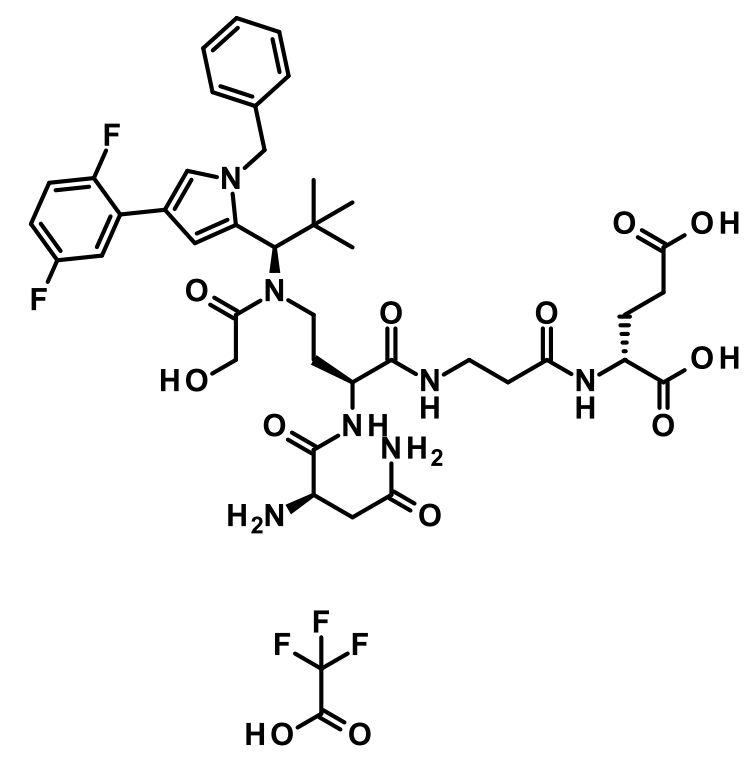

$N$-[(2S)-4-[\{(1R)-1-[1-benzyl-4-(2,5-difluorophenyl)-1H-pyrrol-2-yl]-2,2-dimethylpropyl\} (hydroxyacetyl)amino]-2-\{[ $N^{2}$-(tert-butoxycarbonyl)-D-asparaginyl]amino\}butanoyl]-beta-alanylD-glutamic acid (15.0 mg, $16.2 \mu \mathrm{mol}$ ) was dissolved in 2,2,2-trifluoroethanol ( $3 \mathrm{~mL})$. Zinc chloride (13 mg, $97 \mu \mathrm{mol}$ ) was added, and the reaction was stirred at $50^{\circ} \mathrm{C}$ for 4 hours. The mixture was diluted with water and $28 \mathrm{mg}(97 \mu \mathrm{mol})$ of ethylene diamine- $N, N, N, N$-tetraacetic acid was added. The mixture was stirred for a few minutes. The reaction was concentrated under reduced pressure and the residue was purified by preparative HPLC to yield $6.4 \mathrm{mg}$ of the product.

LC-MS (Method 3): $\mathrm{R}_{\mathrm{t}}=1.44 \mathrm{~min} ; \mathrm{MS}$ (ESIpos): $\mathrm{m} / \mathrm{z}=828[\mathrm{M}+\mathrm{H}]^{+}$

\section{Compound $4 f$}

$N-\{(2 S)-4-[\{(1 \mathrm{R})-1-[1-$ benzyl-4-(2,5-difluorophenyl)-1H-pyrrol-2-yl]-2,2-

dimethylpropyl\}(hydroxyacetyl)amino]-2-[( $N^{2}-\{5-[(2,5-d i o x o p y r r o l i d i n-1-y l) o x y]-5-o x o p e n t a n o y l\}-$ D-asparaginyl)amino]butanoyl\}-beta-alanyl-D-glutamic acid 


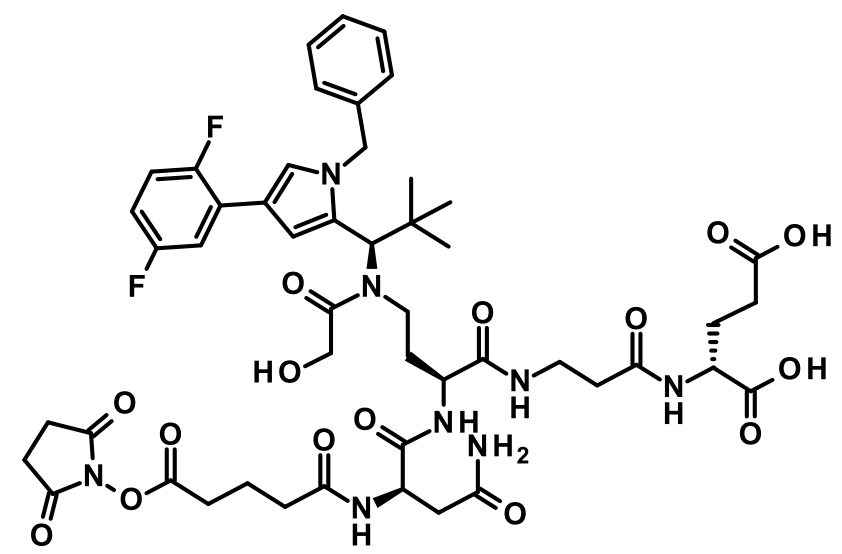

$N-\{(2 S)-2-(D-a s p a r a g i n y l a m i n o)-4-[\{(1 R)-1-[1-$ benzyl-4-(2,5-difluorophenyl)-1H-pyrrol-2-yl]-2,2dimethylpropyl\}(hydroxyacetyl)amino]butanoyl\}-beta-alanyl-D-glutamic $(6.40 \mathrm{mg}, 6.79 \mu \mathrm{mol}$ ) and 1,1'-[(1,5-dioxopentane-1,5-diyl)bis(oxy)]di(pyrrolidine-2,5-dione) (5.5 mg, $17 \mu \mathrm{mol})$ were dissolved in DMF $(4 \mathrm{~mL})$ and $N, N$-diisopropylethylamine $(4.7 \mu \mathrm{L}, 27 \mu \mathrm{mol})$ was added. The reaction was stirred over night at room temperature. The mixture was concentrated under reduced pressure and the residue was purified by preparative HPLC. Concentration of the appropriate fractions and lyophilization yielded $1.6 \mathrm{mg}$ of the product.

LC-MS (Method 3): $\mathrm{R}_{\mathrm{t}}=1.69 \mathrm{~min} ; \mathrm{MS}$ (ESIpos): $\mathrm{m} / \mathrm{z}=1037[\mathrm{M}+\mathrm{H}]^{+}$

\section{Intermediate 23}

Dibenzyl N-[(2S)-4-[\{(1R)-1-[1-benzyl-4-(2,5-difluorophenyl)-1 H-pyrrol-2-yl]-2,2-

dimethylpropyl\}(hydroxyacetyl)amino]-2-(\{N-[(benzyloxy)carbonyl]-L-leucyl\}amino)butanoyl]beta-alanyl-D-glutamate

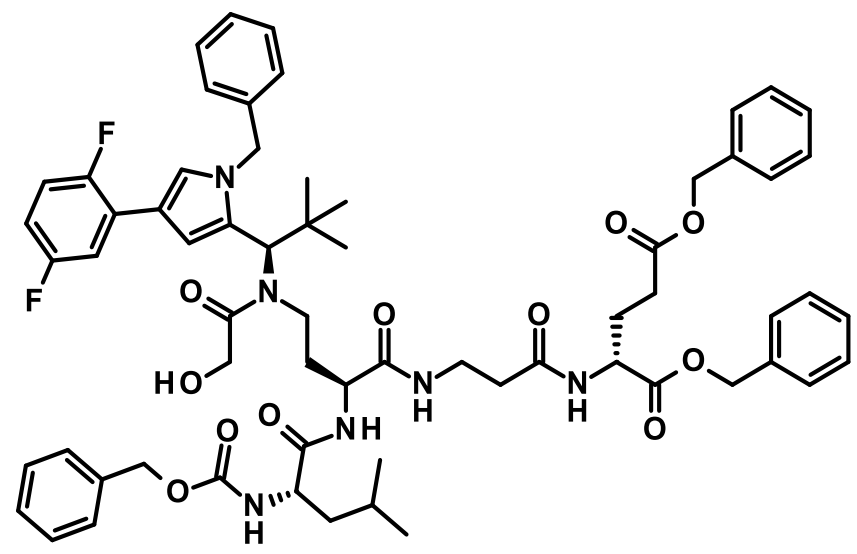

A sloution of dibenzyl $N$-\{(2S)-2-amino-4-[\{(1R)-1-[1-benzyl-4-(2,5-difluorophenyl)-1H-pyrrol-2yl]-2,2-dimethylpropyl\}(hydroxyacetyl)amino]butanoyl\}-beta-alanyl-D-glutamate $(75.0 \mathrm{mg}, 74.4$ $\mu \mathrm{mol})$ and $N, N$-diisopropylethylamine $(39 \mu \mathrm{L}, 220 \mu \mathrm{mol})$ in DMF $(5.0 \mathrm{~mL})$ was supplemented with 2,5-dioxopyrrolidin-1-yl $N$-[(benzyloxy)carbonyl]-L-leucinate $(33.7 \mathrm{mg}, 93.0 \mu \mathrm{mol})$ and the reaction was stirred at room temperature for 2 hours. The mixture was concentrated to dryness 
under reduced pressure and the residue was purified by preparative HPLC to yield $67 \mathrm{mg}$ of the product.

LC-MS (Method 1): $\mathrm{R}_{\mathrm{t}}=1.51 \mathrm{~min} ; \mathrm{MS}$ (ESIpos): $\mathrm{m} / \mathrm{z}=1141[\mathrm{M}+\mathrm{H}]^{+}$

\section{Compound 3q}

$N-[(2 S)-4-[\{(1 R)-1-[1-$ benzyl-4-(2,5-difluorophenyl)-1 H-pyrrol-2-yl]-2,2-

dimethylpropyl\}(hydroxyacetyl)amino]-2-(L-leucylamino)butanoyl]-beta-alanyl-D-glutamic acid

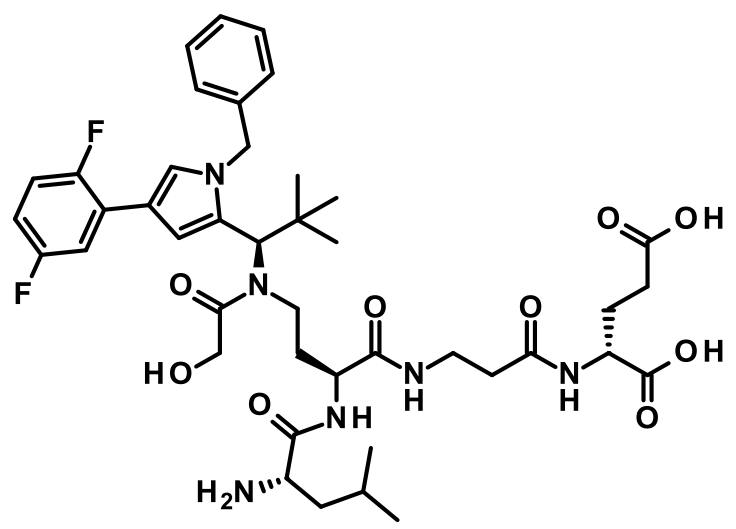

A solution of dibenzyl $N-[(2 S)-4-[\{(1 \mathrm{R})-1-[1-$ benzyl-4-(2,5-difluorophenyl)-1H-pyrrol-2-yl]-2,2dimethylpropyl\}(hydroxyacetyl)amino]-2-(\{N-[(benzyloxy)carbonyl]-L-leucyl\}amino)butanoyl]beta-alanyl-D-glutamate $(67.0 \mathrm{mg}, 58.7 \mu \mathrm{mol})$ in $\mathrm{DCM}(5 \mathrm{~mL})$ and methanol $(5 \mathrm{~mL})$ was supplemented with palladium on charcoal $(10 \%, 15 \mathrm{mg})$. The mixture was hydrogenated at ambient pressure for 2 hours. The solids were filtered off and the residue was washed several times with acetonitrile/water (1:1). The filtrate was concentrated under reduced pressure and the remaining residue was lyophilized to give $49 \mathrm{mg}$ of the title product.

LC-MS (Method 1): $\mathrm{R}_{\mathrm{t}}=0.84 \mathrm{~min} ; \mathrm{MS}$ (ESIneg): $\mathrm{m} / \mathrm{z}=825[\mathrm{M}-\mathrm{H}]^{-}$

\section{Compound 4g}

$N-\{(2 S)-4-[\{(1 \mathrm{R})-1-[1-$ benzyl-4-(2,5-difluorophenyl)-1H-pyrrol-2-yl]-2,2-

dimethylpropyl\}(hydroxyacetyl)amino]-2-[(N-\{5-[(2,5-dioxopyrrolidin-1-yl)oxy]-5-oxopentanoyl\}L-leucyl)amino]butanoyl\}-beta-alanyl-D-glutamic acid 


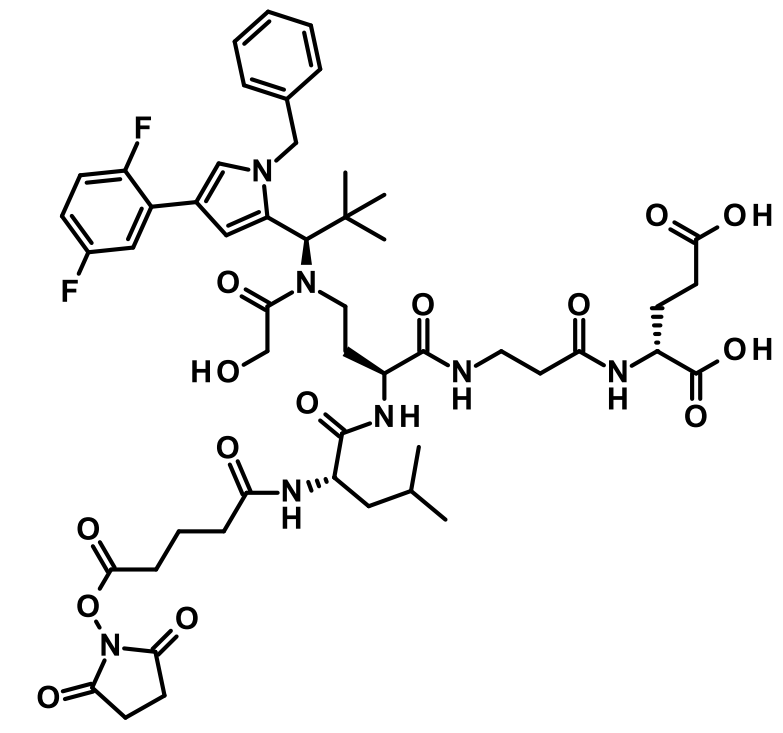

$N$-[(2S)-4-[\{(1R)-1-[1-benzyl-4-(2,5-difluorophenyl)-1 H-pyrrol-2-yl]-2,2-dimethylpropyl\}

(hydroxyacetyl) amino]-2-(L-leucylamino)butanoyl]-beta-alanyl-D-glutamic acid (35.0 mg, 42.3 $\mu \mathrm{mol})$ and 1,1'-[(1,5-dioxopentane-1,5-diyl)bis(oxy)]di(pyrrolidine-2,5-dione) (34.5 mg, 130 $\mu \mathrm{mol})$ were dissolved in DMF $(4 \mathrm{~mL})$ and $N, N$-diisopropylethylamine $(22 \mu \mathrm{L}, 130 \mu \mathrm{mol})$ was added. The reaction was stirred for 30 minutes at room temperature. The mixture was concentrated under reduced pressure and the residue was purified by preparative HPLC. Concentration of the appropriate fractions and lyophilization yielded $21.7 \mathrm{mg}$ of the product.

LC-MS (Method 1): $\mathrm{R}_{\mathrm{t}}=1.02 \mathrm{~min} ; \mathrm{MS}$ (ESIpos): $\mathrm{m} / \mathrm{z}=1038[\mathrm{M}+\mathrm{H}]^{+}$

\section{Intermediate 24}

Dibenzyl N-[(2S)-4-[\{(1R)-1-[1-benzyl-4-(2,5-difluorophenyl)-1H-pyrrol-2-yl]-2,2-

dimethylpropyl\}(hydroxyacetyl)amino]-2-\{[N-(tert-butoxycarbonyl)-L-

glutaminyl]amino\}butanoyl]-beta-alanyl-D-glutamate

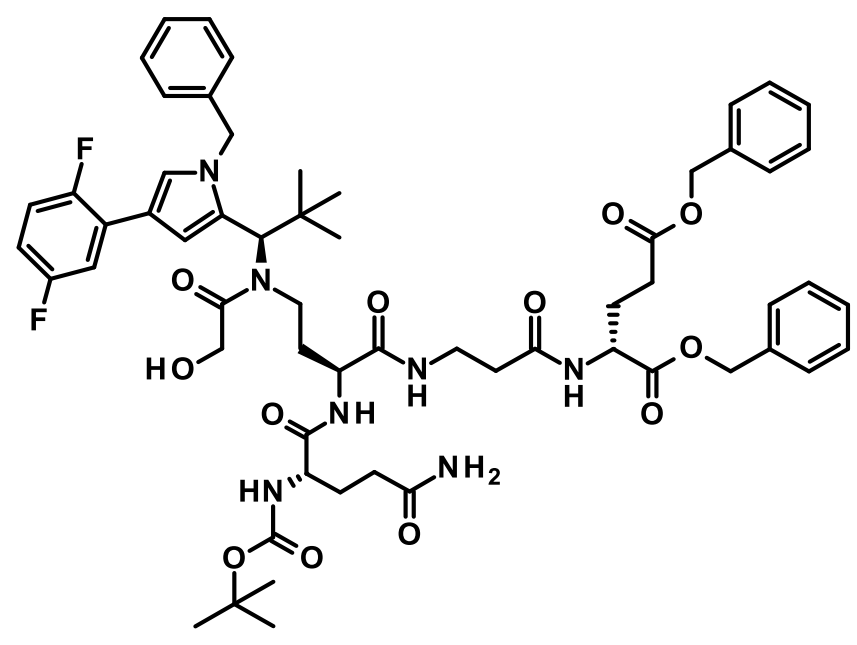

Dibenzyl N-\{(2S)-2-amino-4-[\{(1R)-1-[1-benzyl-4-(2,5-difluorophenyl)-1 H-pyrrol-2-yl]-2,2dimethylpropyl\}(hydroxyacetyl)amino]butanoyl\}-beta-alanyl-D-glutamate (30.0 mg, $31.4 \mu \mathrm{mol}$ ) 
and 2,5-dioxopyrrolidin-1-yl $N^{2}$-(tert-butoxycarbonyl)-L-glutaminate $(12.9 \mathrm{mg}, 37.6 \mu \mathrm{mol})$ were dissolved in DMF $(5 \mathrm{~mL})$ and $N, N$-diisopropylethylamine $(16 \mu \mathrm{L}, 94 \mu \mathrm{mol})$ was added. The reaction was stirred for 2 hours at room temperature. The mixture was concentrated under reduced pressure and the residue was purified by preparative HPLC. Concentration of the appropriate fractions and lyophilization yielded $24.5 \mathrm{mg}$ of the product.

LC-MS (Method 1): $\mathrm{R}_{\mathrm{t}}=1.37 \mathrm{~min}$; MS (ESIpos): $\mathrm{m} / \mathrm{z}=1123[\mathrm{M}+\mathrm{H}]^{+}$

\section{Intermediate 25}

Dibenzyl N-[(2S)-4-[\{(1R)-1-[1-benzyl-4-(2,5-difluorophenyl)-1H-pyrrol-2-yl]-2,2-

dimethylpropyl\}(hydroxyacetyl)amino]-2-(L-glutaminylamino)butanoyl]-beta-alanyl-D-glutamate

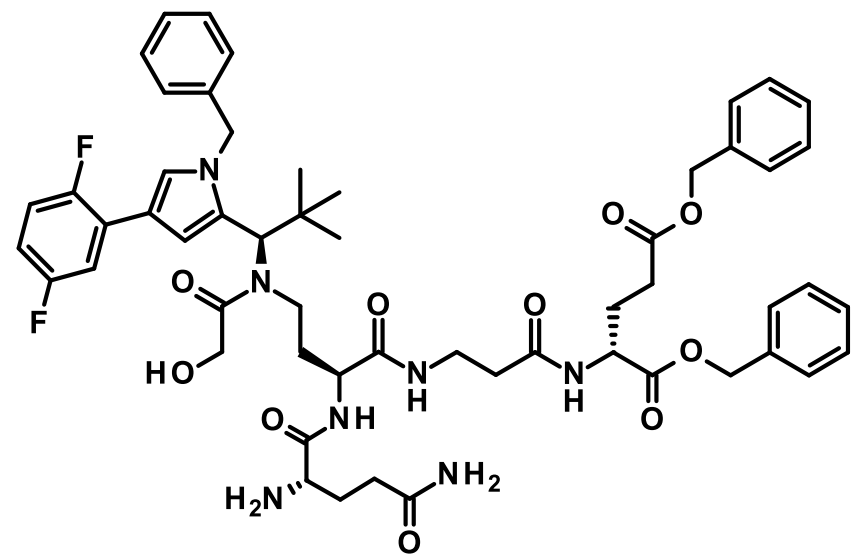<smiles>O=C(O)C(F)(F)F</smiles>

Dibenzyl N-[(2S)-4-[\{(1R)-1-[1-benzyl-4-(2,5-difluorophenyl)-1H-pyrrol-2-yl]-2,2-dimethylpropyl\} (hydroxyacetyl)amino]-2-\{[ $N^{2}$-(tert-butoxycarbonyl)-L-glutaminyl]amino\}butanoyl]-beta-alanyl-Dglutamate $(24.5 \mathrm{mg}, 20.9 \mu \mathrm{mol})$ was dissolved in 2,2,2-trifluoroethanol $(6 \mathrm{~mL})$. Zinc chloride (17 $\mathrm{mg}, 125 \mu \mathrm{mol})$ was added, and the reaction was stirred at $50^{\circ} \mathrm{C}$ for 1.5 hours. The mixture was diluted with water and $37 \mathrm{mg}(125 \mu \mathrm{mol})$ of ethylene diamine- $N, N, N, N$-tetraacetic acid was added. The mixture was stirred for a few minutes. The reaction was concentrated under reduced pressure and the residue was purified by preparative HPLC to yield $23 \mathrm{mg}$ of the product.

LC-MS (Method 3): $\mathrm{R}_{\mathrm{t}}=2.15 \mathrm{~min}$; MS (ESIpos): $\mathrm{m} / \mathrm{z}=1022[\mathrm{M}+\mathrm{H}]^{+}$

\section{Compound 3h}

$N-[(2 S)-4-[\{(1 \mathrm{R})-1-[1$-benzyl-4-(2,5-difluorophenyl)-1 H-pyrrol-2-yl]-2,2-

dimethylpropyl\}(hydroxyacetyl)amino]-2-(L-glutaminylamino)butanoyl]-beta-alanyl-D-glutamic acid 


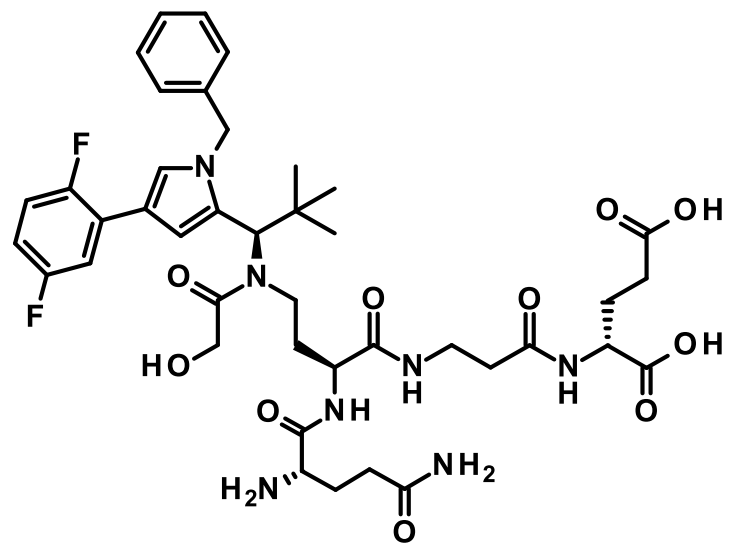

A solution of dibenzyl $N$-[(2S)-4-[\{(1R)-1-[1-benzyl-4-(2,5-difluorophenyl)-1H-pyrrol-2-yl]-2,2dimethylpropyl\}(hydroxyacetyl)amino]-2-(L-glutaminylamino)butanoyl]-beta-alanyl-D-glutamate $(23.0 \mathrm{mg}, 20.2 \mu \mathrm{mol})$ in methanol $(10 \mathrm{~mL})$ was supplemented with palladium on charcoal $(10 \%$, $3 \mathrm{mg}$ ). The mixture was hydrogenated at ambient pressure for 1 hour. The solids were filtered off and the residue was washed several times with acetonitrile/water (1:1). The filtrate was concentrated under reduced pressure and the remaining residue was lyophilized to yield $16 \mathrm{mg}$ of the product.

LC-MS (Method 1): $\mathrm{R}_{\mathrm{t}}=0.81 \mathrm{~min} ; \mathrm{MS}\left(\right.$ ESIpos): $\mathrm{m} / \mathrm{z}=842[\mathrm{M}+\mathrm{H}]^{+}$

\section{Compound 4h}

$N$-\{(2S)-4-[\{(1R)-1-[1-benzyl-4-(2,5-difluorophenyl)-1H-pyrrol-2-yl]-2,2-

dimethylpropyl\}(hydroxyacetyl)amino]-2-[( $N^{2}-\{5-[(2,5-$ dioxopyrrolidin-1-yl)oxy]-5-oxopentanoyl\}L-glutaminyl)amino]butanoyl\}-beta-alanyl-D-glutamic acid

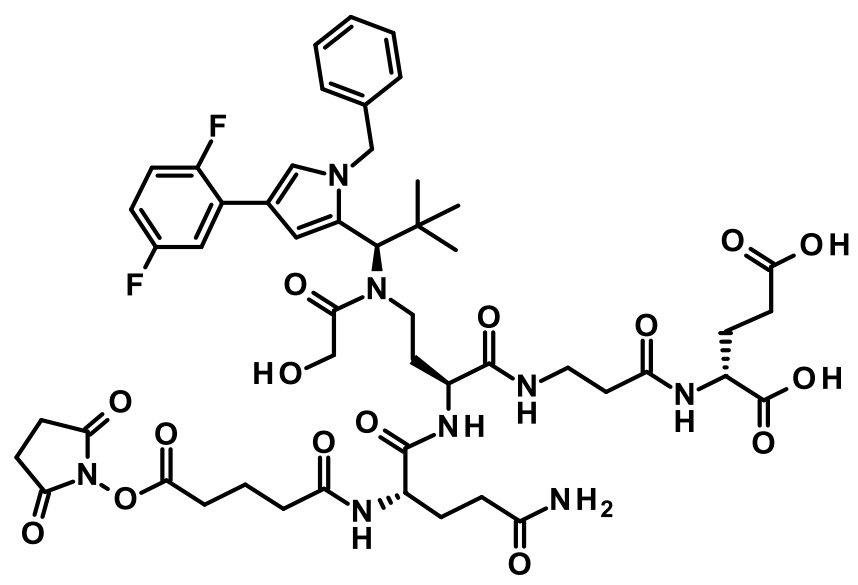

$N$-[(2S)-4-[\{(1R)-1-[1-benzyl-4-(2,5-difluorophenyl)-1H-pyrrol-2-yl]-2,2-dimethylpropyl\}

(hydroxyacetyl)amino]-2-(L-glutaminylamino)butanoyl]-beta-alanyl-D-glutamic acid (16.0 mg, $14.3 \mu \mathrm{mol})$ and 1,1'-[(1,5-dioxopentane-1,5-diyl)bis(oxy)]di(pyrrolidine-2,5-dione) (14 mg, 43 $\mu \mathrm{mol})$ were dissolved in DMF $(4 \mathrm{~mL})$ and $N, N$-diisopropylethylamine $(12 \mu \mathrm{L}, 72 \mu \mathrm{mol})$ was added. The reaction was stirred for 1 hour at room temperature. The mixture was concentrated under 
reduced pressure and the residue was purified by preparative HPLC. Concentration of the appropriate fractions and lyophilization yielded $9.4 \mathrm{mg}$ of the product.

LC-MS (Method 1): $\mathrm{R}_{\mathrm{t}}=0.92 \mathrm{~min}$; MS (ESIpos): $\mathrm{m} / \mathrm{z}=1052[\mathrm{M}+\mathrm{H}]^{+}$

\section{Synthesis of SMOL tool compounds}

\section{Compound 5a}

$N$-(4-carboxybutanoyl)-L-alanyl-L-alanyl- $N^{\top}-\{(2 S)-4-[\{(1 \mathrm{R})-1-[1-$ benzyl-4-(2,5-difluorophenyl)1H-pyrrol-2-yl]-2,2-dimethylpropyl\}(hydroxyacetyl)amino]-1-[(3-\{[(1R)-1,3dicarboxypropyl]amino\}-3-oxopropyl)amino]-1-oxobutan-2-yl\}-L-aspartamide

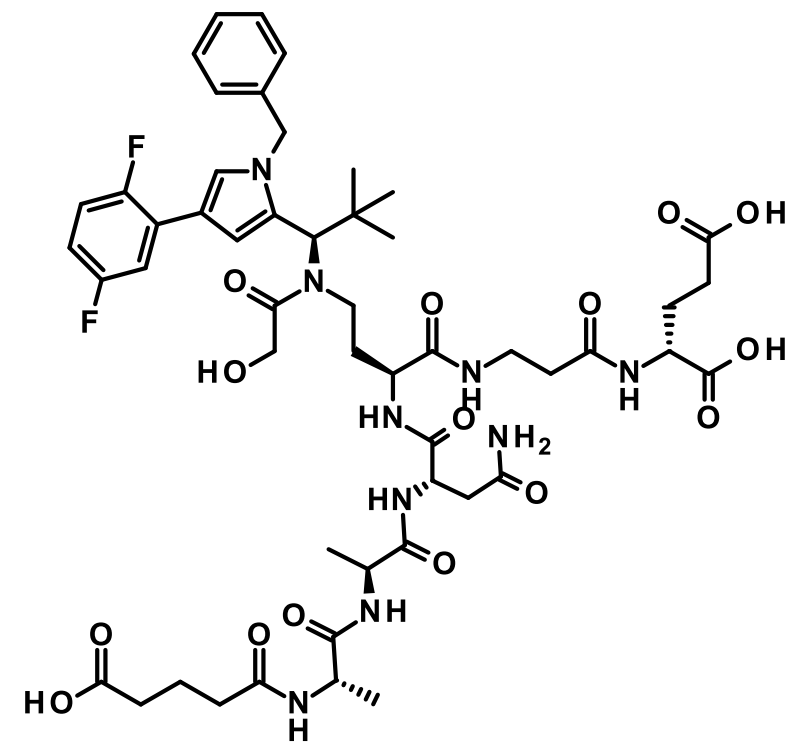

A solution of $N$-\{5-[(2,5-dioxopyrrolidin-1-yl)oxy]-5-oxopentanoyl\}-L-alanyl-L-alanyl- $N^{1}-\{(2 S)-4-$ [\{(1R)-1-[1-benzyl-4-(2,5-difluorophenyl)-1H-pyrrol-2-yl]-2,2-dimethylpropyl\}(hydroxyacetyl) amino]-1-[(3-\{[(1R)-1,3-dicarboxypropyl]amino\}-3-oxopropyl)amino]-1-oxobutan-2-yl\}-Laspartamide $(7.00 \mathrm{mg}, 5.93 \mu \mathrm{mol})$ in acetonitrile/water $(1: 1,2 \mathrm{~mL})$, was supplemented with a saturated solution of sodiumhydrogencarbonate $(100 \mu \mathrm{L})$ and the reaction was stirred for 20 hours at room temperature. TFA $(15 \mu \mathrm{L})$ was added and the mixture was concentrated under reduced pressure. The residue was purified by preparative HPLC. Concentration of the appropriate fractions and lyophilization yielded $1.9 \mathrm{mg}$ of the product.

LC-MS (Method 1): $R_{t}=0.87 \mathrm{~min} ; M S(E S I p o s): ~ m / z=1082[M-H]$ 


\section{Compound 5b}

$N$-(4-carboxybutanoyl)-L-alanyl-D-alanyl- $N^{1}-\{(2 S)-4-[\{(1 \mathrm{R})-1$-[1-benzyl-4-(2,5-difluorophenyl)1H-pyrrol-2-yl]-2,2-dimethylpropyl\}(hydroxyacetyl)amino]-1-[(3-\{[(1R)-1,3-

dicarboxypropyl]amino\}-3-oxopropyl)amino]-1-oxobutan-2-yl\}-L-aspartamide

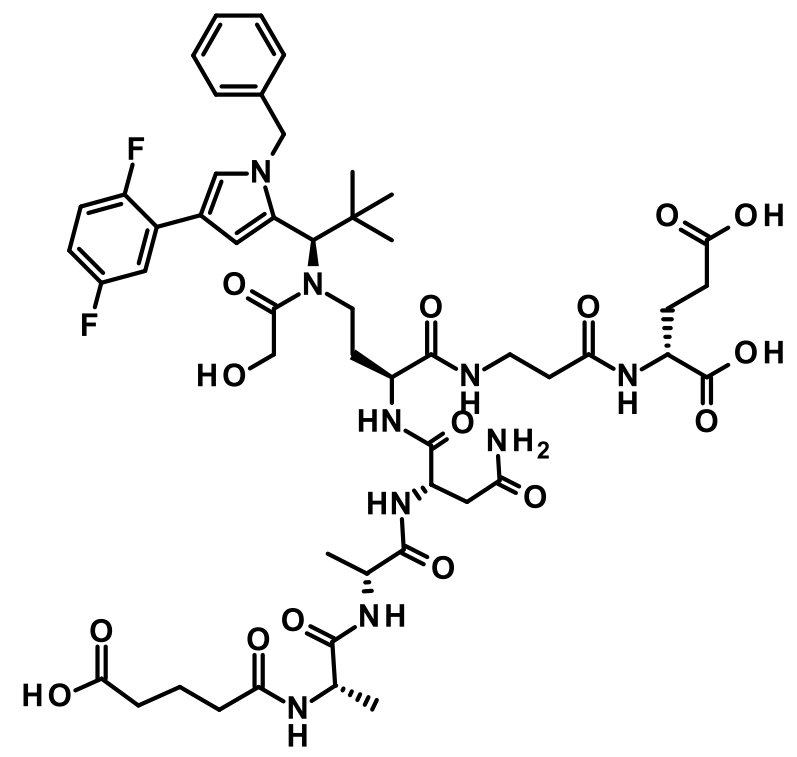

A solution of $N$-\{5-[(2,5-dioxopyrrolidin-1-yl)oxy]-5-oxopentanoyl\}-L-alanyl-D-alanyl- $N^{1}-\{(2 S)-4-$ [\{(1R)-1-[1-benzyl-4-(2,5-difluorophenyl)-1H-pyrrol-2-yl]-2,2-dimethylpropyl\}(hydroxyacetyl) amino]-1-[(3-\{[(1R)-1,3-dicarboxypropyl]amino\}-3-oxopropyl)amino]-1-oxobutan-2-yl\}-Laspartamide $(7.00 \mathrm{mg}, 5.93 \mu \mathrm{mol})$ in acetonitrile/water $(1: 1,2 \mathrm{~mL})$ was supplemented with a saturated solution of sodiumhydrogencarbonate $(100 \mu \mathrm{L})$ and the raction was stirred for 20 hours at room temperature. TFA $(15 \mu \mathrm{L})$ was added and the mixture was concentrated under reduced pressure. The residue was purified by preparative HPLC. Concentration of the appropriate fractions and subsequent lyophilization yielded $2.4 \mathrm{mg}$ of the product.

LC-MS (Method 1): $\mathrm{R}_{\mathrm{t}}=0.91 \mathrm{~min} ; \mathrm{MS}\left(\right.$ ESIpos): $\mathrm{m} / \mathrm{z}=1082[\mathrm{M}-\mathrm{H}]^{-}$

\section{Compound $5 \mathrm{c}$}

$N$-(4-carboxybutanoyl)-L-alanyl- $N$-methyl-L-alanyl- $N^{\prime}-\{(2 S)-4-[\{(1 \mathrm{R})-1-[1-$ benzyl-4-(2,5difluorophenyl)-1 H-pyrrol-2-yl]-2,2-dimethylpropyl\}(hydroxyacetyl)amino]-1-[(3-\{[(1R)-1,3dicarboxypropyl]amino\}-3-oxopropyl)amino]-1-oxobutan-2-yl\}-L-aspartamide 


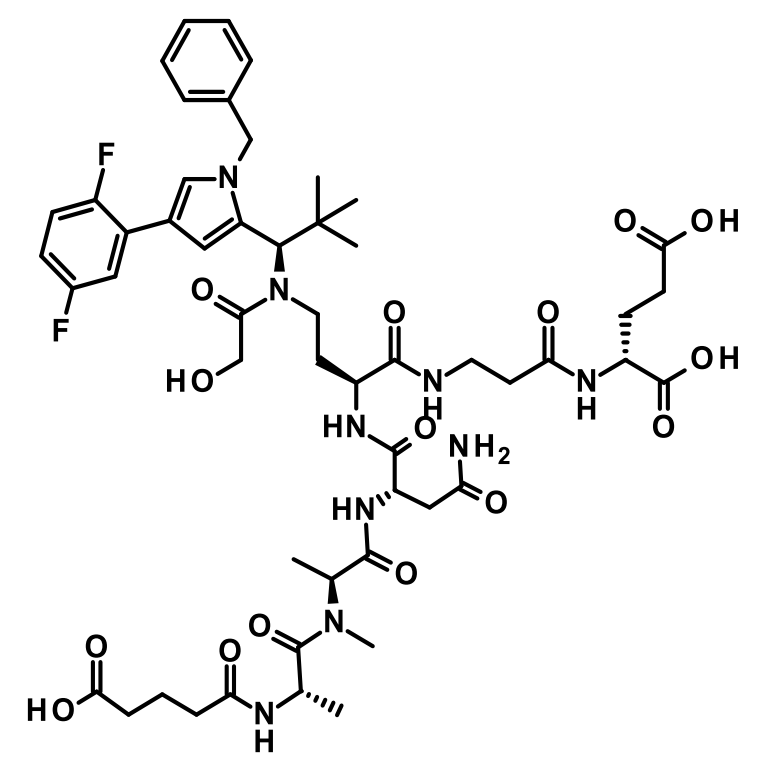

A solution of $N$-\{5-[(2,5-dioxopyrrolidin-1-yl)oxy]-5-oxopentanoyl\}-L-alanyl- $N$-methyl-L-alanyl- $N$ \{(2S)-4-[\{(1R)-1-[1-benzyl-4-(2,5-difluorophenyl)-1H-pyrrol-2-yl]-2,2-dimethylpropyl\} (hydroxyacetyl)amino]-1-[(3-\{[(1R)-1,3-dicarboxypropyl]amino\}-3-oxopropyl)amino]-1oxobutan-2-yl\}-L-aspartamide $(12.0 \mathrm{mg}, 10.0 \mu \mathrm{mol})$ in acetonitrile/water $(1: 1,4 \mathrm{~mL})$ was supplemented with a saturated solution of sodiumhydrogencarbonate $(480 \mu \mathrm{L})$ and the raction was stirred for 2 hours at room temperature. TFA $(50 \mu \mathrm{L})$ was added and the mixture was concentrated under reduced pressure. The residue was purified by preparative HPLC. Concentration of the appropriate fractions and lyophilization yielded $8 \mathrm{mg}$ of the product.

LC-MS (Method 1): $R_{t}=0.92 \mathrm{~min} ;$ MS (ESIpos): $\mathrm{m} / \mathrm{z}=1096$ [M-H]

\section{Intermediate 26}

Dibenzyl N-[(2S)-4-[\{(1R)-1-[1-benzyl-4-(2,5-difluorophenyl)-1H-pyrrol-2-yl]-2,2dimethylpropyl\}(hydroxyacetyl)amino]-2-(\{N $N^{2}$ [5-(benzyloxy)-5-oxopentanoyl]-Lasparaginyl\}amino)butanoyl]-beta-alanyl-D-glutamate 


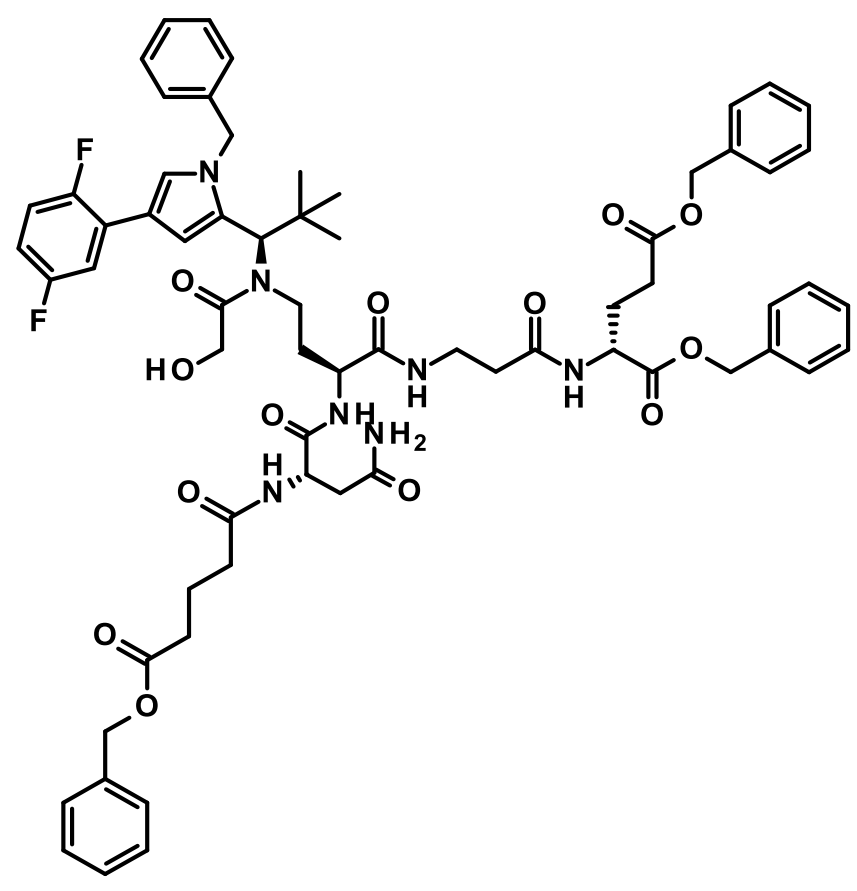

A solution of dibenzyl $N$-\{(2S)-2-(L-asparaginylamino)-4-[\{(1R)-1-[1-benzyl-4-(2,5difluorophenyl)-1 H-pyrrol-2-yl]-2,2-dimethylpropyl\}(hydroxyacetyl)amino]butanoyl\}-beta-alanylD-glutamate $(14.0 \mathrm{mg}, 12.5 \mu \mathrm{mol})$ was supplemented with $N, N$-diisopropylethylamine $(6.5 \mu \mathrm{L}$, $37 \mu \mathrm{mol})$ and HATU $(7.12 \mathrm{mg}, 18.7 \mu \mathrm{mol})$ and the reaction was stirred for 2 hours at room temperature. The mixture was concentrated to dryness under reduced pressure and the residue was purified by preparative HPLC to yield $12 \mathrm{mg}$ of the product.

LC-MS (Method 3): $\mathrm{R}_{\mathrm{t}}=2.53 \mathrm{~min}$; MS (ESIpos): $\mathrm{m} / \mathrm{z}=1212[\mathrm{M}+\mathrm{H}]^{+}$

\section{Compound 5e}

$N-[(2 S)-4-[\{(1 R)-1-[1-$ benzyl-4-(2,5-difluorophenyl)-1 H-pyrrol-2-yl]-2,2-

dimethylpropyl\}(hydroxyacetyl)amino]-2-\{[ $N^{2}$-(4-carboxybutanoyl)-L-

asparaginyl]amino\}butanoyl]-beta-alanyl-D-glutamic acid 


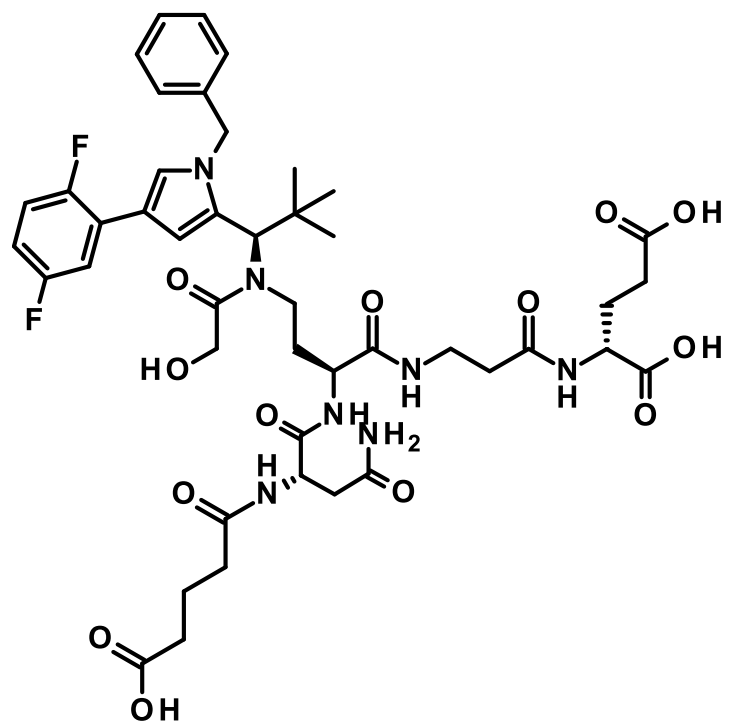

A solution of dibenzyl $N$-[(2S)-4-[\{(1R)-1-[1-benzyl-4-(2,5-difluorophenyl)-1H-pyrrol-2-yl]-2,2dimethylpropyl\}(hydroxyacetyl)amino]-2-(\{N-[5-(benzyloxy)-5-oxopentanoyl]-L-asparaginyl $\}$ amino)butanoyl]-beta-alanyl-D-glutamate (12.4 mg, $10.2 \mu \mathrm{mol})$ in DCM/methanol $(1.1,5 \mathrm{~mL})$ was supplemented with palladium on charcoal $(10 \%, 5.8 \mathrm{mg})$. The mixture was hydrogenated at ambient pressure for 1 hour. The solids were filtered off and the residue was washed several times with acetonitrile/water (1:1). The filtrate was concentrated under reduced pressure and the remaining residue was lyophilized to yield $9.6 \mathrm{mg}$ of the product.

LC-MS (Method 1): $\mathrm{R}_{\mathrm{t}}=0.88 \mathrm{~min} ; \mathrm{MS}$ (ESIpos): $\mathrm{m} / \mathrm{z}=940[\mathrm{M}-\mathrm{H}]^{-}$

\section{Active metabolite 8}

$\mathrm{N}$-\{(2S)-2-amino-4-[\{(1R)-1-[1-benzyl-4-(2,5-difluorophenyl)-1H-pyrrol-2-yl]-2,2-

dimethylpropyl\}(hydroxyacetyl)amino]butanoyl\}-beta-alanyl-D-glutamic acid<smiles>CC(C)(C)C(c1cc(-c2cc(F)ccc2F)cn1Cc1ccccc1)N(CCC(N)C(=O)NCCC(=O)N[C@@H](CCC(=O)O)C(=O)O)C(=O)CO</smiles>

A solution of dibenzyl $N$-\{(2S)-2-amino-4-[\{(1R)-1-[1-benzyl-4-(2,5-difluorophenyl)-1H-pyrrol-2yl]-2,2-dimethylpropyl\}(hydroxyacetyl)amino]butanoyl\}-beta-alanyl-D-glutamate (Compound 2, $70.0 \mathrm{mg}, 66.3 \mu \mathrm{mol})$ in methanol $(15 \mathrm{~mL})$ was supplemented with palladium on charcoal $(10 \%$, $7 \mathrm{mg}$ ). The mixture was hydrogenated at ambient pressure for 1 hour. The solids were filtered off and the residue was washed several times with acetonitrile/water (1:1). The filtrate was 
concentrated under reduced pressure and the remaining residue was lyophilized to yield $54 \mathrm{mg}$ of the product.

LC-MS (Method 1): $\mathrm{R}_{\mathrm{t}}=0.80 \mathrm{~min} ; \mathrm{MS}\left(\right.$ ESIpos): $\mathrm{m} / \mathrm{z}=714[\mathrm{M}+\mathrm{H}]^{+}$

\section{Synthesis of ADCs}

The antibodies used herein are described in WO 2015/096982 A1, ${ }^{\mathrm{S} 1}$ WO2015/189143 A1, ${ }^{\mathrm{S} 3}$ and WO2016/207094 A1. ${ }^{\mathrm{S}}$

TPP-1015: an anti-HER-2 antibody (IgG1)), an in-house produced version of Trastuzumab having the same peptide sequence as Trastuzumab; $\$ 1$

TPP-7007: an antagonistic anti-TWEAKR antibody (IgG1):\$4

TPP-2658: an agonistic anti-TWEAKR-antibody; (IgG1); \$1,S3

TPP-5657: an isotype control antibody, $(\lg G 1)^{S 4}$

\section{$\underline{\text { ADCs } 6 a \text { and } 7 a}$}

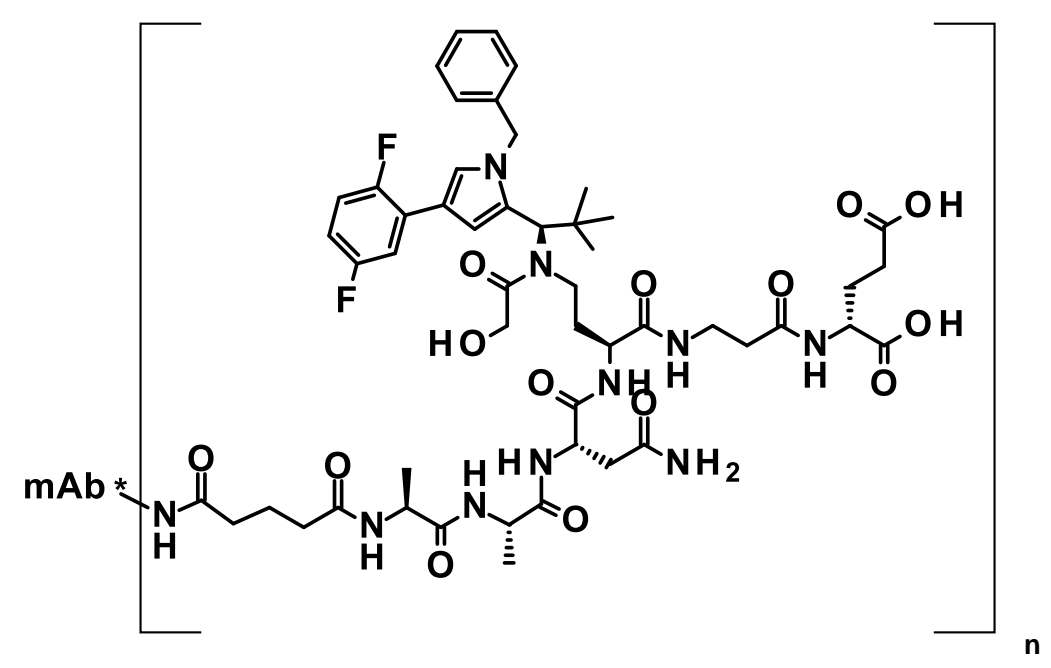

Anti-TWEAKR ADC with TPP-7007 (Compound 6a):

A solution of anti-TWEAKR antibody TPP-7007 in PBS buffer ( $1 \mathrm{~mL}, 10 \mathrm{mg} / \mathrm{mL}$ ) was supplemented with Compound $4 \mathrm{a}(0.38 \mathrm{mg}, 0.34 \mu \mathrm{mol})$ dissolved in DMSO $(50 \mu \mathrm{L})$ and the mixture was stirred for 1 hour at room temperature. Compound $4 \mathrm{a}(0.38 \mathrm{mg}, 0.34 \mu \mathrm{mol})$ dissolved in DMSO $(50 \mu \mathrm{L})$ was added. After stirring for an additional hour at room temperature, the mixture was diluted to $5 \mathrm{~mL}$ with PBS buffer and then applied to PBS-equilibrated PD 10 columns (Sephadex ${ }^{\circledR}$ G-25, GE Healthcare) and eluted with PBS buffer. The sample was diluted 
to a total volume of $14 \mathrm{~mL}$ with PBS buffer. The ADC solution was concentrated by ultracentrifugation and rediluted with PBS buffer $(\mathrm{pH}=7.2)$.

Protein concentration: $7.81 \mathrm{mg} / \mathrm{mL}$

Drug-to-antibody ratio (DAR): 3.2

\section{Anti-HER2 ADC with TPP-1015 (Compound 7a):}

A solution of trastuzumab TPP-1015 in PBS buffer $(0.5 \mathrm{~mL}, 10 \mathrm{mg} / \mathrm{mL})$ was supplemented with Compound $4 \mathrm{a}(0.2 \mathrm{mg}, 0.17 \mu \mathrm{mol})$ dissolved in DMSO $(50 \mu \mathrm{L})$ and the mixture was stirred for 1 hour at room temperature. Compound $4 \mathrm{a}(0.2 \mathrm{mg}, 0.17 \mu \mathrm{mol})$ dissolved in DMSO $(50 \mu \mathrm{L})$ was added. After stirring for an additional hour at room temperature the mixture was diluted to 2.5 $\mathrm{mL}$ with PBS buffer and then applied to PBS-equilibrated PD 10 columns (Sephadex ${ }^{\circledR}$ G-25, GE Healthcare) and eluted with PBS buffer. The ADC solution was concentrated by ultracentrifugation and rediluted with PBS buffer $(\mathrm{pH}=7.2)$.

Protein concentration: $2.06 \mathrm{mg} / \mathrm{mL}$

DAR: 6.3

ADCs $6 b, 6 b^{*}, 7 b$ and isotype $6 b$

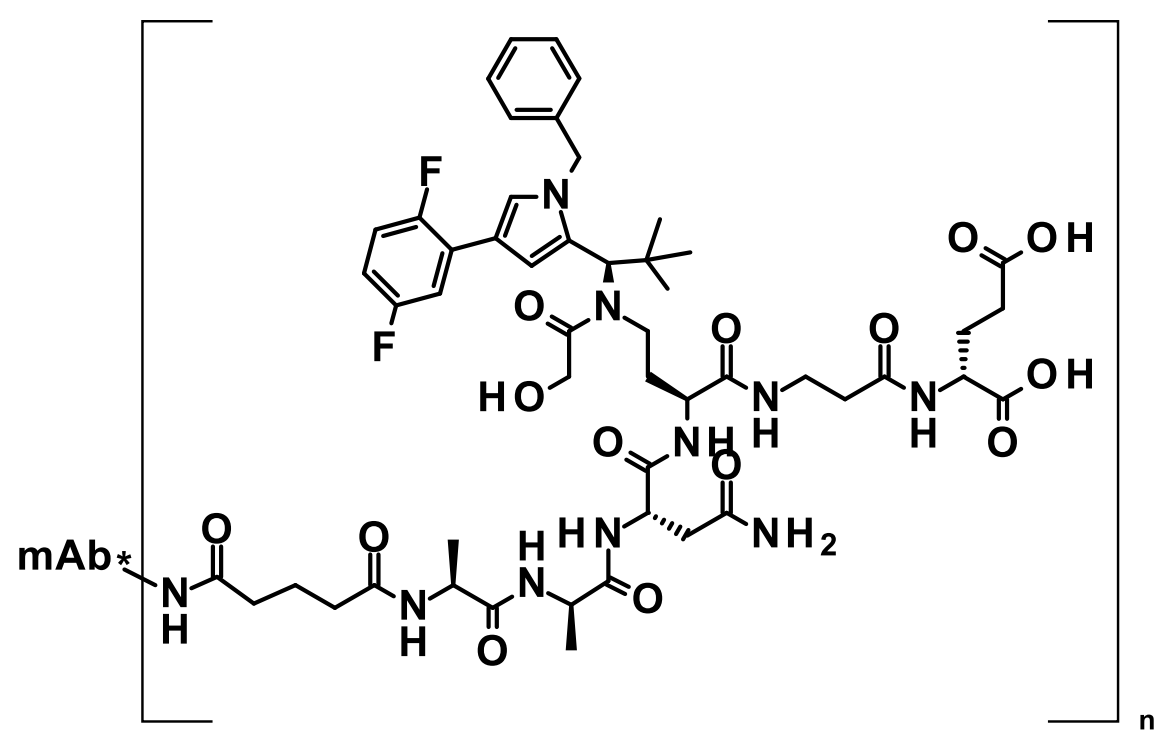

\section{Anti-TWEAKR ADC with TPP-7007 (Compound 6b):}

A solution of anti-TWEAKR antibody TPP-7007 in PBS buffer (4 mL, $10 \mathrm{mg} / \mathrm{mL}$ ) was supplemented with Compound $4 \mathrm{~b}(1.58 \mathrm{mg}, 1.34 \mu \mathrm{mol})$ dissolved in DMSO (200 $\mu \mathrm{L})$ and the mixture was stirred for 1 hour at room temperature. Compound $4 \mathrm{~b}(1.58 \mathrm{mg}, 1.34 \mu \mathrm{mol})$ dissolved in DMSO $(200 \mu \mathrm{L})$ was added. After stirring for an additional hour at room temperature 
the mixture was diluted to $5 \mathrm{~mL}$ with PBS buffer and then applied to PBS-equilibrated PD 10 columns (Sephadex ${ }^{\circledR}$ G-25, GE Healthcare) and eluted with PBS buffer. The sample was diluted to a total volume of $28 \mathrm{~mL}$ with PBS buffer. The ADC solution was concentrated by ultracentrifugation and rediluted with PBS buffer $(\mathrm{pH}=7.2)$.

Protein concentration: $6.92 \mathrm{mg} / \mathrm{mL}$

DAR: 4.6

\section{Anti-TWEAKR ADC with TPP-2658 (Compound 6b*)}

A solution of the anti-TWEAKR antibody TPP-2658 in PBS buffer $(0.307 \mathrm{~mL}, 16.3 \mathrm{mg} / \mathrm{mL})$ was supplemented with Compound $4 \mathrm{~b}(0.23 \mathrm{mg}, 0.17 \mu \mathrm{mol})$ dissolved in DMSO (50 $\mu \mathrm{L})$ and the mixture was stirred for 1 hour at room temperature. Compound $4 \mathrm{~b}(0.23 \mathrm{mg}, 0.17 \mu \mathrm{mol})$ dissolved in DMSO $(50 \mu \mathrm{L})$ was added. After stirring for an additional hour at room temperature the mixture was diluted to $2.5 \mathrm{~mL}$ with PBS buffer and then applied to PBS-equilibrated PD 10 columns (Sephadex ${ }^{\circledR}$ G-25, GE Healthcare) and eluted with PBS buffer. The ADC solution was concentrated by ultracentrifugation and rediluted with PBS buffer $(\mathrm{pH}=7.2)$.

Protein concentration: $2.21 \mathrm{mg} / \mathrm{mL}$

DAR: 5.7

Anti-HER2 ADC with TPP-1015 (Compound 7b):

A solution of Herceptin antibody TPP-1015 in PBS buffer $(0.9 \mathrm{~mL}, 11 \mathrm{mg} / \mathrm{mL})$ was supplemented with Compound $4 \mathrm{~b}(0.39 \mathrm{mg}, 0.33 \mu \mathrm{mol})$ dissolved in DMSO $(50 \mu \mathrm{L})$ and the mixture was stirred for 1 hour at room temperature. Compound $4 \mathrm{~b}(0.39 \mathrm{mg}, 0.33 \mu \mathrm{mol})$ dissolved in DMSO (50 $\mu \mathrm{L})$ was added. After stirring for an additional hour at room temperature the mixture was diluted to $2.5 \mathrm{~mL}$ with PBS buffer and then applied to PBS-equilibrated PD 10 columns (Sephadex ${ }^{\circledR}$ G-25, GE Healthcare) and eluted with PBS buffer. The ADC solution was concentrated by ultracentrifugation and rediluted with PBS buffer $(\mathrm{pH}=7.2)$.

Protein concentration: $1.47 \mathrm{mg} / \mathrm{mL}$

DAR: 3.0

Isoype control ADC with TPP-5657 (Compound isotype 6b)

A solution of the isotype antibody TPP-5657 in PBS buffer ( $4 \mathrm{~mL}, 10 \mathrm{mg} / \mathrm{mL}$ ) was supplemented with Compound $4 \mathrm{~b}(1.57 \mathrm{mg}, 1.33 \mu \mathrm{mol})$ dissolved in DMSO $(200 \mu \mathrm{L})$ and the mixture was stirred for 1 hour at room temperature. Compound 4b (1.57 mg, $1.33 \mu \mathrm{mol})$ dissolved in DMSO (200 
$\mu \mathrm{L}$ ) was added. After stirring for an additional hour at room temperature the mixture was diluted to $5 \mathrm{~mL}$ with PBS buffer and then applied to PBS-equilibrated PD 10 columns (Sephadex ${ }^{\circledR} \mathrm{G}$ 25, GE Healthcare) and eluted with PBS buffer. The ADC solution was concentrated by ultracentrifugation and rediluted with PBS buffer $(\mathrm{pH}=7.2)$.

Protein concentration: $6.70 \mathrm{mg} / \mathrm{mL}$

DAR: 4.9

\section{$\underline{\text { ADCs } 6 c, 6 c^{\star}, 7 c \text { and isotype } 6 c}$}

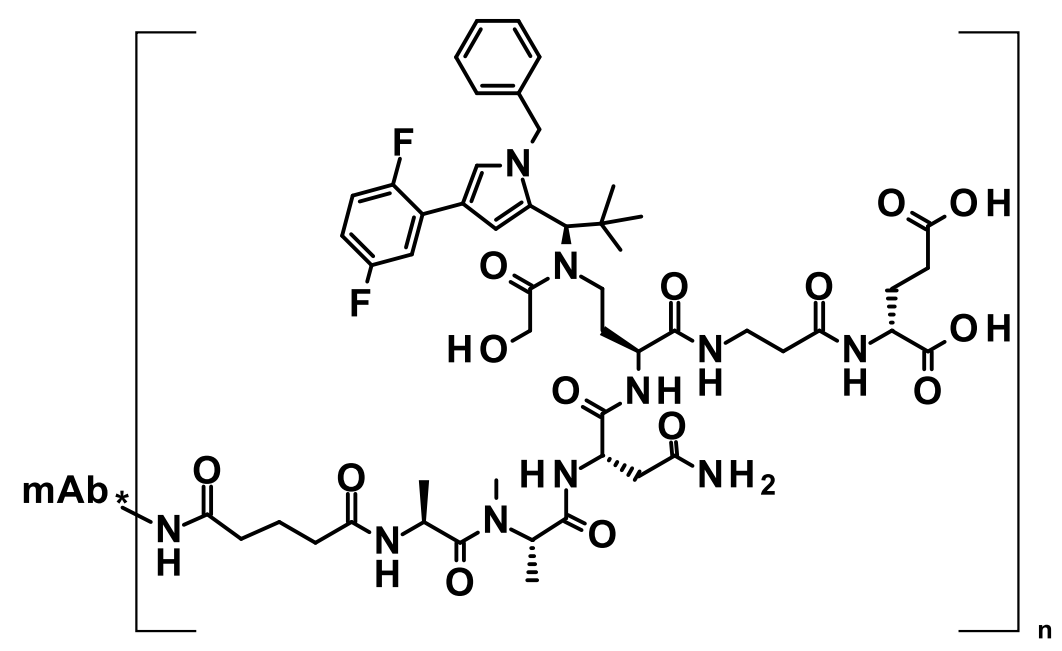

Anti-TWEAKR ADC (TPP-7007) (Compound 6c):

A solution of anti-TWEAKR antibody TPP-7007 in PBS buffer (4 mL, $10 \mathrm{mg} / \mathrm{mL}$ ) was supplemented with Compound 4c (1.59 mg, $1.33 \mu \mathrm{mol})$ dissolved in DMSO (200 $\mu \mathrm{L})$ and the mixture was stirred for 1 hour at room temperature. Compound $4 \mathrm{c}(1.59 \mathrm{mg}, 1.33 \mu \mathrm{mol})$ dissolved in DMSO $(200 \mu \mathrm{L})$ was added. After stirring for an additional hour at room temperature the mixture was diluted to $5 \mathrm{~mL}$ with PBS buffer and then applied to PBS-equilibrated PD 10 columns (Sephadex ${ }^{\circledR}$ G-25, GE Healthcare) and eluted with PBS buffer. The sample was diluted to a total volume of $28 \mathrm{~mL}$ with PBS buffer. The ADC solution was concentrated by ultracentrifugation and rediluted with PBS buffer $(\mathrm{pH}=7.2)$.

Protein concentration: $6.98 \mathrm{mg} / \mathrm{mL}$

DAR: 4.3 
A solution of the TWEAKR antibody TPP-2658 in PBS buffer $(0.5 \mathrm{~mL}, 10 \mathrm{mg} / \mathrm{mL})$ was supplemented with Compound $4 \mathrm{c}(0.20 \mathrm{mg}, 0.17 \mu \mathrm{mol})$ dissolved in DMSO $(50 \mu \mathrm{L})$ and the mixture was stirred for 1 hour at room temperature. Compound $4 \mathrm{c}(0.20 \mathrm{mg}, 0.17 \mu \mathrm{mol})$ dissolved in DMSO $(50 \mu \mathrm{L})$ was added. After stirring for an additional hour at room temperature the mixture was diluted to $2.5 \mathrm{~mL}$ with PBS buffer and then applied to PBS-equilibrated PD 10 columns (Sephadex ${ }^{\circledR}$ G-25, GE Healthcare) and eluted with PBS buffer. The ADC solution was concentrated by ultracentrifugation and rediluted with PBS buffer $(\mathrm{pH}=7.2)$.

Protein concentration: $2.07 \mathrm{mg} / \mathrm{mL}$

DAR: 5.6

Anti-HER2 ADC (TPP-1015) (Compound 7c):

A solution of Herceptin antibody TPP-1015 in PBS buffer $(0.5 \mathrm{~mL}, 10 \mathrm{mg} / \mathrm{mL})$ was supplemented with Compound $4 \mathrm{c}(0.20 \mathrm{mg}, 0.17 \mu \mathrm{mol})$ dissolved in DMSO $(50 \mu \mathrm{L})$ and the mixture was stirred for 1 hour at room temperature. Compound $4 \mathrm{c}(0.20 \mathrm{mg}, 0.17 \mu \mathrm{mol})$ dissolved in DMSO (50 $\mu \mathrm{L})$ was added. After stirring for an additional hour at room temperature the mixture was diluted to $2.5 \mathrm{~mL}$ with PBS buffer and then applied to PBS-equilibrated PD 10 columns (Sephadex ${ }^{\circledR} \mathrm{G}-25$, GE Healthcare) and eluted with PBS buffer. The ADC solution was concentrated by ultracentrifugation and rediluted with PBS buffer $(\mathrm{pH}=7.2)$.

Protein concentration: $2.05 \mathrm{mg} / \mathrm{mL}$

DAR: 5.4

\section{Isotype control ADC with TPP-5657 (Compound isotype 6c)}

A solution of the isotype antibody TPP-5657 in PBS buffer ( $4 \mathrm{~mL}, 10 \mathrm{mg} / \mathrm{mL})$ was supplemented with Compound 4c (1.59 mg, $2.67 \mu \mathrm{mol})$ dissolved in DMSO $(200 \mu \mathrm{L})$ and the mixture was stirred for 1 hour at room temperature. Compound 4c (1.59 mg, $2.67 \mu \mathrm{mol})$ dissolved in DMSO (200 $\mu \mathrm{L}$ ) was added. After stirring for an additional hour at room temperature the mixture was diluted to $5 \mathrm{~mL}$ with PBS buffer and then applied to PBS-equilibrated PD 10 columns (Sephadex ${ }^{\circledR}$ G25, GE Healthcare) and eluted with PBS buffer. The ADC solution was concentrated by ultracentrifugation and rediluted with PBS buffer $(\mathrm{pH}=7.2)$.

Protein concentration: $6.88 \mathrm{mg} / \mathrm{mL}$

DAR: 5.6 


\section{$\underline{A D C 6 d}$}<smiles>CCCN(CCC)[C@@H](C)C(=O)N(CC[C@H](NC(=O)[C@H](CC(N)=O)NC(=O)[C@H](C)N(C)C(=O)[C@H](C)NC(=O)CCCC(=O)NCC)C(=O)NCCC(=O)N[C@@H](CCC(=O)O)C(=O)O)C(=O)CO</smiles>

A solution of anti-TWEAKR antibody TPP-7007 in PBS buffer $(0.5 \mathrm{~mL}, 10 \mathrm{mg} / \mathrm{mL})$ was supplemented with Compound $4 \mathrm{~d}(0.2 \mathrm{mg}, 0.17 \mu \mathrm{mol})$ dissolved in DMSO (50 $\mu \mathrm{L})$ and the mixture was stirred for 1 hour at room temperature. Compound $4 \mathrm{~d}(0.2 \mathrm{mg}, 0.17 \mu \mathrm{mol})$ dissolved in DMSO $(50 \mu \mathrm{L})$ was added. After stirring for an additional hour at room temperature the mixture was diluted to $5 \mathrm{~mL}$ with PBS buffer and then applied to PBS-equilibrated PD 10 columns (Sephadex ${ }^{\circledR}$ G-25, GE Healthcare) and eluted with PBS buffer. The ADC solution was concentrated by ultracentrifugation and rediluted with PBS buffer $(\mathrm{pH}=7.2)$.

Protein concentration: $2.23 \mathrm{mg} / \mathrm{mL}$

DAR: 4.5

\section{ADCs $6 e, 6 e^{\star}, 7 e$ and isotype $6 e$}

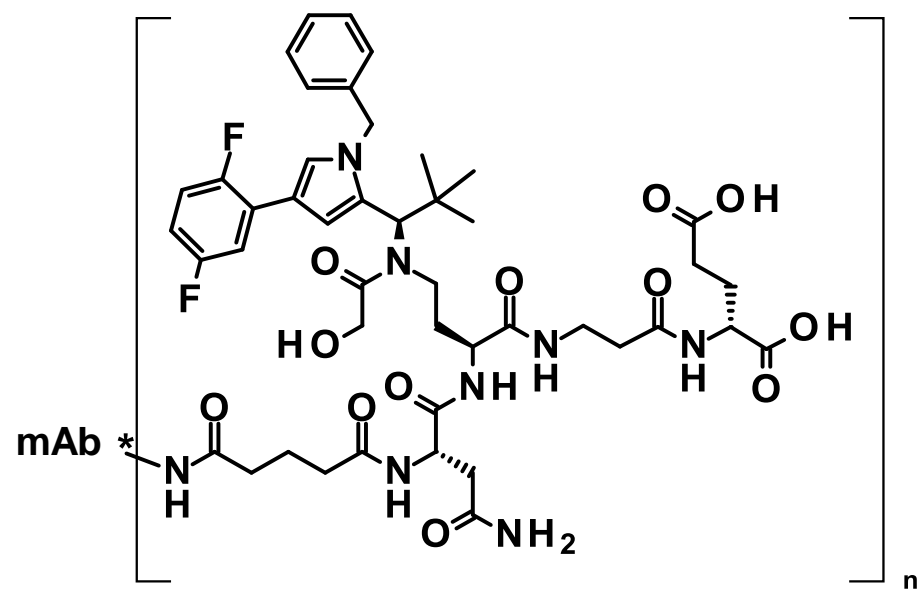


A solution of TWEAKR antibody TPP-7007 in PBS buffer ( $4 \mathrm{~mL}, 10 \mathrm{mg} / \mathrm{mL}$ ) was supplemented with Compound $4 \mathrm{e}(1.39 \mathrm{mg}, 1.33 \mu \mathrm{mol})$ dissolved in DMSO $(200 \mu \mathrm{L})$ and the mixture was stirred for 1 hour at room temperature. Compound 4e (1.39 mg, $1.33 \mu \mathrm{mol})$ dissolved in DMSO (200 $\mu \mathrm{L})$ was added. After stirring for an additional hour at room temperature the mixture was diluted to $5 \mathrm{~mL}$ with PBS buffer and then applied to PBS-equilibrated PD 10 columns (Sephadex ${ }^{\circledR}$ G25, GE Healthcare) and eluted with PBS buffer. The ADC solution was concentrated by ultracentrifugation and rediluted with PBS buffer $(\mathrm{pH}=7.2)$.

Protein concentration: $7.47 \mathrm{mg} / \mathrm{mL}$

DAR: 6.6

\section{Anti-TWEAKR ADC with TPP-2658 (Compound 6e*)}

A solution of the TWEAKR antibody TPP-2658 antibody in PBS buffer $(0.4 \mathrm{~mL}, 11 \mathrm{mg} / \mathrm{mL})$ was supplemented with Compound $4 \mathrm{e}(0.17 \mathrm{mg}, 0.17 \mu \mathrm{mol})$ dissolved in DMSO $(50 \mu \mathrm{L})$ and the mixture was stirred for 1 hour at room temperature. Compound $4 \mathrm{e}(0.17 \mathrm{mg}, 0.17 \mu \mathrm{mol})$ dissolved in DMSO $(50 \mu \mathrm{L})$ was added. After stirring for an additional hour at room temperature the mixture was diluted to $2.5 \mathrm{~mL}$ with PBS buffer and then applied to PBS-equilibrated PD 10 columns (Sephadex ${ }^{\circledR}$ G-25, GE Healthcare) and eluted with PBS buffer. The ADC solution was concentrated by ultracentrifugation, rediluted with PBS buffer $(\mathrm{pH}=7.2)$.

Protein concentration: $1.66 \mathrm{mg} / \mathrm{mL}$

DAR: 7.0

\section{Anti-HER2 ADC with TPP-1015 (Compound 7e):}

A solution of the Trastuzumab antibody TPP-1015 in PBS buffer $(0.41 \mathrm{~mL}, 11 \mathrm{mg} / \mathrm{mL})$ was supplemented with Compound $4 \mathrm{e}(0.17 \mathrm{mg}, 0.17 \mu \mathrm{mol})$ dissolved in DMSO $(50 \mu \mathrm{L})$ and the mixture was stirred for 1 hour at room temperature. Compound $4 \mathrm{e}(0.17 \mathrm{mg}, 0.17 \mu \mathrm{mol})$ dissolved in DMSO $(50 \mu \mathrm{L})$ was added. After stirring for an additional hour at room temperature the mixture was diluted to $2.5 \mathrm{~mL}$ with PBS buffer and then applied to PBS-equilibrated PD 10 columns (Sephadex ${ }^{\circledR}$ G-25, GE Healthcare) and eluted with PBS buffer. The ADC solution was concentrated by ultracentrifugation and rediluted with PBS buffer $(\mathrm{pH}=7.2)$.

Protein concentration: $2.32 \mathrm{mg} / \mathrm{mL}$ 
DAR: 6.9

\section{Isoype control ADC with TPP-5657 (Compound isotype 6e)}

A solution of the isotype antibody TPP-5657 in PBS buffer $(0.4 \mathrm{~mL}, 10 \mathrm{mg} / \mathrm{mL})$ was supplemented with Compound $4 \mathrm{e}(1.39 \mathrm{mg}, 1.33 \mu \mathrm{mol})$ dissolved in DMSO $(200 \mu \mathrm{L})$ and the mixture was stirred for 1 hour at room temperature. Compound $4 \mathrm{e}(1.39 \mathrm{mg}, 1.33 \mu \mathrm{mol})$ dissolved in DMSO $(200 \mu \mathrm{L})$ was added. After stirring for an additional hour at room temperature the mixture was diluted to $5 \mathrm{~mL}$ with PBS buffer and then applied to PBS-equilibrated PD 10 columns (Sephadex ${ }^{\circledR}$ G-25, GE Healthcare) and eluted with PBS buffer. The ADC solution was concentrated by ultracentrifugation and rediluted with PBS buffer $(\mathrm{pH}=7.2)$.

Protein concentration: $7.59 \mathrm{mg} / \mathrm{mL}$

DAR: 6.0

\section{ADCs $6 f$ and $7 f$}

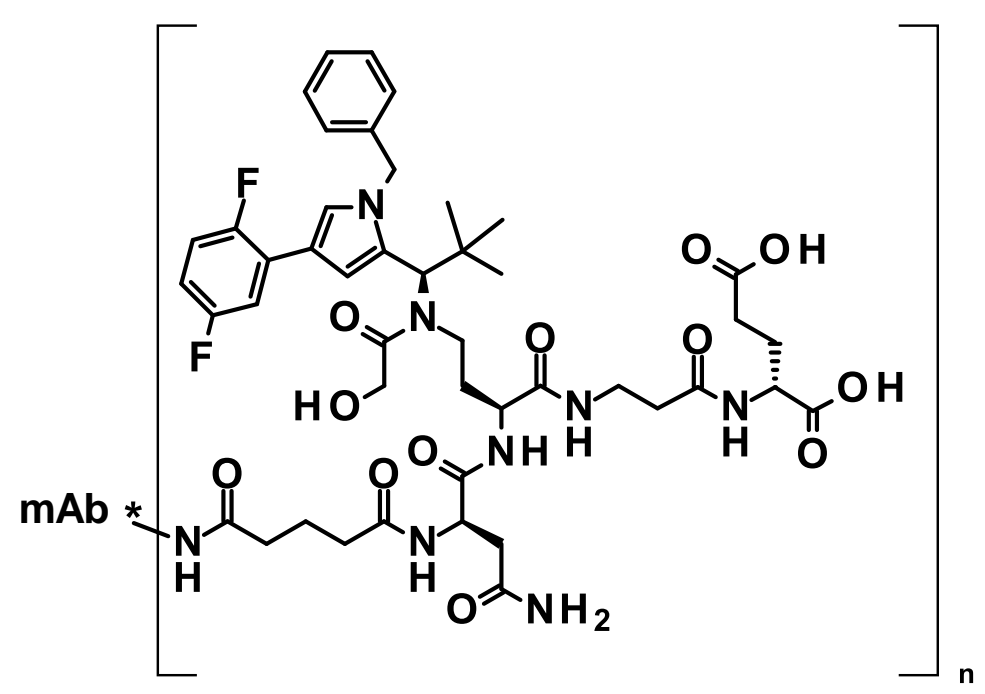

Anti-TWEAKR ADC with TPP-7007 (Compound 6f):

A solution of TWEAKR antibody TPP-7007 in PBS buffer $(0.5 \mathrm{~mL}, 8 \mathrm{mg} / \mathrm{mL})$ was supplemented with Compound $4 \mathrm{f}(0.15 \mathrm{mg}, 0.13 \mu \mathrm{mol})$ dissolved in DMSO $(50 \mu \mathrm{L})$ and the mixture was stirred for 1 hour at room temperature. Compound $4 \mathrm{f}(0.15 \mathrm{mg}, 0.13 \mu \mathrm{mol})$ dissolved in DMSO $(50 \mu \mathrm{L})$ was added. After stirring for an additional hour at room temperature the mixture was diluted to $2.5 \mathrm{~mL}$ with PBS buffer and then applied to PBS-equilibrated PD 10 columns (Sephadex ${ }^{\circledR}$ G-25, GE Healthcare) and eluted with PBS buffer. The ADC solution was concentrated by ultracentrifugation and rediluted with PBS buffer $(\mathrm{pH}=7.2)$.

Protein concentration: $2.56 \mathrm{mg} / \mathrm{mL}$ 
DAR: 3.4

\section{Anti-HER2 ADC with TPP-1015 (Compound 7f):}

A solution of Trastuzumab antibody TPP-1015 in PBS buffer $(0.5 \mathrm{~mL}, 8 \mathrm{mg} / \mathrm{mL})$ was supplemented with Compound $4 \mathrm{f}(0.15 \mathrm{mg}, 0.13 \mu \mathrm{mol})$ dissolved in DMSO $(50 \mu \mathrm{L})$ and the mixture was stirred for 1 hour at room temperature. Compound $4 \mathrm{f}(0.15 \mathrm{mg}, 0.13 \mu \mathrm{mol})$ dissolved in DMSO $(50 \mu \mathrm{L})$ was added. After stirring for an additional hour at room temperature the mixture was diluted to $2.5 \mathrm{~mL}$ with PBS buffer and then applied to PBS-equilibrated PD 10 columns (Sephadex $^{\circledR}$ G-25, GE Healthcare) and eluted with PBS buffer. The ADC solution was concentrated by ultracentrifugation and rediluted with PBS buffer $(\mathrm{pH}=7.2)$.

Protein concentration: $2.54 \mathrm{mg} / \mathrm{mL}$

DAR: 5.4

\section{ADCs $6 \mathrm{~g}$ and $7 \mathrm{~g}$}

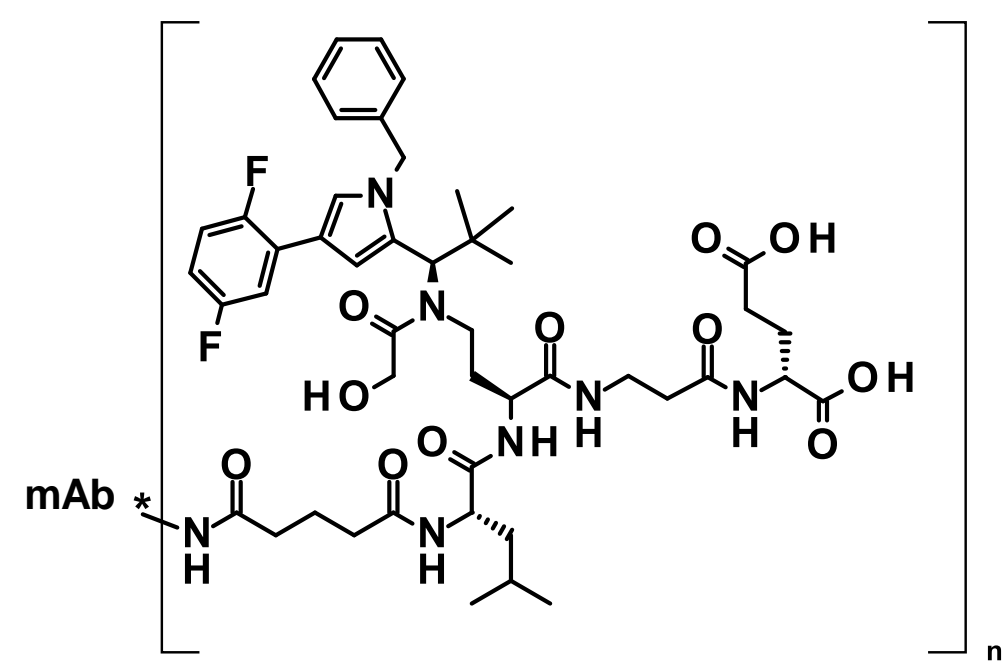

Anti-TWEAKR ADC with TPP-7007 (Compound 6g):

A solution of TWEAKR antibody TPP-7007 in PBS buffer $(0.5 \mathrm{~mL}, 10 \mathrm{mg} / \mathrm{mL})$ was supplemented with Compound $4 \mathrm{~g}(0.17 \mathrm{mg}, 0.17 \mu \mathrm{mol})$ dissolved in DMSO $(50 \mu \mathrm{L})$ and the mixture was stirred for 1 hour at room temperature. Compound $4 \mathrm{~g}(0.17 \mathrm{mg}, 0.17 \mu \mathrm{mol})$ dissolved in DMSO $(50 \mu \mathrm{L})$ was added. After stirring for an additional hour at room temperature the mixture was diluted to $2.5 \mathrm{~mL}$ with PBS buffer and then applied to PBS-equilibrated PD 10 columns (Sephadex ${ }^{\circledR} \mathrm{G}-25$, GE Healthcare) and eluted with PBS buffer. The ADC solution was concentrated by ultracentrifugation and rediluted with PBS buffer $(\mathrm{pH}=7.2)$.

Protein concentration: $1.89 \mathrm{mg} / \mathrm{mL}$ 
DAR: 4.5

\section{Anti-HER2 ADC with TPP-1015 (Compound 7g):}

A solution of Trastuzumab antibody TPP-1015 in PBS buffer $(0.5 \mathrm{~mL}, 10 \mathrm{mg} / \mathrm{mL})$ was supplemented with Compound $4 \mathrm{~g}(0.17 \mathrm{mg}, 0.17 \mu \mathrm{mol})$ dissolved in DMSO $(50 \mu \mathrm{L})$ and the mixture was stirred for 1 hour at room temperature. Compound $4 \mathrm{~g}(0.17 \mathrm{mg}, 0.17 \mu \mathrm{mol})$ dissolved in DMSO $(50 \mu \mathrm{L})$ was added. After stirring for an additional hour at room temperature the mixture was diluted to $2.5 \mathrm{~mL}$ with PBS buffer and then applied to PBS-equilibrated PD 10 columns (Sephadex ${ }^{\circledR}$ G-25, GE Healthcare) and eluted with PBS buffer. The ADC solution was concentrated by ultracentrifugation and rediluted with PBS buffer $(\mathrm{pH}=7.2)$.

Protein concentration: $1.80 \mathrm{mg} / \mathrm{mL}$

DAR: 6.4

\section{$\underline{\text { ADCs } 6 h \text { and } 7 \mathrm{~h}}$}<smiles>CCCC[C@H](NCCC(=O)N[C@@H](CCC(=O)O)C(=O)O)C(=O)N(CC[C@H](NC(=O)[C@H](CCC(N)=O)NC(=O)CCCC(=O)NCC)C(C)(C)C)C(=O)CO</smiles>

\section{Anti-TWEAKR ADC with TPP-7007 (Compound 6h):}

A solution of TWEAKR antibody TPP-7007 in PBS buffer $(0.5 \mathrm{~mL}, 10 \mathrm{mg} / \mathrm{mL})$ was supplemented with Compound 4h (0.185 mg, $0.17 \mu \mathrm{mol})$ dissolved in DMSO $(50 \mu \mathrm{L})$ and the mixture was stirred for 1 hour at room temperature. Compound $4 \mathrm{~h}(0.18 \mathrm{mg}, 0.17 \mu \mathrm{mol})$ dissolved in DMSO $(50 \mu \mathrm{L})$ was added. After stirring for an additional hour at room temperature the mixture was diluted to $2.5 \mathrm{~mL}$ with PBS buffer and then applied to PBS-equilibrated PD 10 columns (Sephadex ${ }^{\circledR} \mathrm{G}-25$, GE Healthcare) and eluted with PBS buffer. The ADC solution was concentrated by ultracentrifugation and rediluted with PBS buffer $(\mathrm{pH}=7.2)$.

Protein concentration: $2.63 \mathrm{mg} / \mathrm{mL}$ 
DAR: 4.3

\section{Anti-HER2 ADC with TPP-1015 (Compound 7h):}

A solution of Trastuzumab antibody TPP-1015 in PBS buffer $(0.5 \mathrm{~mL}, 10 \mathrm{mg} / \mathrm{mL})$ was supplemented with Compound $4 \mathrm{~h}(0.18 \mathrm{mg}, 0.17 \mu \mathrm{mol})$ dissolved in DMSO $(50 \mu \mathrm{L})$ and the mixture was stirred for 1 hour at room temperature. Compound hg $(0.18 \mathrm{mg}, 0.17 \mu \mathrm{mol})$ dissolved in DMSO $(50 \mu \mathrm{L})$ was added. After stirring for an additional hour at room temperature the mixture was diluted to $2.5 \mathrm{~mL}$ with PBS buffer and then applied to PBSequilibrated PD 10 columns (Sephadex ${ }^{\circledR}$ G-25, GE Healthcare) and eluted with PBS buffer. The ADC solution was concentrated by ultracentrifugation and rediluted with PBS buffer $(\mathrm{pH}=$ $7.2)$.

Protein concentration: $2.27 \mathrm{mg} / \mathrm{mL}$

DAR: 6.0 


\section{Analytical characterization of ADCs}

\section{a. Analysis of aggregation by SEC-HPLC and determination of DAR and concentration}

The monomer content of all ADCs was determined by size exclusion chromatography (SEC). Here, $50 \mu \mathrm{L}$ of aliquots the ADCs were analyzed using an Agilent $1260 \mathrm{HPLC}$ system with detection at $280 \mathrm{~nm}$ and $260 \mathrm{~nm}$. A Superdex 200 10/300 GL column from GE Healthcare (Lot No: $10194037 ; 10 \times 310 \mathrm{~mm}, 13 \mu \mathrm{m}$ particle size) was used at a flow rate of $1 \mathrm{~mL} / \mathrm{min}$ using isocratic condition. The mobile phase consisted of PBS buffer $(\mathrm{pH}=7.2)$. For the determination of the monomer content, the \% peak area of the monomer peak at $280 \mathrm{~nm}$ was calculated. The observed side products were dimers or aggregates. All ADCs showed a monomer content of $\geq$ $94 \%$.

The toxophore load (DAR) was determined by UV absorption during SEC. The ratio $R$ of the peak area of the monomer peak at $260 \mathrm{~nm}$ and at $280 \mathrm{~nm}$ was determined and the DAR was calculated as:

$D A R=\frac{\varepsilon_{A b}^{\lambda_{\text {drug }}}-R \cdot \varepsilon_{A b}^{280}}{R \cdot \varepsilon_{D}^{280}-\varepsilon_{D}^{\lambda_{\text {drug }}}}$

where $\varepsilon$ stands for the molar extinction coefficients of the antibody (Ab) and the drug (D), and

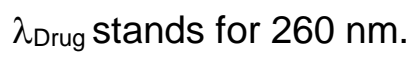

The extinction coefficients of the antibody at a wavelength of $280 \mathrm{~nm}$ and of the drug at a wavelength $260 \mathrm{~nm}$ were determined experimentally. Mean values of different antibodies were used for calculation. The following wavelengths and extinction coefficients were determined and used for the DAR calculations:

\begin{tabular}{|c|c|c|}
\hline & $\begin{array}{c}\varepsilon(280 \mathrm{~nm}) \\
{[1 / \mu \mathrm{M}]}\end{array}$ & $\begin{array}{c}\varepsilon(260 \mathrm{~nm}) \\
{[1 / \mu \mathrm{M}]}\end{array}$ \\
\hline Antibody & 0.2284 & 0.1163 \\
\hline $\begin{array}{c}\text { Toxophore } \\
\text { (KSPi) }\end{array}$ & 0.010 & 0.014 \\
\hline
\end{tabular}

The concentration of ADCs was determined by measuring the absorption at $280 \mathrm{~nm}$. The concentration was calculated using the absorption coefficient of the respective antibody. To take into account the absorbance of the toxophore at $280 \mathrm{~nm}$, the concentration was corrected using the following equation:

concentration $=$ preliminary concentration $/\left[1+\mathrm{DARuv} *\left(\boldsymbol{\varepsilon}_{\text {Toxophore } 280 \mathrm{~nm}} / \boldsymbol{\varepsilon}_{\text {Antibody } 280 \mathrm{~nm}}\right)\right]$ 
where "preliminary concentration" is the concentration being calculated only using the extinction coefficient of the antibody, DARuv is the drug load of the respective ADC determined by UV absorption, and $\varepsilon_{\text {Toxophore } 280 \mathrm{~nm}}$ and $\boldsymbol{\varepsilon}_{\text {Antibody } 280 \mathrm{~nm}}$ are the extinction coefficients at $280 \mathrm{~nm}$ of the toxophore and the antibody, respectively.

\section{b. Distribution of the payload on ADC, analytical method and data}

The determination of the distribution of the payload on the ADC was carried out by mass spectrometry. After deglycosylation with PNGaseF at $37^{\circ} \mathrm{C}$ over night, the ADC samples were acidified and diluted to a concentration of $1 \mathrm{pmol} / \mu \mathrm{L}$. After HPLC desalting, distribution of the payload was analyzed by mass spectrometry using an Impact II ESI-Q/Tof (Bruker Daltonics). All spectra over the signal in the TIC (Total Ion Chromatogram) were added and the molecular weight of the individual conjugated species were calculated based on MaxEnt deconvolution (additional signals marked with * explained as mass spectrometry derived ionization fragments).

Anti-TWEAKR ADC with TPP-7007 (Compound 6a):

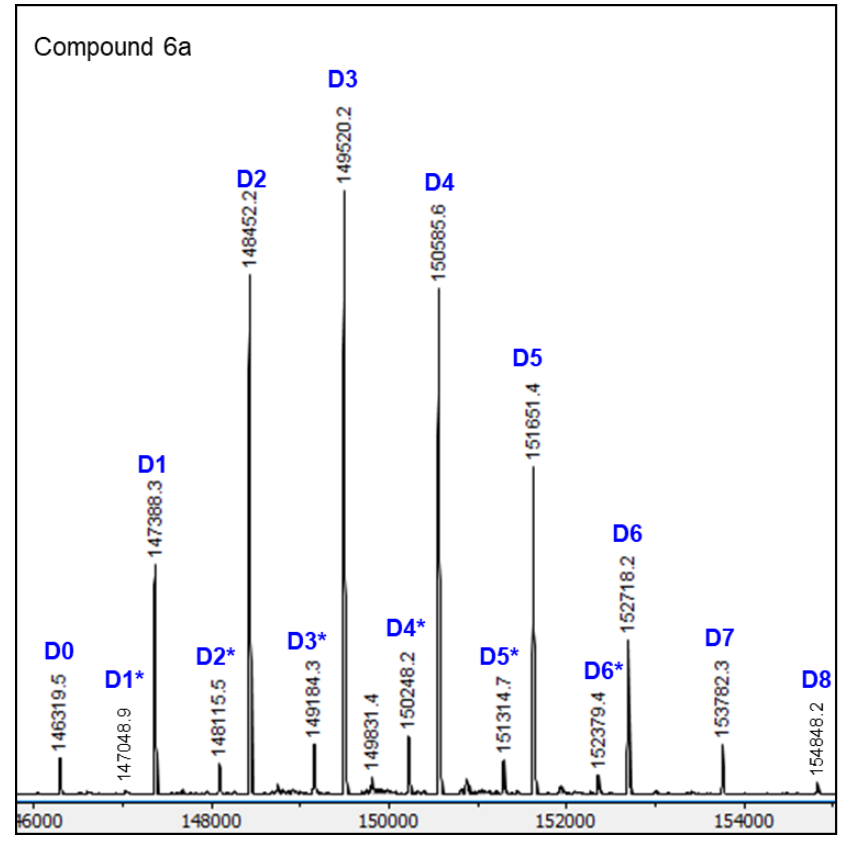


Anti-HER2 ADC with TPP-1015 (Compound 7a):

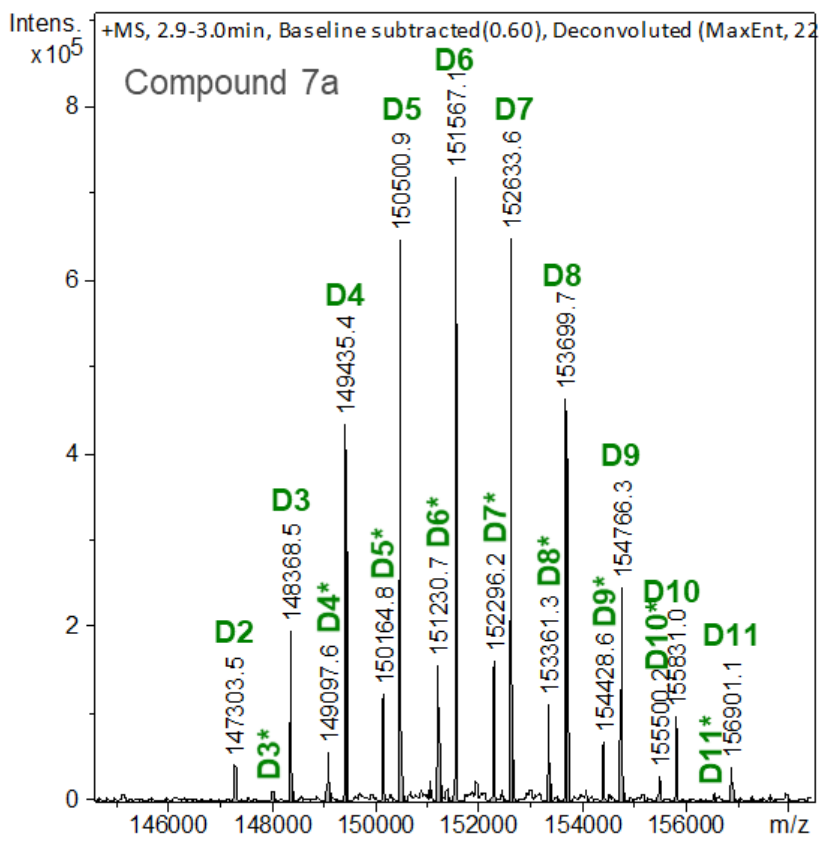

Anti-TWEAKR ADC with TPP-7007 (Compound 6b):

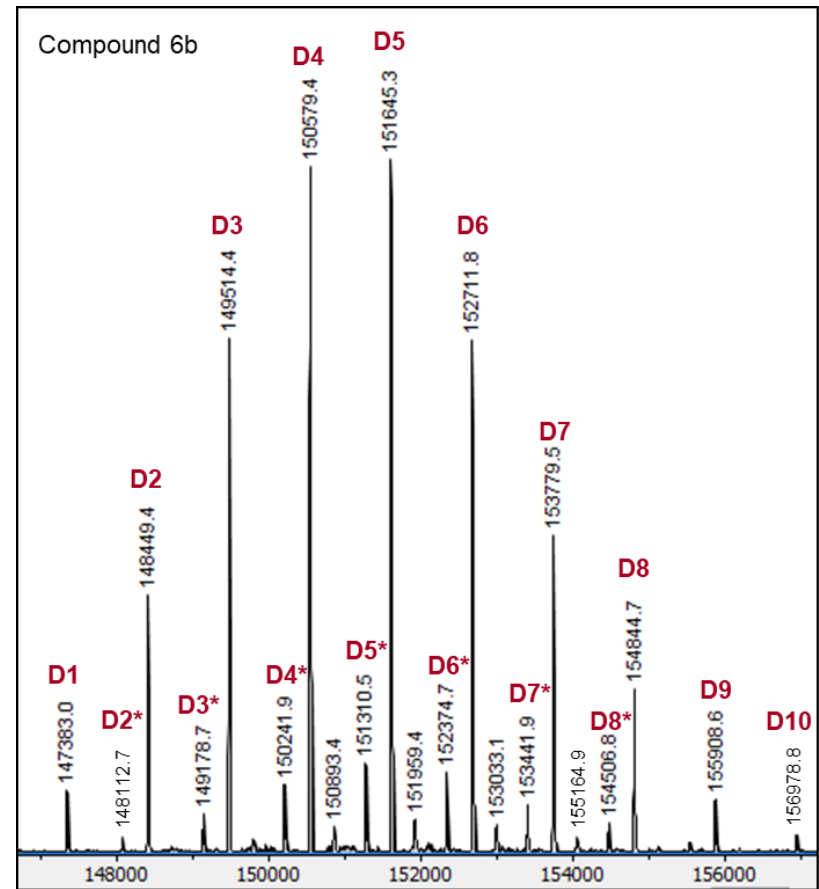


Anti-TWEAKR ADC with TPP-7007 (Compound 6c):

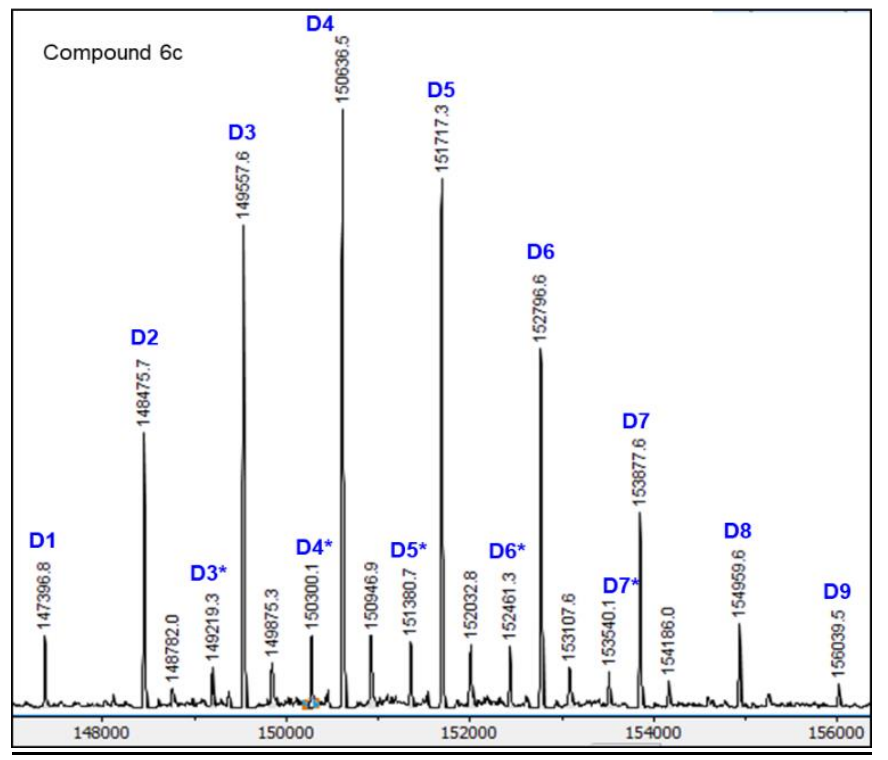

Anti-HER2 ADC with TPP-1015 (Compound 7c):

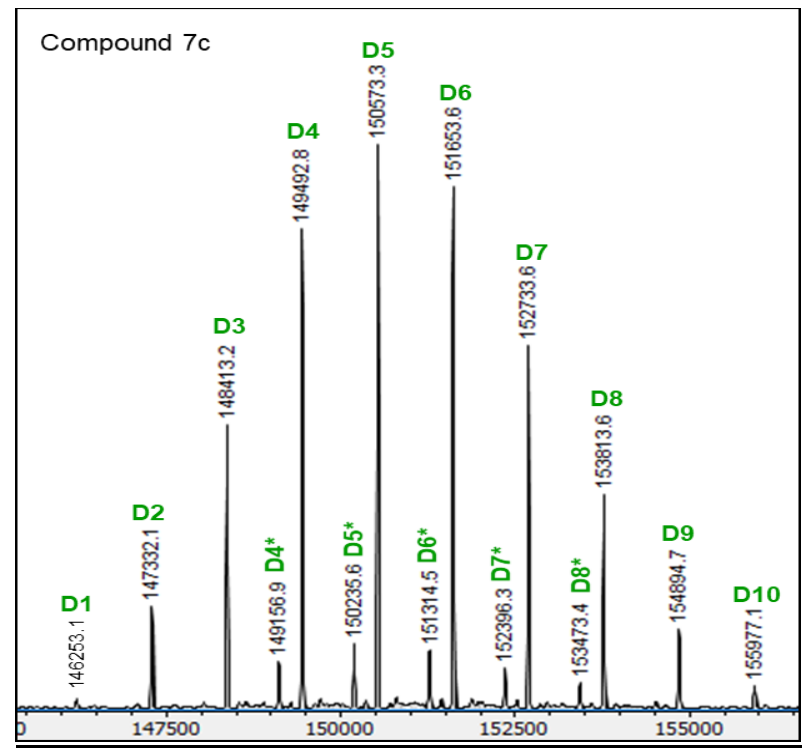


Anti-TWEAKR ADC with TPP-7007 (Compound 6d)

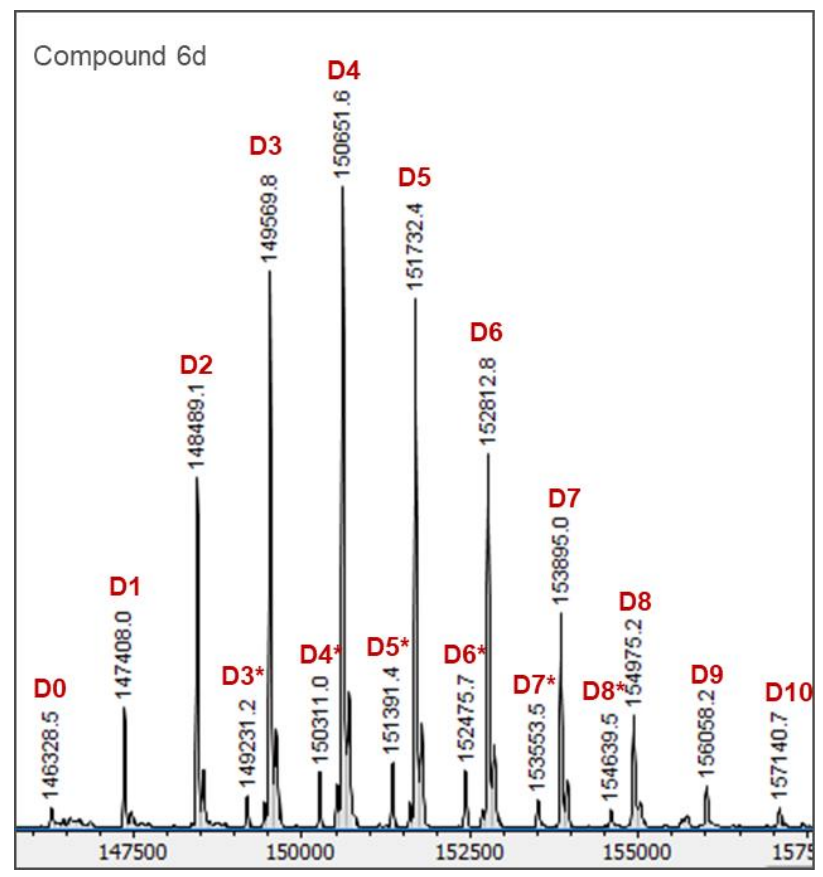

Anti-TWEAKR ADC with TPP-7007 (Compound 6e):

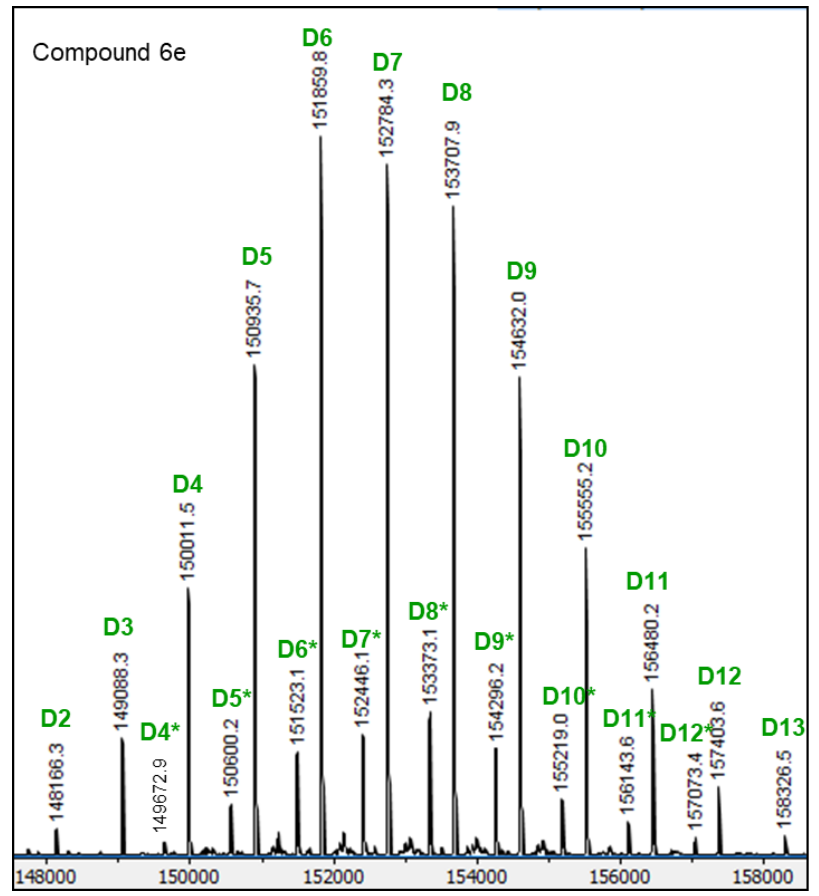


Anti-HER2 ADC (TPP-1015) (Compound 7e):

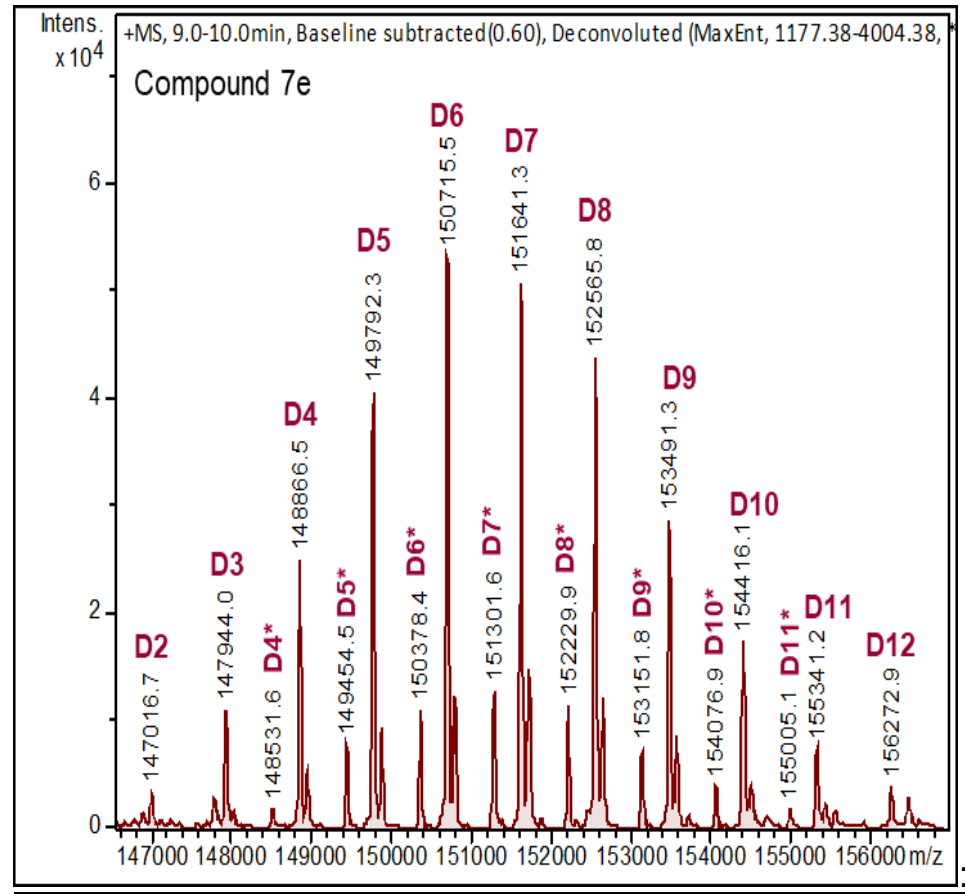

Isotype control ADC with TPP-5657 (Isotype 6c):

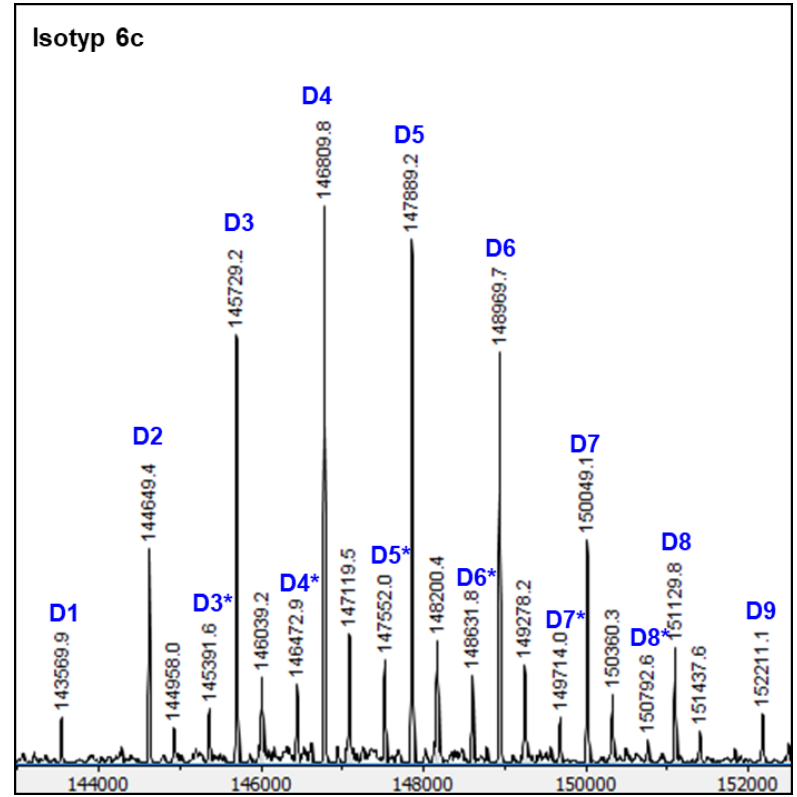




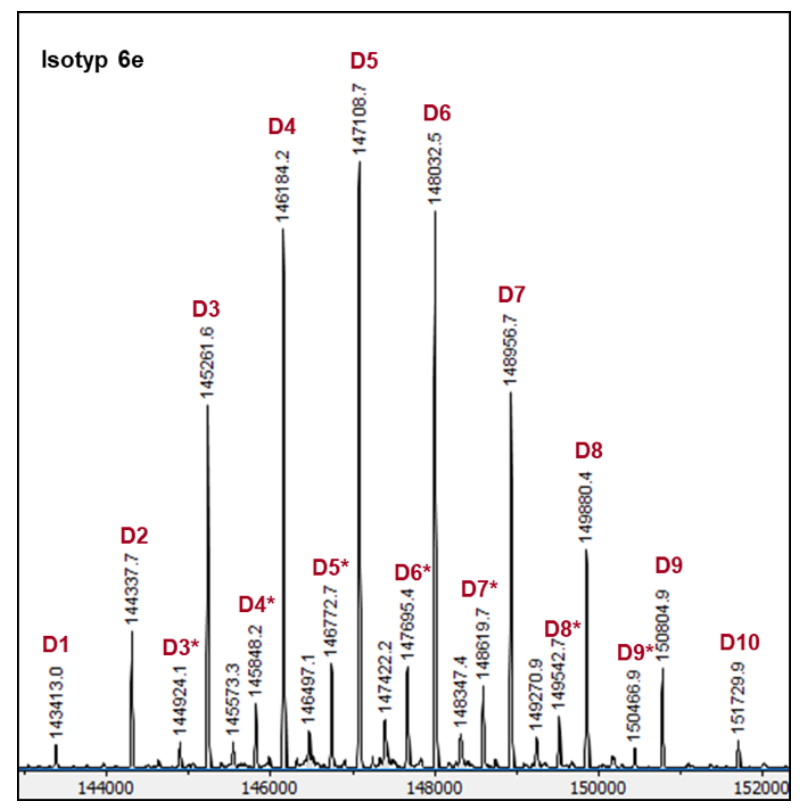

\section{In vitro assays}

Biophysical evaluation and cellular characterization of the purified antibodies was performed before using them for conjugation.

\section{a. Surface plasmon resonance (SPR)}

Binding assays were performed on a Biacore T200 instrument at $25^{\circ} \mathrm{C}$ with a CM5 sensor chip and assay buffer HBS-EP+. IgGs were captured via an amine coupled anti-Fc capture Ab and recombinant human target molecule was used as analyte at concentrations ranging from 1.56 $200 \mathrm{nM}$. Data were fit to a 1:1 Langmuir binding model.

\section{b. Flow cytometry}

Binding of antibodies to target expressing cells was analyzed by flow cytometry. Additionally, TWEAKR expression in tumor cell lines was assessed by quantitative flow cytometry with the QIFI kit (Dako, K0078) using the anti-TWEAKR mouse IgG2a (BAY-039) and the FITCconjugated goat anti-mlgG detection antibody.

\section{c. Internalization}

Internalization was monitored via fluorescent labelling of specific anti-TWEAKR antibodies and an isotype control antibody. The fluorescent dye was conjugated to lysines of the antibody. Then, cancer cells were incubated with the labelled antibody. The fluorescence measurement was 
carried out using the InCell Analyser 1000 (GE Healthcare). This was followed by kinetic evaluation via measurement of the parameters granule counts/cell and total granule intensity/cell.

Table S1: Summary of the biophysical and cellular data of anti-TWEAKR antibodies in NCIH292 cells. SPR analysis was performed with recombinant human TWEAKR as antigen/analyte for the anti-TWEAKR antibodies.

\begin{tabular}{|c|c|c|c|}
\hline Antibody & $\begin{array}{c}\text { Surface } \\
\text { Plasmon } \\
\text { Resonance: } \\
\mathbf{K}_{\mathbf{d}}[\mathrm{M}]\end{array}$ & $\begin{array}{c}\text { Binding to NCI- } \\
\text { H292 cells: } \\
\text { EC }_{50}[\mathrm{M}]\end{array}$ & $\begin{array}{c}\text { Internalization in NCI- } \\
\text { H292 cells: } \\
\text { Granule count/cell }\end{array}$ \\
\hline $\begin{array}{c}\text { TPP-2658 } \\
\text { Agonistic anti- } \\
\text { TWEAKR Ab }\end{array}$ & $1.3 \mathrm{E}-08$ & $4.3 \mathrm{E}-10$ & 22 \\
\hline $\begin{array}{c}\text { TPP-7007 } \\
\text { Antagonistic anti- } \\
\text { TWEAKR Ab }\end{array}$ & $1.4 \mathrm{E}-09$ & $8.0 \mathrm{E}-10$ & 28 \\
\hline $\begin{array}{c}\text { Isotype control } \\
\text { Ab }\end{array}$ & n.a & no binding & $0-0.3$ \\
\hline
\end{tabular}

\section{d. Cell proliferation assays}

\section{Determination of $\mathrm{IC}_{50}$ by CellTiterGlo assay:}

The cytotoxicity of anti-TWEAKR and corresponding isotype control ADCs, SMOL KSP inhibitors, and payload metabolites was determined in TWEAKR-positive NCI-H292, BxPC3, and LoVo cancer cell lines. Cells were treated with indicated compounds for $72 \mathrm{~h}$ and the CellTiter Glo (CTG) cell viability assay was performed according to manufacturer's instructions (Promega, Madison, WI).

\section{Determination of $\mathrm{IC}_{50}$ by MTT assay:}

The cytotoxicity of anti-HER2 and corresponding isotype control ADCs, KSP inhibitors, and payload metabolites was determined in the HER2-positive breast cancer cell line KPL-4. Cells were treated with the indicated compounds of interest for $96 \mathrm{~h}$ and the MTT cell proliferation assay was performed according to manufacturer's instructions (ATCC).

\section{e. Legumain cleavage assay}

Activation buffer: $50 \mathrm{mM}$ sodium acetate buffer/ $100 \mathrm{mM} \mathrm{NaCl}, \mathrm{pH} 4.0$ Assay buffer: $50 \mathrm{mM}$ MES buffer/ $250 \mathrm{mM} \mathrm{NaCl}, \mathrm{pH} 5.0$ 
$10 \mu \mathrm{g}$ of recombinant human legumain (R\&D systems) was added to $100 \mu \mathrm{L}$ of activation buffer and incubated for $2 \mathrm{~h}$ at $37^{\circ} \mathrm{C}$, before $4.9 \mathrm{~mL}$ of assay buffer was added (final concentration of recombinant human legumain: $2 \mu \mathrm{g} / \mathrm{mL}$ ).

For each test sample, a $500 \mu \mathrm{L}$ aliquot of the compound solution $(6 \mu \mathrm{M})$ was added to $500 \mu \mathrm{L}$ of legumain solution. The solution was incubated at $37^{\circ} \mathrm{C}$. At different time points $(5 \mathrm{~min}, 15 \mathrm{~min}$, $30 \mathrm{~min}, 45 \mathrm{~min}, 90 \mathrm{~min}, 3 \mathrm{~h}$ and $24 \mathrm{~h}$ ) a $50 \mu \mathrm{L}$ sample was taken and added to $100 \mu \mathrm{L}$ of icecold methanol. For the untreated control $(0 \mathrm{~h})$, ice-cold methanol was pipetted in a tube before the legumain and compound solutions were added. Samples were stored at $-20^{\circ} \mathrm{C}$ or analyzed directly by HPLC or LC-MS. The metabolite (product) was measured and the kinetic evaluation was performed.

\section{f. Elastase cleavage assay}

Assay buffer: $\mathrm{H}_{2} \mathrm{O}$

For each test sample, Elastase (Sigma E8140-1U) solution (3 $\mu \mathrm{g} / \mathrm{mL}$ final concentration) was added to the compound solution (final concentration of $100 \mathrm{nM}$ ). For ADCs, the payload concentration was calculated based on the respective DAR and set to a final concentration of $100 \mathrm{nM}$. The samples were incubated at $37^{\circ} \mathrm{C}$ with shaking at $600 \mathrm{rpm}$. At different time points ( $4 \mathrm{~h}, 24 \mathrm{~h}$ and $48 \mathrm{~h}$ ), a $50 \mu \mathrm{L}$ sample was taken. Immediately afterwards, the enzymatic activity was stopped by adding $100 \mu \mathrm{L}$ of ice-cold methanol. For the untreated control $(0 \mathrm{~h})$, ice-cold methanol was pipetted in a tube before the enzyme and compound solutions were added. Samples were stored at $-20^{\circ} \mathrm{C}$ or analyzed directly by HPLC or LC-MS. The metabolite (product) was measured and the kinetic evaluation was performed.

\section{g. Cathepsin B cleavage assay}

Assay buffer: 50 mM Natriumphosphate buffer / 2 mM DTT

For each test sample, Cathepsin B (Sigma C8571-25UG) solution (2.8 $\mu \mathrm{g} / \mathrm{mL}$ final concentration) was added to the compound solution (final concentration of $32 \mu \mathrm{M}$ ). The concentration of the ADC solution was calculated based on the respective DAR. The samples were incubated at $40^{\circ} \mathrm{C}$ with shaking at $600 \mathrm{rpm}$. At different time points ( $4 \mathrm{~h}, 24 \mathrm{~h}$ and $48 \mathrm{~h}$ ), a $50 \mu \mathrm{L}$ sample was taken. Immediately afterwards, the enzymatic activity was stopped by adding $100 \mu \mathrm{L}$ of ice-cold methanol. For the untreated control $(0 \mathrm{~h})$, ice-cold methanol was pipetted in a tube before the enzyme and compound solutions were added. Samples were stored at $-20^{\circ} \mathrm{C}$ or analyzed directly by HPLC or LC-MS. The metabolite (product) was measured and the kinetic evaluation was performed. 


\section{h. Quantification of metabolite formation from ADCs}

For quantification of the ADC metabolites released from ADCs, cancer cells were incubated with ADCs $6 b^{*}, 6 c^{*}$ and $6 \mathrm{e}^{*}$ for up to $72 \mathrm{~h}$. Cell lysates and corresponding supernatants were collected at various time points and the active payload metabolite was quantified by LC-MS. For calibration, the cell homogenate (for cell lysate) or cell culture medium (for supernatant), was spiked with $0.6-1000 \mu \mathrm{g} / \mathrm{L}$ of active metabolite 8. Samples were analyzed using HPLC coupled to a triple-quadrupole mass spectrometer API 4500 (AB Sciex).

\section{i. Preparation of rat lysosome extracts}

The preparation of lysosomes from rat liver was performed based on published protocols of Lardeux et al. ${ }^{\mathrm{S} 5}$ and Graham et al. $^{\mathrm{S6}}$ and modified as described. Briefly, fresh liver was isolated from male Wistar rats and homogenized in homogenization buffer containing $0.25 \mathrm{M}$ sucrose (AppliChem), $1 \mathrm{mM} \mathrm{Na}{ }_{2}$ EDTA (Sigma Aldrich) and $10 \mathrm{mM} \mathrm{HEPES} \mathrm{(Alfa} \mathrm{Aesar)} \mathrm{at} \mathrm{pH} \mathrm{7.} \mathrm{After}$ centrifugation at $3,000 \mathrm{~g}$ for $10 \mathrm{~min}$, supernatant was subjected to an ultracentrifugation step at $17,000 \mathrm{~g}$ for $10 \mathrm{~min}$ to harvest the crude lysosomal fraction. The remaining pellet was immediately resuspended in $5 \mathrm{~mL}$ lysis buffer (25 mM HEPES, $150 \mathrm{mM} \mathrm{NaCl}, 0.1 \%$ Triton X$100, \mathrm{pH} 5.0$ ) and kept frozen at $-80^{\circ} \mathrm{C}$ until use for lysosomal stability assay.

\section{j. Lysosomal stability assay}

The lysosomal extract was mixed 1:10 with citrate buffer $(0.09 \mathrm{M}$, Sigma Aldrich) and ADCs 6a$c$ and $6 e$ were added at a final concentration of $50 \mu \mathrm{g} / \mathrm{mL}$ to investigate lysosomal stability. As a control, a cathepsin-cleavable ADC was incubated under the same conditions. Incubation at $37^{\circ} \mathrm{C}$ was stopped after $0,1,2,6,24$ and 48 hours by adding $150 \mu \mathrm{L}$ of acetonitrile to a $50 \mu \mathrm{L}$ sample. After acetonitrile precipitation, samples were analyzed for the formation of metabolite 8 or corresponding metabolite of the control ADC using HPLC coupled to a triple-quadrupole mass spectrometer API 4500 (AB Sciex). Results are expressed as \% formation of the metabolite. Therefore, a $\mathrm{C}_{\max }$ concentration of metabolite was calculated using the molar ADC concentration in the assay multiplied by the respective drug load of the ADC resulting in the maximum concentration of metabolite that can be achieved upon cleavage from the ADC (represents $C_{\max }$ of $100 \%)$.

\begin{tabular}{c|ccccc} 
Time $[\mathrm{h}]$ & \multicolumn{5}{|c}{ Metabolite release from $\mathbf{A D C}\left[\%\right.$ of $\left.\mathbf{c}_{\text {max }}\right]$} \\
& $\mathbf{6} \mathbf{a}$ & $\mathbf{6 b}$ & $\mathbf{6} \mathbf{c}$ & $\mathbf{6 e}$ & control \\
\hline 1 & 0.7 & 0.2 & 0.1 & 0.2 & 8 \\
2 & 1 & 0.4 & 0.2 & 0.2 & 13 \\
6 & 2 & 0.9 & 0.3 & 0.2 & 23 \\
24 & 11 & 3 & 0.5 & 0.3 & 55 \\
48 & 18 & 4 & 0.8 & 0.7 & 85
\end{tabular}

Table S2. Formation of metabolites from the ADCs 6a-c, 6e and control ADC (cathepsin cleavable ADC 1.3 in ref. (S2) after 1, 2, 6, 24 and $48 \mathrm{~h}$. 


\section{k. Caco-2 assay}

The cell permeability of a substance can be investigated by means of in vitro testing in a flux assay using Caco-2 cells. ${ }^{\text {S7 }}$ For this purpose, the cells were cultured for 15-16 days on 24-well filter plates. For the determination of permeation, the respective working example was applied in a HEPES buffer to the cells either apically (A) or basally (B) and incubated for 2 hours. After 0 hours and after 2 hours, samples were collected from the cis- and trans-compartments. The samples were separated by HPLC (Agilent 1200, Böblingen, Germany) using reverse phase columns. The HPLC system was coupled via a Turbo Ion Spray Interface to a Triple Quadropol mass spectrometer API 4000 (Applied Biosystems Applera, Darmstadt, Germany). The permeability was evaluated on the basis of a Papp value, which was calculated using the formula published by Schwab et al. ${ }^{\text {s }}$

\begin{tabular}{|l|c|c|}
\hline & SMOL KSP Inhibitor A (R= H) & Active metabolite 8 \\
\hline Caco-2 transporter B $\rightarrow$ A $(\mathbf{n m} / \mathbf{s})$ & 213 & 2.7 \\
\hline
\end{tabular}

\section{In vivo studies}

For the cell line-derived in vivo models NCl-H292 (NSCLC, ATCC) or Ku-19-19 (urothelial cancer, DSMZ), either $1 \times 10^{\wedge} 6$ cells or $2 \times 10^{\wedge} 6$ cells, respectively, in $100 \mu \mathrm{L}$ medium/ matrigel $(1: 1)$ were inoculated subcutaneously into the flank of female NMRI nu/nu mice (Janvier, France) with $n=10$ per group. Vehicle (PBS) or the anti-TWEAKR or isotype control ADCs were applied i.v. when tumors reached a size of approximately $100 \mathrm{~mm}^{3}$. Animals were treated with $5 \mathrm{mg} / \mathrm{kg}$ ADC (volume: $5 \mathrm{~mL} / \mathrm{kg})$ as a QWx2 (NCl-H292) or a QWx3 (Ku-19-19) schedule as indicated in the figure legends. Tumor size and body weight was determined two to three times per week. All animal studies were conducted in line with the German Animal Welfare Act. Statistical analysis was performed using the One-Way-ANOVA (GraphPad Prism 7) based on logtransformed data. The obtained $p$-values were adjusted for multiple comparisons. 
Table S3. Summary of efficacy and maximum body weight loss data of $\mathrm{NCl}-\mathrm{H} 292$ human nonsmall cell lung cancer (NSCLC) xenograft model ( $\mathrm{n}=10$ mice/ group).

\begin{tabular}{|c|c|c|c|c|c|c|c|c|c|}
\hline Compound & $\begin{array}{l}\text { Dose }(\mathrm{mg} / \mathrm{kg}) \\
\text { Schedule }\end{array}$ & $T / C^{a}$ & $\begin{array}{l}\text { Adjusted } \\
\text { p value }\end{array}$ & $\begin{array}{c}\text { Max. } \\
\text { Body } \\
\text { weight } \\
\text { change }^{\mathrm{c}} \\
(\%)\end{array}$ & $\begin{array}{l}\text { Response } \\
\text { rate }^{d}\end{array}$ & CR & PR & SD & PD \\
\hline $\begin{array}{l}\text { Vehicle } \\
\text { PBS }\end{array}$ & $5 \mathrm{mg} / \mathrm{kg}, \mathrm{QW} \times 2$ & 1.00 & & -2.94 & $0 \%$ & 0 & 0 & 0 & 10 \\
\hline $\begin{array}{c}\text { TWEAKR-ADC 6b } \\
\text { TPP-7007 }\end{array}$ & $5 \mathrm{mg} / \mathrm{kg}, \mathrm{QW} \times 2$ & 0.05 & 0.9999 & $-0,56$ & $80 \%$ & 0 & 8 & 1 & 0 \\
\hline $\begin{array}{c}\text { Isotype control ADC 6b } \\
\text { TPP-5657 }\end{array}$ & $5 \mathrm{mg} / \mathrm{kg}, \mathrm{QW} \times 2$ & 1.02 & $<0.0001$ & -1.77 & $0 \%$ & 0 & 0 & 0 & 10 \\
\hline $\begin{array}{c}\text { TWEAKR-ADC 6c } \\
\text { TPP-7007 }\end{array}$ & $5 \mathrm{mg} / \mathrm{kg}, \mathrm{QW} \times 2$ & 0.05 & 0.9968 & -0.31 & $90 \%$ & 0 & 9 & 1 & 0 \\
\hline $\begin{array}{c}\text { Isotype control ADC 6c } \\
\text { TPP-5657 }\end{array}$ & $5 \mathrm{mg} / \mathrm{kg}, \mathrm{QW} \times 2$ & 0.95 & $<0.0001$ & -0.63 & $0 \%$ & 0 & 0 & 0 & 10 \\
\hline $\begin{array}{c}\text { TWEAKR-ADC 6e } \\
\text { TPP-7007 }\end{array}$ & $5 \mathrm{mg} / \mathrm{kg}, \mathrm{QW} \times 2$ & 0.06 & 0.2737 & -1.07 & 80 & 0 & 8 & 1 & 0 \\
\hline $\begin{array}{c}\text { Isotype control ADC 6e } \\
\text { TPP-5657 }\end{array}$ & $5 \mathrm{mg} / \mathrm{kg}, \mathrm{QW} \times 2$ & 1.35 & 0.9999 & -2.61 & $0 \%$ & 0 & 0 & 4 & 10 \\
\hline
\end{tabular}

a) $\mathrm{T} / \mathrm{C}=$ Treatment/Control (vehicle) ratio, calculated from mean tumor volumes on day 17 after start of treatment when the vehicle group was still in the experiment or from mean tumor volumes on day 14 for isotype control ADC 6e.

b) One-way ANOVA followed by Dunnets's multiple comparisons test, adjusted $p$ value in comparison to vehicle, $\mathrm{p}<0.05$ was considered statistically significant.

c) Body weight change: The maximum mean body weight change on day 17 after start of treatment (day 14 for the isotype control ADC 6e) expressed as percentage of the starting weight of the animal. Weight loss greater than $20 \%$ was considered toxic.

d) Response: $P D=$ progressive disease, the number of tumors exhibiting $>20 \%$ tumor increase; $\mathrm{SD}=$ stable disease, the number of tumors exhibiting $<30 \%$ tumor shrinkage and $<20 \%$ tumor increase; $\mathrm{PR}=$ partial response, the number of tumors exhibiting $>30 \%$ tumor shrinkage; $\mathrm{CR}=$ complete response, the number of non-measureable tumors at end of experiment. 
Table S4. Summary of efficacy and maximum body weight loss data of Ku-19-19 human urothelial cancer xenograft model ( $\mathrm{n}=10$ mice/ group).

\begin{tabular}{|c|c|c|c|c|c|c|c|c|c|}
\hline Compound & $\begin{array}{l}\text { Dose }(\mathrm{mg} / \mathrm{kg}) \\
\text { and schedule }\end{array}$ & $T / C^{a}$ & $\begin{array}{l}\text { Adjusted } \\
\text { p value }\end{array}$ & $\begin{array}{c}\text { Max. } \\
\text { Body } \\
\text { weight } \\
\text { change } \\
(\%)\end{array}$ & $\begin{array}{l}\text { Response } \\
\text { rate }^{d}\end{array}$ & CR & PR & SD & PD \\
\hline $\begin{array}{l}\text { Vehicle } \\
\text { PBS }\end{array}$ & $5 \mathrm{mg} / \mathrm{kg}, \mathrm{QW} \times 3$ & 1.00 & & 2.32 & $0 \%$ & 0 & 0 & 0 & 10 \\
\hline $\begin{array}{c}\text { TWEAKR-ADC } 6 \mathrm{~b} \\
\text { TPP-7007 }\end{array}$ & $5 \mathrm{mg} / \mathrm{kg}, \mathrm{QW} \times 3$ & 0.14 & $<0,0001$ & 2.93 & $30 \%$ & 0 & 3 & 1 & 6 \\
\hline $\begin{array}{c}\text { Isotype control ADC 6b } \\
\text { TPP-5657 }\end{array}$ & $5 \mathrm{mg} / \mathrm{kg}, \mathrm{QW} \times 3$ & 1.91 & 0,2086 & -6.78 & $0 \%$ & 0 & 0 & 0 & 10 \\
\hline $\begin{array}{l}\text { TWEAKR-ADC 6c } \\
\text { TPP-7007 }\end{array}$ & $5 \mathrm{mg} / \mathrm{kg}, \mathrm{QW} \times 3$ & 0.11 & 0,0016 & 2.71 & $60 \%$ & 0 & 6 & 3 & 1 \\
\hline $\begin{array}{c}\text { Isotype control ADC 6c } \\
\text { TPP-5657 }\end{array}$ & $5 \mathrm{mg} / \mathrm{kg}, \mathrm{QW} \times 3$ & 2.25 & 0,9747 & -5.00 & $0 \%$ & 0 & 0 & 0 & 10 \\
\hline $\begin{array}{c}\text { TWEAKR-ADC } 6 e \\
\text { TPP-7007 }\end{array}$ & $5 \mathrm{mg} / \mathrm{kg}, \mathrm{QW} \times 3$ & 0.13 & 0,0003 & -4.4 & $40 \%$ & 0 & 4 & 6 & 0 \\
\hline $\begin{array}{c}\text { Isotype control ADC 6e } \\
\text { TPP-5657 }\end{array}$ & $5 \mathrm{mg} / \mathrm{kg}, \mathrm{QW} \times 3$ & 1.53 & 0,9993 & -1.13 & $0 \%$ & 0 & 0 & 0 & 10 \\
\hline
\end{tabular}

a) $\mathrm{T} / \mathrm{C}=$ Treatment/Control (vehicle) ratio, calculated from mean tumor volumes on day 16 after start of treatment.

b) One-way ANOVA followed by Dunnets's multiple comparisons test, adjusted $p$ value in comparison to vehicle, $\mathrm{p}<0.05$ was considered statistically significant.

c) Body weight change: The maximum mean body weight change on day 16 after start of treatment expressed as percentage of the starting weight of the animal. Weight loss greater than $20 \%$ was considered toxic.

d) Response: $P D=$ progressive disease, the number of tumors exhibiting $>20 \%$ tumor increase; $\mathrm{SD}=$ stable disease, the number of tumors exhibiting $<30 \%$ tumor shrinkage and $<20 \%$ tumor increase; $P R=$ partial response, the number of tumors exhibiting $>30 \%$ tumor shrinkage; $C R=$ complete response, the number of non-measureable tumors at end of experiment. 


\section{Literature (Supporting Information)}

(S1)Lerchen, H.-G., Wittrock, S., Griebenow, N., Stelte-Ludwig, B., Sommer, A., Berndt, S., Mahlert, C., Lobell, M., Terjung, C., Greven, S., PCT Int. Appl. 2015, WO 2015096982 A1. (S2)Lerchen, H.-G., Wittrock, S., Stelte-Ludwig, B., Sommer, A., Berndt, S., Griebenow, N., Rebstock, A.-S., Johannes, S., Cancho-Grande, Y., Mahlert, C., Greven, S., Terjung, C. (2018) Angew. Chem. Int. Ed., 57, 15243; Angew. Chem. 130, 15463.

(S3)Votsmeier, C., Hammer, S., Berndt, S., Gritzan, U., Zubov, D., Zierz, R., Linden, L., Christian, S., Harrenga, A., Birkenfeld, J., Freiberg, C., Golfier, S., Eicker, A., Greven, S., Stelte-Ludwig, B., Raschke, M., Glück, J. M., PCT Int. Appl. 2015, WO2015189143 A1 20151217.

(S4)Lerchen, H.-G., Rebstock, A.-S., Cancho-Grande, Y., Wittrock, S., Stelte-Ludwig, B., Maersch, S., Gritzan, U., Mahlert, C., Greven, S., Sommer, A., Berndt, S., Dietz, L., PCT Int. Appl. 2016, WO2016207094 A1.

(S5) Lardeux, B., Gouhot, B., Forestier, M. (1983) Analytical Biochemistry, 131, 160.

(S6) Graham, J., Ford, T., Rickwood, D. (1994) Analytical Biochemistry, 220, 367.

(S7)Troutman, M. D. and Thakker, D. R. (2003) Pharm. Res., 20, 1210.

(S8)Schwab, D., Fischer, H., Tabatabaei, A., Poli, S., Huwyler, J. (2003) J. Med. Chem., 46, 1716.

\section{Cover page}

High resolution image of living cells was used as background. Living cells were analysed using STED microscopy (Abberior Expert line). ADC was labelled with STAR580 (green) and lysosomes were stained with SIR-lysosme (red). Costaining in a fixed single cell using $\mathrm{pH}$-sensitive dye as antibody label and LAMP-1 staining for lysosomal surface detection. The merged image depicted here reveals high level of co-localization of ADC in the lysosomes (yellow).

We thank THE NEW ATLANTIC (Cologne) for the design of the cover page art funded by Bayer AG. 